2 ${ }^{\text {ND }}$ INTERNATIONAL CONFERENCE

AARHUS UNIVERSITY

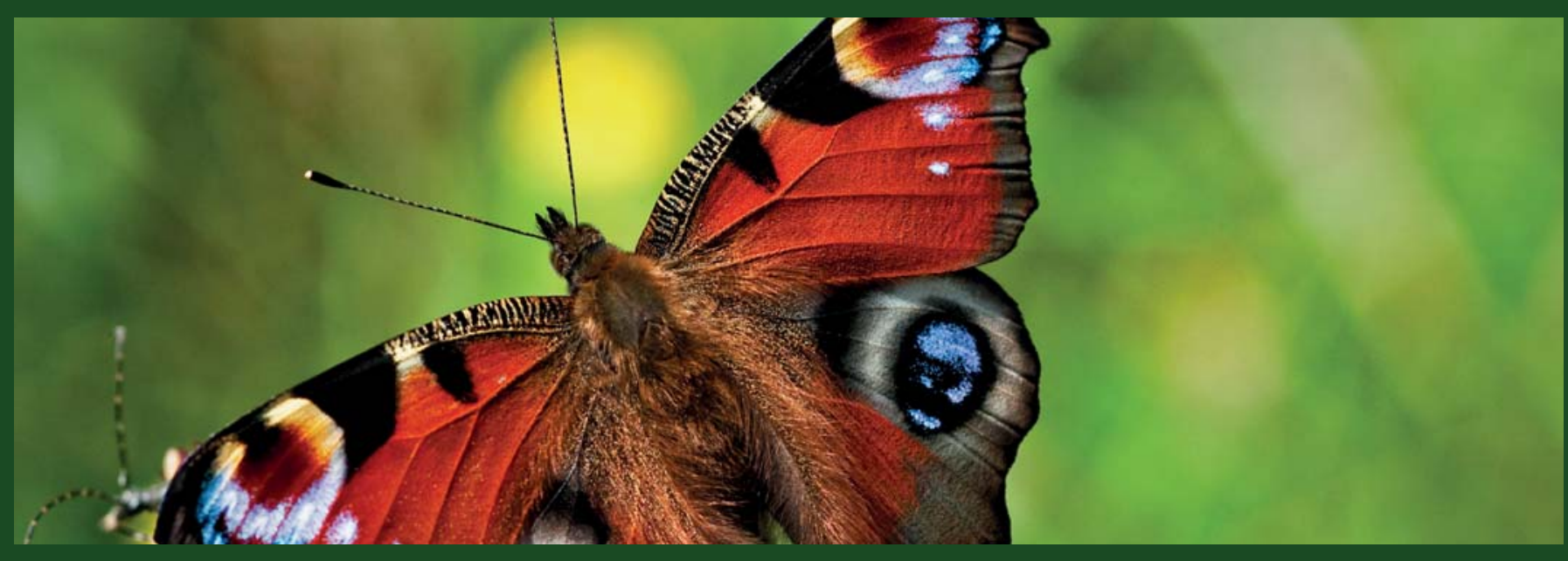

\title{
SCIENCE FOR THE ENVIRONMENT
}

\section{MAPPING KNOWLEDGE NEEDS FOR FUTURE HORIZONS}

3-4 October 2013 
Publisher: $\quad$ Aarhus University, DCE - Danish Centre for Environment and Energy $\odot$

URL: http://dce.au.dk

Year of publication: 2013

Layout: $\quad$ AU Silkeborg

Cover photo: Mark Robinson

Number of pages: $\quad 124$

ISBN: 978-87-7156-028-2

Printed by: Rosendahls Schultz Grafisk A/S

Printed on: GALERIE ART Silk

$$
\begin{aligned}
& \sqrt{7}{ }^{M I X} \\
& \begin{array}{c}
\text { From responsible } \\
\text { sources }
\end{array} \\
& \begin{array}{ll}
\underset{\text { wywniscory }}{\text { FSC }} & \text { FSC }{ }^{\circ} \text { C068122 }
\end{array}
\end{aligned}
$$


$2^{N D}$ INTERNATIONAL

CONFERENCE

\section{SCIENCE FOR THE ENVIRONMENT}

MAPPING KNOWLEDGE NEEDS FOR FUTURE HORIZONS

3-4 October 2013 


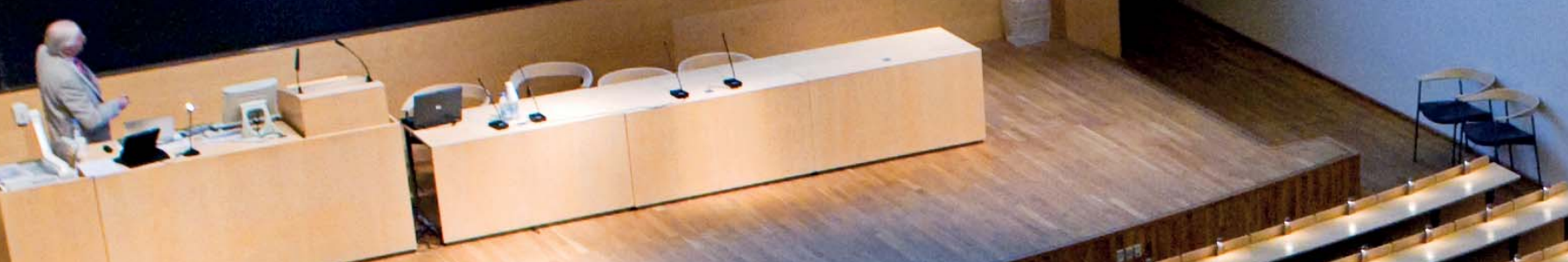

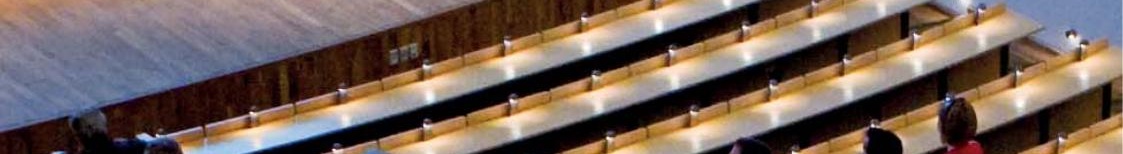

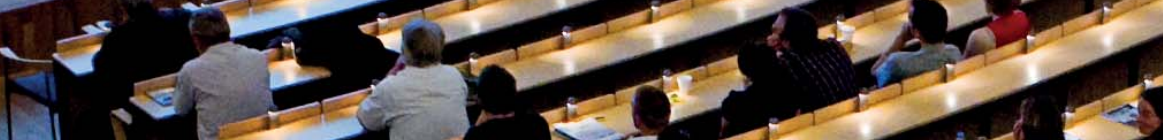

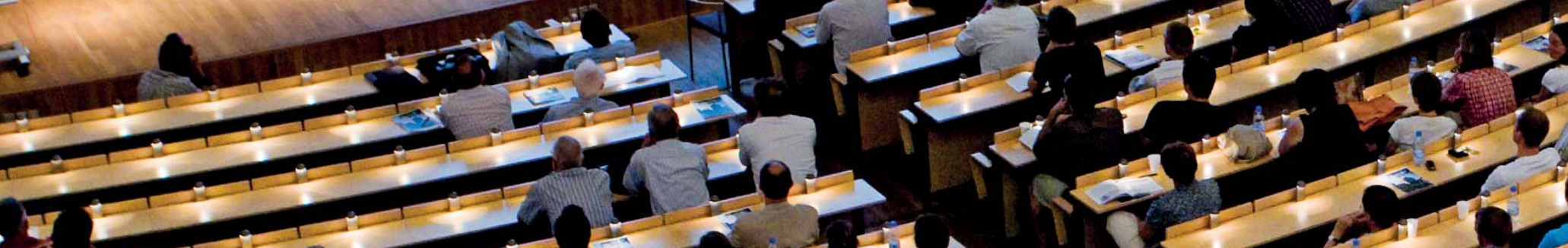

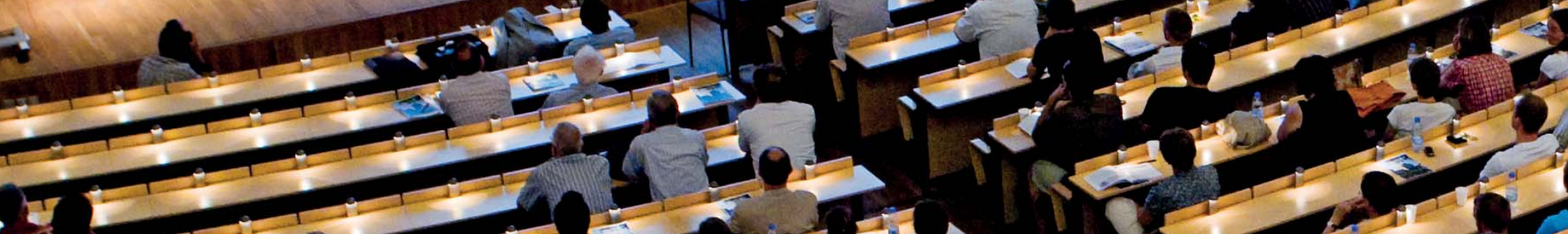

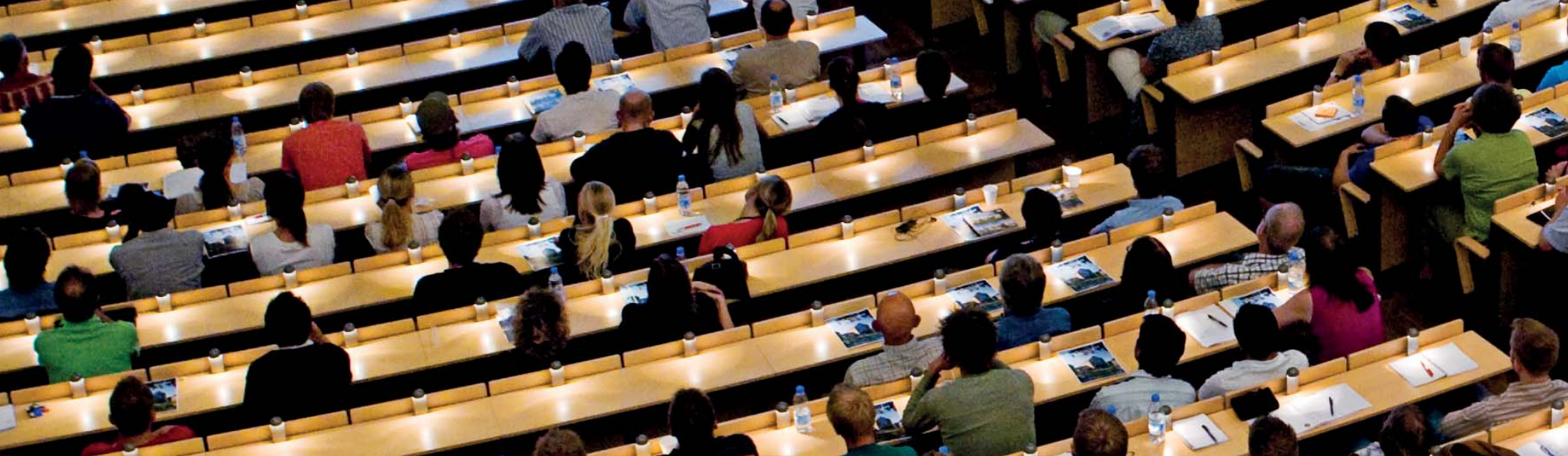
$6+1+5+2=$ (1) (.) 


\section{CONTENT}

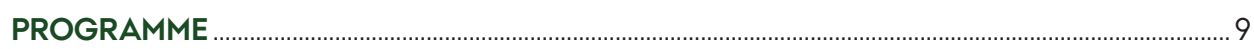

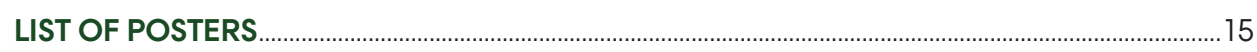

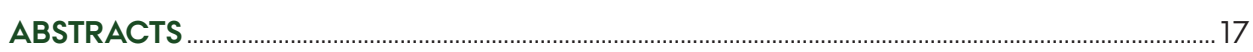

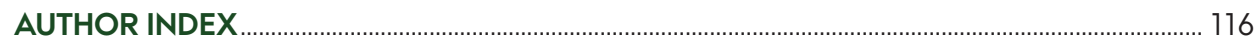

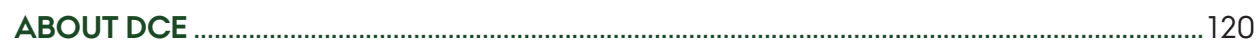

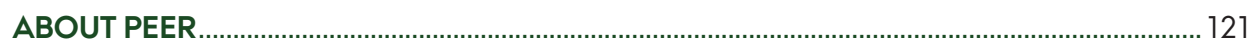

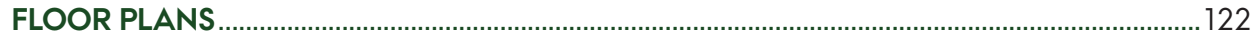




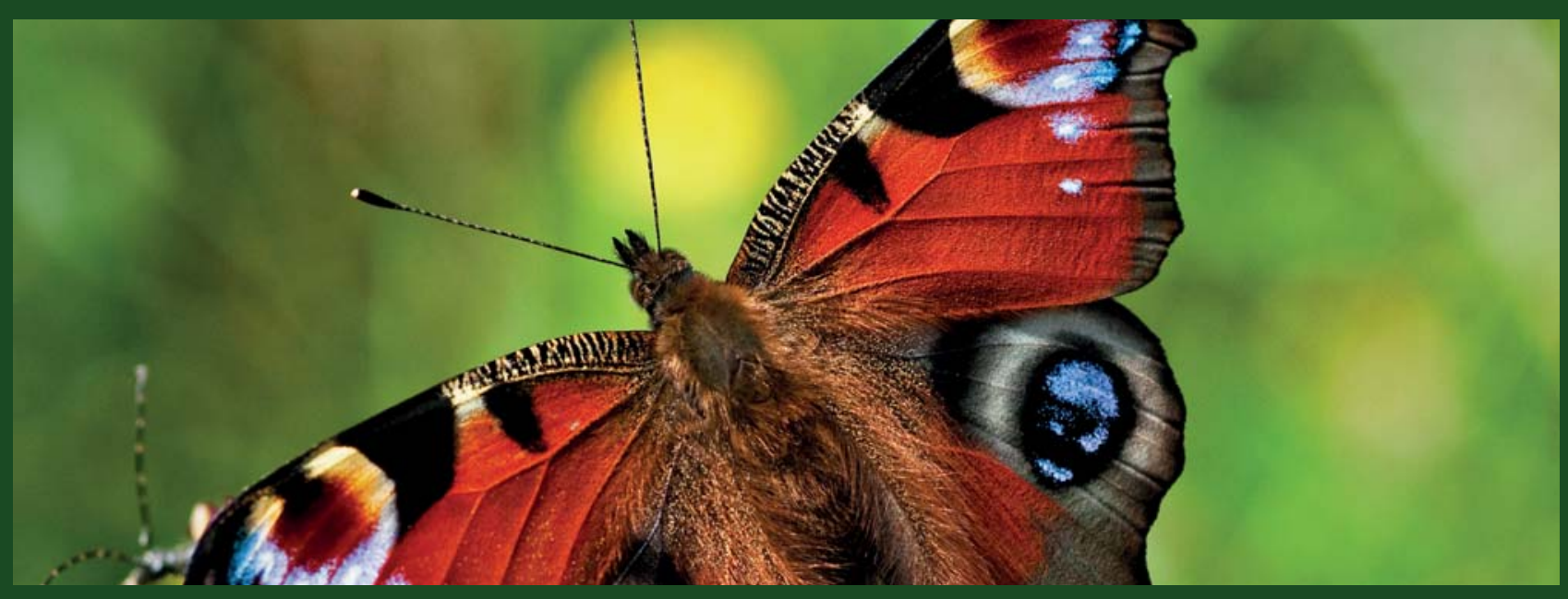




\title{
SCIENCE FOR THE ENVIRONMENT CONFERENCE 3-4 OCTOBER 2013, AARHUS, DENMARK
}

\author{
VENUE \\ Lakeside Lecture Theatres \\ Bartholins Allé 3 \\ 8000 Aarhus C
}

Auditorium 1-5 locations: see floor plans, page 122 and 123.

\section{CATERING}

Lunches and coffee breaks will be served in the foyer on the first floor.

\section{DINNER}

The conference dinner takes place on October 3'rd 19:30 h. at 'Turbinehallen' Kalkvarksvej 12, Aarhus C. Doors will open at $18.30 \mathrm{~h}$.

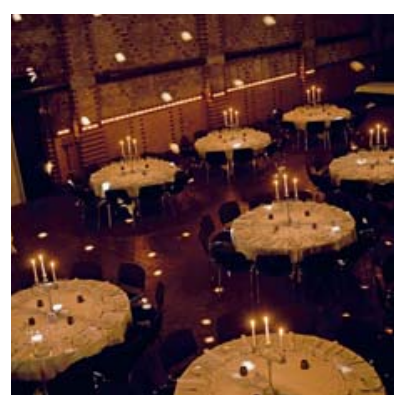

\section{REGISTRATION DESK OPENING HOURS}

Thursday October 3 $3^{\text {rd: }: 000 ~-~ 18: 30 ~ h . ~}$

Friday October $4^{\text {th: }}: 8: 00-16: 30$ h.

\section{INTERNET/WI-FI}

You have been assigned a personal code that you will find behind your name tag.

\section{CLOAKROOM}

Items can be stored in the manned cloakroom free of charge. The cloakroom is situated on the ground level and will be open throughout the conference.

\section{CONFERENCE SECRETARIAT}

The conference secretariat can be contacted throughout the conference as well as after the event.

Phone: +4530183121

E-mail: environment2013@au.dk

http://dce-conference.au.dk 


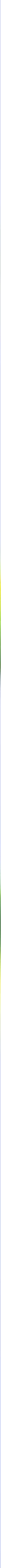




\section{Local Organising Committee}

- Anja Skjoldborg Hansen (Chair)

- Hans Sanderson

- Peter Borgen Sørensen

- Helge Rørdam Olesen

- Karin Balle Madsen

- Cecilie Simone Sundling

\section{Scientific Committee}

- Hans Sanderson, (Chair)

Department of Environmental Science, Aarhus University, Denmark

- Marianne Thomsen,

Department of Environmental Science, Aarhus University, Denmark

- Helge Rørdam Olesen,

Department of Environmental Science, Aarhus University, Denmark

- Peter Borgen Sørensen,

Department of Bioscience, Aarhus University, Denmark

- Christopher John Topping,

Department of Bioscience, Aarhus University, Denmark

- Birgitte Egelund Olsen,

Department of Law, Aarhus University, Denmark

- Jeppe Lœssøe,

Department of Education, Aarhus University, Denmark

- Nicholas Corker,

Centre for Ecology and Hydrology (CEH), UK

- Mikael Hildén,

Finnish Environment Institute (SYKE), Finland

- Sander Jansen,

Alterra, Wageningen University and Research Centre, The Netherlands

- Joachim Maes,

JRC-IES, European Commission

- Dominique Laborde,

Irstea, France

- Ursula Schmitz,

UFZ, Germany

Coffee, tea and other drinks will be served in $100 \%$ compostable, biodegradable corn starch cups. Water will be clean Danish tap water served in reusable pitchers, to reduce on the use of resources and transport of plastic bottles.

The conference bag is an organic fair-trade cotton tote bag in natural white. The print on the bag is non-toxic. The conference bag contains a long-lasting, $80 \%$ biodegradable pen, made from wood powder and a vegetable based plastic. The folder is made of $100 \%$ recycled craft paperboard, completely chlorine-free (TCF). The stickers produced for the folders are made in a Nordic Eco-labeled printing house and stickers are $\mathrm{CO}_{2}$-neutral. The abstract book is printed on FSC-certified paper with non-toxic print. 


\section{PROGRAMME}

\section{WEDNESDAY OCTOBER $2^{\text {ND }}$}

17.00-18.30 Reception and early registration, Town Hall

\section{THURSDAY OCTOBER $3^{\text {RD }}$}

8.00-9.00 Registration at Lakeside Lecture Theatres, Aarhus University

$9.00-10.30$

\section{Auditorium 1}

Per Kirkeby

Opening session

Chair: Hanne Bach, Director of DCE - Danish Centre for Environment and Energy,

Aarhus University

Niels Christian Nielsen, Dean, Faculty of Science and Technology, Aarhus University Jean-Marc Bournigal, Director of Irstea (France) and chair of PEER

- Partnership for European Environmental Research

Anne Glover, Chief Scientific Advisor to the European Commission

Andrea Tilche, Head of Unit, DG Research, European Commission

Hans Bruyninckx, Director of European Environment Agency (EEA)

Claus Stig Pedersen, Head of Sustainability Development, Novozymes

\subsection{0-10.50 Coffee break}

\subsection{0-12.50 Key-note speakers}

Chair: Hans Sanderson

David Gee, Co-author: Late lessons from early warnings, EEA

Frans Berkhout, Amsterdam Global Change Institute

Anil Markandya, BC3, The Basque Climate Change Research Centre

Roger Street, UKCIP, Environmental Change Institute at the University of Oxford 


\section{THURSDAY OCTOBER $3^{\text {RD }}$}

\begin{tabular}{|c|c|c|c|c|}
\hline & $\begin{array}{l}\text { Auditorium } 1 \\
\text { Per Kirkeby }\end{array}$ & $\begin{array}{l}\text { Auditorium } 2 \\
\text { Merethe Barker }\end{array}$ & $\begin{array}{l}\text { Auditorium } 3 \\
\text { Eduard Biermann }\end{array}$ & $\begin{array}{l}\text { Auditorium } 4 \\
\text { Jeppe Vontillius }\end{array}$ \\
\hline \multirow[t]{2}{*}{$13.30-15.10$} & $\begin{array}{l}\text { Adaptation - } 1 \\
\text { Session } 1 \\
\text { Chair: Sergio Castelliari } \\
\text { Rapporteur: Hans } \\
\text { Sanderson }\end{array}$ & $\begin{array}{l}\text { Mitigation - } 1 \\
\text { Session } 2 \\
\text { Chair: Joachim Audet } \\
\text { Rapporteur: Birgitte Ege- } \\
\text { lund Olsen }\end{array}$ & $\begin{array}{l}\text { Resource Efficiency - } 1 \\
\text { Session } 3 \\
\text { Chair: Joachim Maes } \\
\text { Rapporteur: } \\
\text { Marianne Thomsen }\end{array}$ & $\begin{array}{l}\text { Green Economy - } 1 \\
\text { Session } 4 \\
\text { Chair: Nicholas Corker } \\
\text { Rapporteur: Anja Skjold- } \\
\text { borg Hansen }\end{array}$ \\
\hline & $\begin{array}{l}\text { P.A. Harrison et al. } \\
\text { The potential for ad- } \\
\text { aptation to offset the } \\
\text { cross-sectoral impacts of } \\
\text { climate change on Eu- } \\
\text { ropean natural resource } \\
\text { sectors } 1.1 \\
\text { F. Bosello et al. } \\
\text { Identifying key chal- } \\
\text { lenges to developing } \\
\text { climate adaptation strate- } \\
\text { gies in Europe } 1.2 \\
\text { T. Taylor et al. } \\
\text { Towards a Marginal Ad- } \\
\text { aptation Cost Curve for } \\
\text { Health: A critical synthe- } \\
\text { sis } 1.3 \\
\text { O. Gebhardt et al. } \\
\text { Decision support for cli- } \\
\text { mate change adaptation } \\
\text { under uncertainty } 1.4 \\
\text { B. Bockhorn et al. } \\
\text { Challenges for stormwa- } \\
\text { ter infiltration in urban } \\
\text { areas } 1.5\end{array}$ & $\begin{array}{l}\text { J.H. Bønløkke et al. } \\
\text { Effects of a very low en- } \\
\text { ergy building scenario in } \\
\text { Europe on health } 2.1 \\
\text { K. Peterkova } \\
\text { Calculating Potential for } \\
\text { Emission's Reduction via } \\
\text { Supply Chain Contracts } \\
2.2 \\
\text { J. Audet et al. } \\
\text { Greenhouse gas emis- } \\
\text { sions from a Danish ripar- } \\
\text { ian wetland before and } \\
\text { after restoration } 2.3 \\
\text { H.K. Nielsen et al. } \\
\text { Sustainability and road } \\
\text { transport in Norway } 2.4 \\
\text { U.S. Brandt \& G.T. Svendsen } \\
\text { Carbon leakage, renew- } \\
\text { able energy and coali- } \\
\text { tions } 2.5\end{array}$ & $\begin{array}{l}\text { C. Ditlefsen et al. } \\
\text { Ground Source heating } \\
\text { and cooling - elements } \\
\text { in a sustainable energy } \\
\text { supply } 3.1 \\
\text { L. Lamorgese \& D. } \\
\text { Geneletti } \\
\text { Addressing equity in land } \\
\text { use decisions: A case } \\
\text { study in the Oil and Gas } \\
\text { sector } 3.2 \\
\text { T. Kuhn et al. } \\
\text { Energy policy, food, } \\
\text { and climate change - a } \\
\text { numerical simulation ap- } \\
\text { proach } 3.3 \\
\text { A.R. Tan et al. } \\
\text { Analysing (in)efficiencies } \\
\text { in the use of raw materi- } \\
\text { als and underlying driv- } \\
\text { ers - what are existing } \\
\text { knowledge gaps and } \\
\text { research needs? } 3.4 \\
\text { M. Garnier et al. } \\
\text { Climate change and } \\
\text { water. Identification of } \\
\text { the research needs in } \\
\text { Europe } 3.5\end{array}$ & $\begin{array}{l}\text { N. Tabesh \& N.T. Bey- } \\
\text { dokhti } \\
\text { Investigation of textile } \\
\text { wastewater treatment, } \\
\text { using a system of Sub } \\
\text { Surfaceconstructed wet- } \\
\text { land } 4.1 \\
\text { C.-G. Thulin et al. } \\
\text { Multipurpose wildlife: Food, } \\
\text { recreation and biodiversity } \\
\text { combined } 4.2 \\
\text { S.G. Sommer et al. } \\
\text { Biogas from beet pulp } \\
\text { and source separated } \\
\text { household waste- Energy } \\
\text { production and Green- } \\
\text { house Gas Reduction } 4.3 \\
\text { T. Dalgaard } \\
\text { Models for multi- } \\
\text { criteria sustainability as- } \\
\text { sessment of a new more } \\
\text { biobased and circular } \\
\text { economy } 4.4 \\
\text { R. Merli et al. } \\
\text { EMAS regulation in italian } \\
\text { clusters: investigating } \\
\text { the involvement of local } \\
\text { stakeholders } 4.5\end{array}$ \\
\hline
\end{tabular}

15.10-15.30 Coffee break 


\begin{tabular}{|c|c|c|c|c|c|}
\hline & $\begin{array}{l}\text { Auditorium } 1 \\
\text { Per Kirkeby }\end{array}$ & $\begin{array}{l}\text { Auditorium } 2 \\
\text { Merethe Barker }\end{array}$ & $\begin{array}{l}\text { Auditorium } 3 \\
\text { Eduard Biermann }\end{array}$ & $\begin{array}{l}\text { Auditorium } 4 \\
\text { Jeppe Vontillius }\end{array}$ & $\begin{array}{l}\text { Auditorium } 5 \\
\text { William Scharff }\end{array}$ \\
\hline $.30-17.10$ & $\begin{array}{l}\text { BASE } \\
\text { Special session } 5 \\
\text { Chair: Hans Sanderson } \\
\text { Rapporteur: } \\
\text { Sergio Castelliari }\end{array}$ & $\begin{array}{l}\text { LIAISE } \\
\text { Special session } 6 \\
\text { Chair. Jacques Janssen } \\
\text { Rapporteur: Sander } \\
\text { Janssen }\end{array}$ & $\begin{array}{l}\text { Bioresources } \\
\text { Session } 7 \\
\text { Chair: Marianne } \\
\text { Thomsen } \\
\text { Rapporteur: Helge } \\
\text { Rørdam Olesen }\end{array}$ & $\begin{array}{l}\text { Rebound effects } \\
\text { Special session } 8 \\
\text { Chair and rappor- } \\
\text { teur: Anja Peters } \\
\text { and Martin Soland }\end{array}$ & $\begin{array}{l}\text { Afromaison } \\
\text { Special session } 9 \\
\text { Chair: Nils Ferrand } \\
\text { Rapporteur: } \\
\text { Dominique Laborde }\end{array}$ \\
\hline & $\begin{array}{l}\text { D. Russel et al. } \\
\text { A BASE project } \\
\text { analysis of EU Mem- } \\
\text { ber State Climate } \\
\text { Change Adaptation } \\
\text { Strategies: Compar- } \\
\text { ing approaches and } \\
\text { drawing lessons } 5.1 \\
\text { F. Bosello et al. } \\
\text { Integrating top- } \\
\text { down and bot- } \\
\text { tom-up perspectives } \\
\text { in adaptation as- } \\
\text { sessment } 5.2 \\
\text { X. Li et al. } \\
\text { BASE: A robust strat- } \\
\text { egy for adaptation } \\
\text { case study research } \\
\mathbf{5 . 3} \\
\text { G. Penha-Lopes et al. } \\
\text { Case-Studies - their } \\
\text { potential and chal- } \\
\text { lenges within BASE } \\
\text { project } 5.4 \\
\text { A. Jeuken et al. } \\
\text { BASE: integrated } \\
\text { adaptation path- } \\
\text { ways at EU level } \\
\text { - how to combine } \\
\text { case data with } \\
\text { models } 5.5\end{array}$ & $\begin{array}{l}\text { T. Söderman et al. } \\
\text { The LIAISE ap- } \\
\text { proach to co-de- } \\
\text { signing knowledge } \\
\text { on impact assess- } \\
\text { ment } 6.1 \\
\text { O. Roosenschoon } \\
\text { et al. } \\
\text { The shared IA tool- } \\
\text { box } 6.2 \\
\text { N. Glasner et al. } \\
\text { Impact assessment } \\
\text { of soil protection } \\
\text { policies in Eu- } \\
\text { rope } 6.3 \\
\text { S. Janssen et al. } \\
\text { Impact assessment } \\
\text { for Sustainable de- } \\
\text { velopment: A vision } \\
\text { for future develop- } \\
\text { ment } 6.4\end{array}$ & $\begin{array}{l}\text { M. Seghetta et al. } \\
\text { Circular resource } \\
\text { flows from algae } \\
\text { production } 7.1 \\
\text { J.K. Petersen et al. } \\
\text { Mussel production } \\
\text { to utilize excess nu- } \\
\text { trients in fjords - is } \\
\text { it cost-costeffec- } \\
\text { tive as mitigation } \\
\text { measure? } 7.2 \\
\text { A. Trémier et al. } \\
\text { Eco-efficient post } \\
\text { treatment of diges- } \\
\text { tate from single and } \\
\text { mixed biogas plants } \\
7.3 \\
\text { K. Spilling et al. } \\
\text { The potential of us- } \\
\text { ing algae as feed- } \\
\text { stock for biofuel, a } \\
\text { Nordic perspective } \\
7.4 \\
\text { I. Johannsen } \\
\text { Getting value out of } \\
\text { biomass, high value } \\
\text { chemicals from } \\
\text { lignocellulosis } 7.5\end{array}$ & $\begin{array}{l}\text { M. Soland } \\
\text { Environmental re- } \\
\text { sponsibility denial } \\
\text { due to optimism in } \\
\text { green technology } \\
8.1 \\
\text { H.J. Walnum } \\
\text { Interdisciplinary } \\
\text { understanding of } \\
\text { macro-rebound ef- } \\
\text { fects } 8.2 \\
\text { H. Marth \& A. Peters } \\
\text { Developing a policy } \\
\text { guideline for re- } \\
\text { bound effects } 8.3 \\
\text { C. Sartorius \& M. } \\
\text { Pfaff } \\
\text { Measuring Mac- } \\
\text { roeconomic Re- } \\
\text { bound Effects for } \\
\text { Non-energetic Re- } \\
\text { sources } 8.4 \\
\text { A. Peters et al. } \\
\text { Exploring and ana- } \\
\text { lyzing relevance } \\
\text { and psychological } \\
\text { drivers of rebound } \\
\text { effects } 8.5\end{array}$ & $\begin{array}{l}\text { N. Ferrand et al. } \\
\text { Participatory } \\
\text { planning and role } \\
\text { playing games for } \\
\text { multilevel INRM in } \\
\text { Africa } 9.1 \\
\text { R. Ducrot et al. } \\
\text { Conditions and } \\
\text { results of a joint } \\
\text { monitoring and } \\
\text { evaluation protocol } \\
\text { in } 5 \text { countries } 9.2 \\
\text { A. Kabaseke et al. } \\
\text { The Rwenzori Moun- } \\
\text { tain case (UG): A } \\
\text { pilot for large scale } \\
\text { social extension, } \\
\text { exploration and in- } \\
\text { stitutionalization of a } \\
\text { change strategy for } \\
\text { Integrated Natural } \\
\text { Resource Manage- } \\
\text { ment from grass root } \\
\text { to regional level } 9.3 \\
\text { D. Mori } \\
\text { A way to plan, play, } \\
\text { assess and moni- } \\
\text { tor a participative } \\
\text { integrated natural } \\
\text { resource manage- } \\
\text { ment (INRM) in Inner } \\
\text { Niger Delta (IND) in } \\
\text { general and three } \\
\text { (3) municipalities } \\
\text { level in particular } \\
\text { in the frame of FP7 } \\
\text { AFROMAISON } 9.4\end{array}$ \\
\hline
\end{tabular}




\section{FRIDAY OCTOBER $4^{\text {TH }}$}

\begin{tabular}{|c|c|c|c|c|c|}
\hline & $\begin{array}{l}\text { Auditorium } 1 \\
\text { Per Kirkeby }\end{array}$ & $\begin{array}{l}\text { Auditorium } 2 \\
\text { Merethe Barker }\end{array}$ & $\begin{array}{l}\text { Auditorium } 3 \\
\text { Eduard Biermann }\end{array}$ & $\begin{array}{l}\text { Auditorium } 4 \\
\text { Jeppe Vontillius }\end{array}$ & $\begin{array}{l}\text { Auditorium } 5 \\
\text { William Scharff }\end{array}$ \\
\hline 9.00-10.40: & $\begin{array}{l}\text { Sebastian Helgen- } \\
\text { berger, University of } \\
\text { Natural Resources and } \\
\text { Life Sciences, Vienna: } \\
\text { Transformative Research } \\
\text { in Europe: Can research } \\
\text { accompany societal } \\
\text { change? Should it? } \\
\text { Adaptation - } 2 \\
\text { Session } 10 \\
\text { Chair: Helle Ørsted } \\
\text { Nielsen } \\
\text { Rapporteur: Ursula } \\
\text { Schmitz }\end{array}$ & & $\begin{array}{l}\text { Ecosystem services - } 1 \\
\text { Session } 12 \\
\text { Chair: Eeva Primmer } \\
\text { Rapporteur: Joachim } \\
\text { Maes }\end{array}$ & $\begin{array}{l}\text { Gender, energy and } \\
\text { climate change } \\
\text { Special session } 13 \\
\text { Chairs and rappor- } \\
\text { teurs: Susan Bucking- } \\
\text { ham \& Inés Sánchez } \\
\text { de Madariaga }\end{array}$ & $\begin{array}{l}\text { JPI Climate } \\
\text { Special session } 11 \\
\text { Chair: Eva Banos } \\
\text { de Guisasola } \\
\text { Rapporteur: Hans } \\
\text { Sanderson }\end{array}$ \\
\hline & $\begin{array}{l}\text { R.J. Klein \& S. Juhola } \\
\text { A Framework for Nor- } \\
\text { dic Actor-Oriented } \\
\text { Climate Adaptation } \\
\text { Research } 10.1 \\
\text { M. Hildén et al. } \\
\text { A BASE-analysis of } \\
\text { adaptation in coastal } \\
\text { areas - what can EU } \\
\text { policies do? } 10.2 \\
\text { S. Weiland et al. } \\
\text { The EU climate ad- } \\
\text { aptation strategy: An } \\
\text { evaluation of its 'pro- } \\
\text { gramme theory' } 10.3 \\
\text { H.Ø. Nielsen et al. } \\
\text { How will the EU } \\
\text { climate adaptation } \\
\text { strategy affect EU } \\
\text { agricultural poli- } \\
\text { cies? } 10.4 \\
\text { A. Iglesias et al. } \\
\text { Water for people and } \\
\text { for the environment: } \\
\text { Linking modelling } \\
\text { and participatory } \\
\text { approaches to define } \\
\text { adaptation in the } \\
\text { Tagus basin, Iberian } \\
\text { Peninsula } 10.5\end{array}$ & & $\begin{array}{l}\text { R. Alkemade \& T. } \\
\text { Lazarova } \\
\text { Consequences of } \\
\text { EU environmental } \\
\text { policies for ecosys- } \\
\text { tem service provision } \\
\text { elsewhere } 12.1 \\
\text { C. Schleyer \& J. } \\
\text { Hauck } \\
\text { The ecosystem ser- } \\
\text { vices concept in EU } \\
\text { policies: A review of } \\
\text { regulatory frame- } \\
\text { works } 12.2 \\
\text { E. Primmer et al. } \\
\text { How does governance } \\
\text { contribute to conserva- } \\
\text { tion of biodiversity and } \\
\text { ecosystem services: A } \\
\text { conceptual model of } \\
\text { knowledge use and } \\
\text { the effects of argu- } \\
\text { ments and policies } 12.3 \\
\text { S. Borgström \& J. Similä } \\
\text { Developing regula- } \\
\text { tory frameworks for } \\
\text { green infrastructure: } \\
\text { Issues to be ad- } \\
\text { dressed } 12.4 \\
\text { J. Maes } \\
\text { Mapping and assess- } \\
\text { ment of ecosystems } \\
\text { and their services: De- } \\
\text { veloping a knowledge } \\
\text { base for mainstream- } \\
\text { ing ecosystem services } \\
\text { into EU policies } 12.5\end{array}$ & $\begin{array}{l}\text { Inés Sánchez de } \\
\text { Madariaga } \\
\text { Presentation of COST } \\
\text { network gender STE: } \\
\text { Mapping the state of the } \\
\text { art in Gender, Energy } \\
\text { and Climate Change } \\
\text { Karen Morrow } \\
\text { Women's Participation } \\
\text { in Climate Change } \\
\text { Governance; why we } \\
\text { need it, how we can } \\
\text { reduce barriers } \\
\text { Hilda Rohmer } \\
\text { Impact of gen- } \\
\text { der differences in } \\
\text { transport on energy } \\
\text { consumption and } \\
\text { climate change } \\
\text { Sherilyn MacGregor } \\
\text { The politics of en- } \\
\text { ergy consumption in } \\
\text { the North: feminist } \\
\text { challenges to domi- } \\
\text { nant discourses } \\
\text { Berit Aasen } \\
\text { A gendered view } \\
\text { from the South: ac- } \\
\text { cess to energy and } \\
\text { impact of climate } \\
\text { change } \\
\text { Marcella Schmidt } \\
\text { Women facing } \\
\text { change: the climate } \\
\text { dimension } \\
\text { Richard Langlais } \\
\text { Who responds to cli- } \\
\text { mate change best? } \\
\text { A perspective from } \\
\text { Swedish municipalities } \\
\text { Discussion }\end{array}$ & $\begin{array}{l}\text { 1. Discussion of key } \\
\text { questions on the } \\
\text { science-policy in- } \\
\text { terface } \\
\text { 2. A general pres- } \\
\text { entation of JPI } \\
\text { climate } \\
\text { 3. Identification of } \\
\text { knowledge gaps } \\
\text { Moving towards } \\
\text { Reliable Decadal } \\
\text { Climate Predictions: } \\
\text { Sylvie Joussaume } \\
\text { (France) and Sanna } \\
\text { Sorvari (Finland) } \\
\text { Researching } \\
\text { Climate Service } \\
\text { Development and } \\
\text { Deployment: } \\
\text { Roger Street (UK) } \\
\text { Sustainable Trans- } \\
\text { formations of Soci- } \\
\text { ety in the Face of } \\
\text { Climate Change: } \\
\text { Lisa Almesjö, } \\
\text { Sebastian Helgen- } \\
\text { berger (AU) } \\
\text { Decision-support } \\
\text { methods and tools } \\
\text { for Climate Change: } \\
\text { Gregor Laumann } \\
\text { (GE) } \\
\text { Integrating the } \\
\text { JPI climate: Roger } \\
\text { Street (UK) }\end{array}$ \\
\hline
\end{tabular}




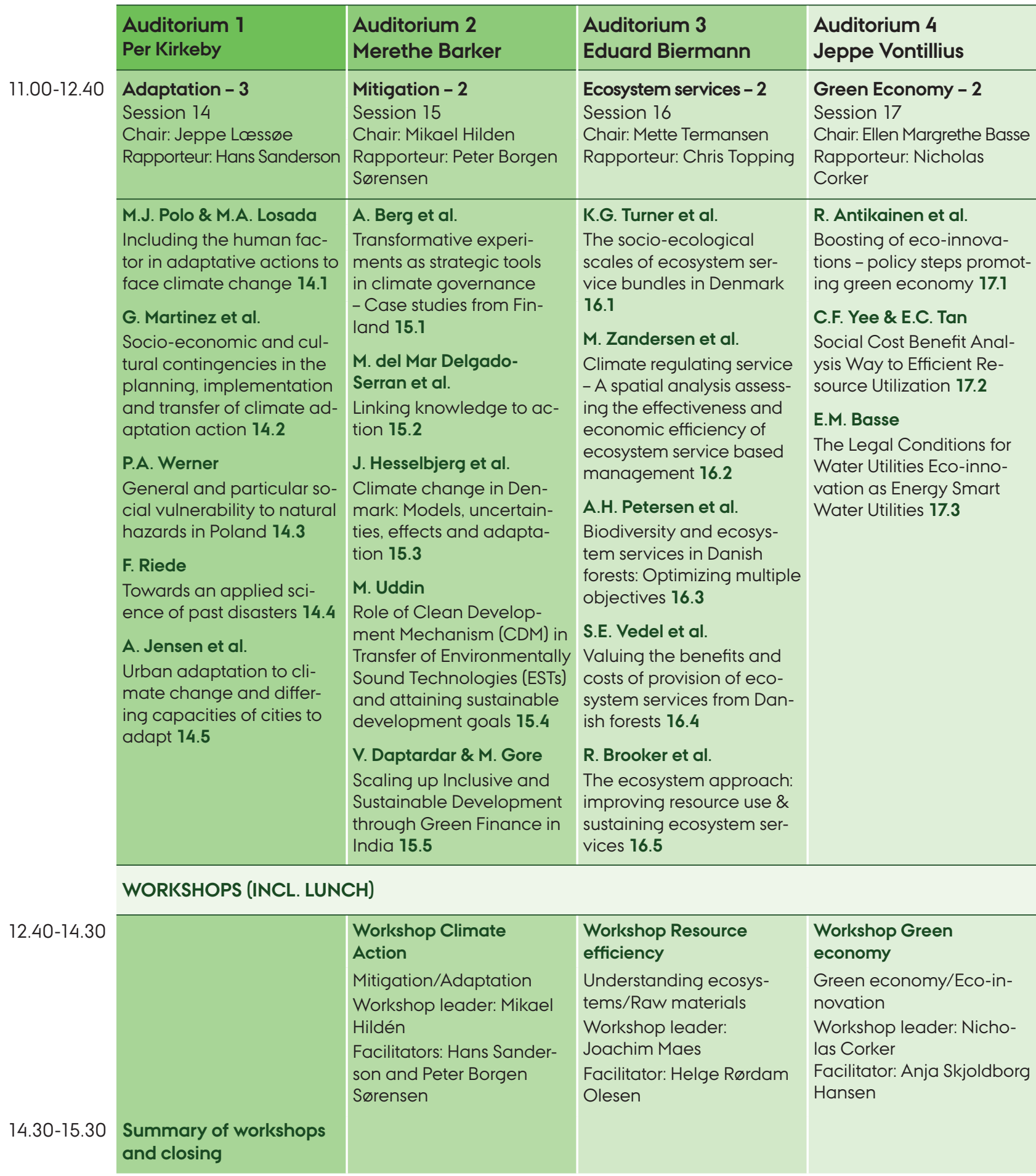



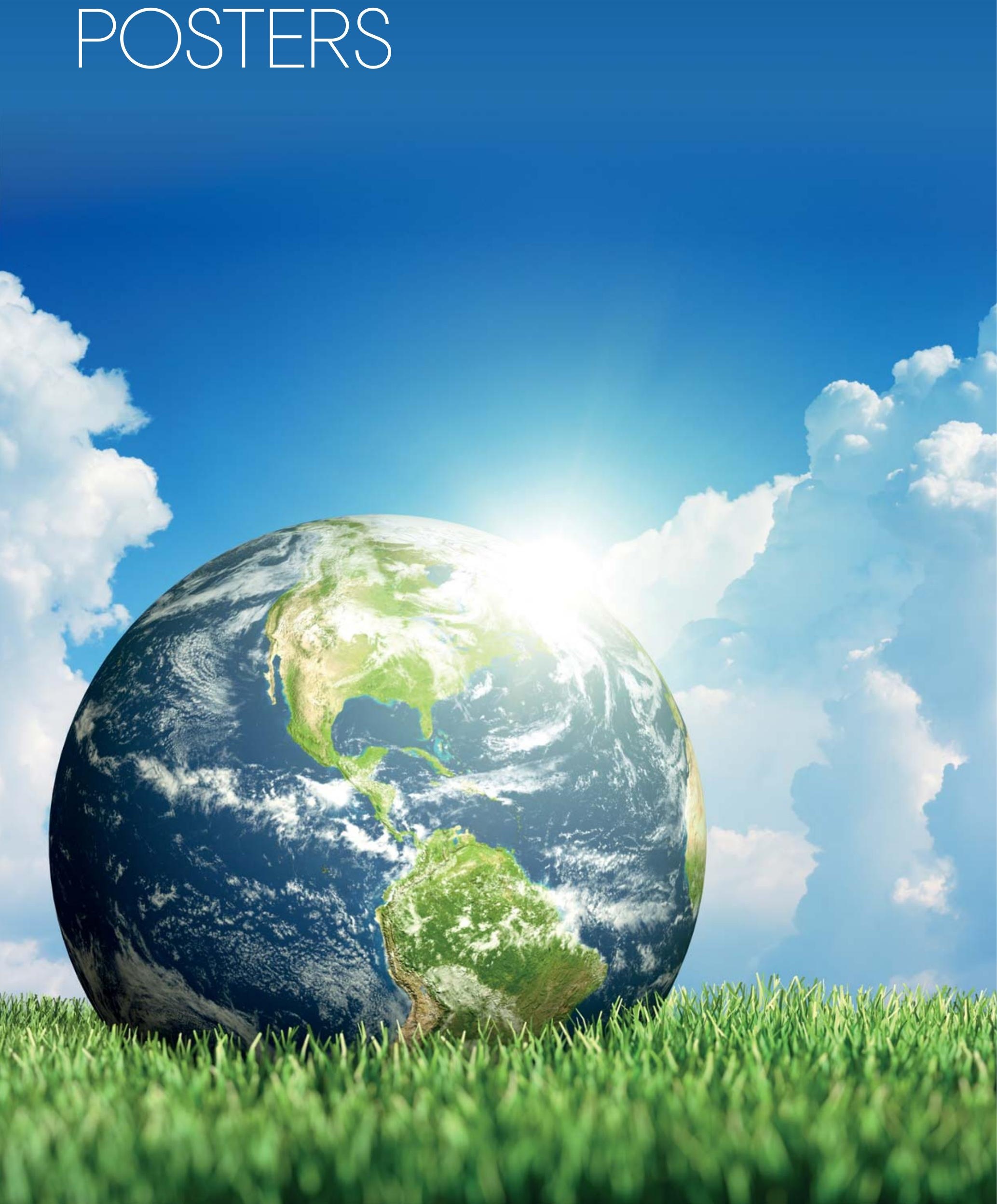


\section{LIST OF POSTERS}

\begin{tabular}{|c|c|c|}
\hline p.1 & A. Branth Pedersen et al. & Coherent policy instruments for climate change adaptation? \\
\hline p. 2 & S. Weiland et al. & Criteria for evaluating climate adaptation measures: A meta-analysis \\
\hline p.3 & M. Zandersen \& A. Jensen & Ecosystem-based approaches to Climate Adaptation - possibilities and conflicts in urban areas \\
\hline p.4 & D. Vačkář et al. & Exploring ecosystem-based approaches to climate change adaptation \\
\hline p.5 & A. Jensen et al. & Institutional barriers and knowledge in local policies to integrate climate adaptation \\
\hline p.6 & R. Brooker et al. & Translocations for conservation during climate change: an adaptation case study \\
\hline p.7 & M.C. Trannin \& K.L. Garcia & Universidade Estácio de Sá - Brazil 2020: Contribution to innovative adaptation \\
\hline p.8 & W. Al-shabib & $\begin{array}{l}\text { Applications of Intrinsic Conducting Polymer for Wi-Fi Electromagnetic radiation environment } \\
\text { pollution reduction }\end{array}$ \\
\hline p.9 & T. Dalgaard et al. & $\begin{array}{l}\text { DNMARK: Danish Nitrogen Mitigation Assessment: Research and Know-how for a sustainable, } \\
\text { low-Nitrogen food production }\end{array}$ \\
\hline p.10 & H. Sarkheil & $\begin{array}{l}\text { Implementation of HSE MS in the pipeline of southern Pars gas field of Iran and its impact on } \\
\text { green efficiency growth }\end{array}$ \\
\hline p.11 & B. Hasler et al. & $\begin{array}{l}\text { Aquatic ecosystems services in Denmark - spatial mapping of ecosystem services and creation } \\
\text { of green economic accounting }\end{array}$ \\
\hline p.12 & M. Probonas et al. & Illegal use of poisoned baits and their effects on biodiversity in Crete, Greece \\
\hline p.13 & A. Johansen et al. & $\begin{array}{l}\text { Impact of digestates from anaerobically digested cattle slurry and plant materials on soil mi- } \\
\text { crobial community }\end{array}$ \\
\hline p.14 & L. Thorling \& B. Hansen & Strategies for knowledge based protection of the Danish drinking water resources \\
\hline
\end{tabular}




\section{ABSTRACTS}

1.t.

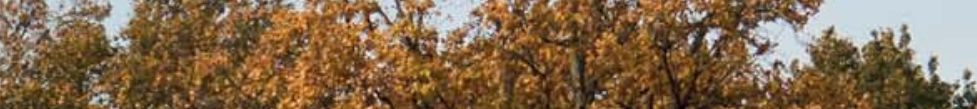

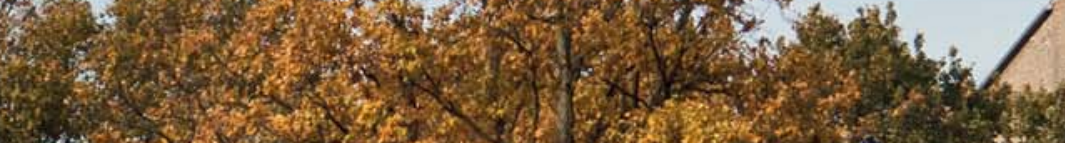

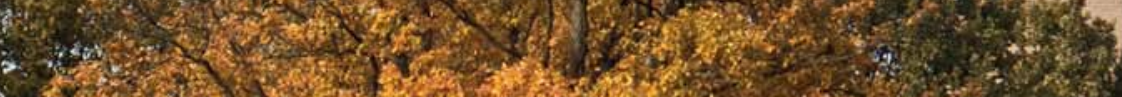

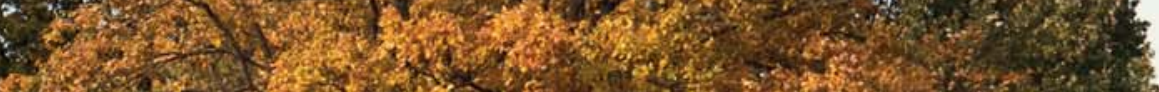

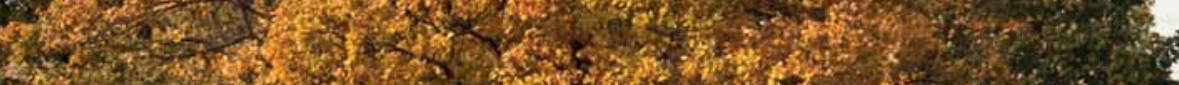

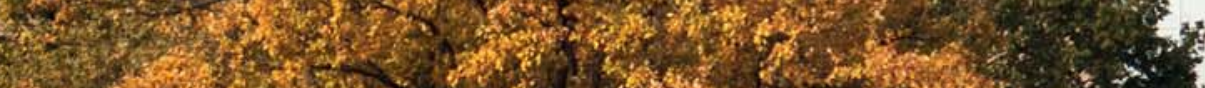

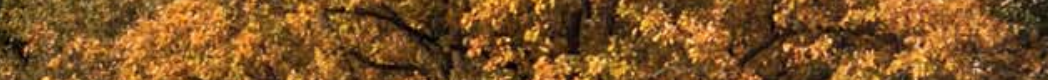

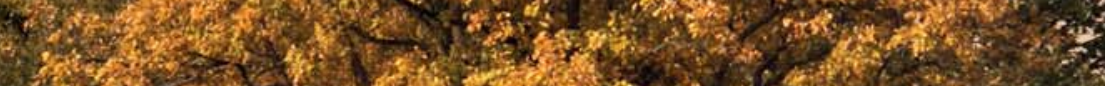

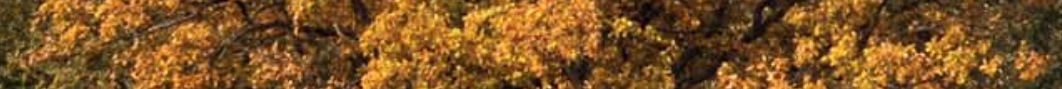

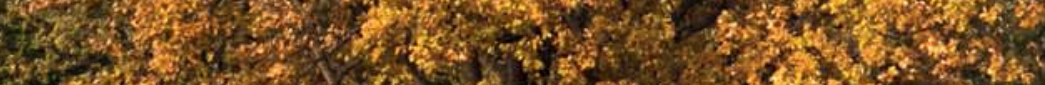

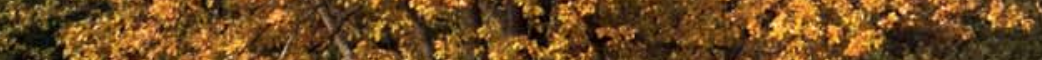
20.

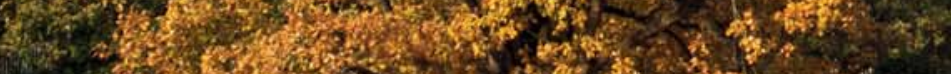

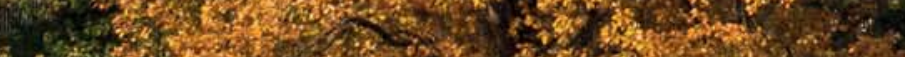

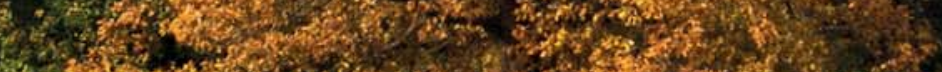

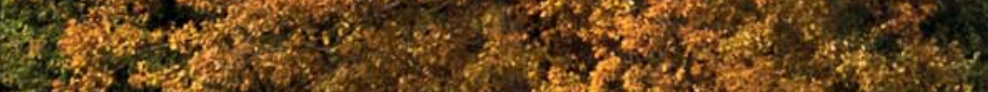
4. W.

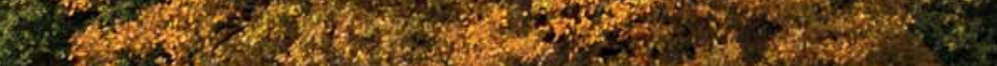

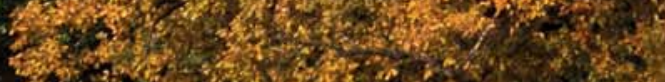

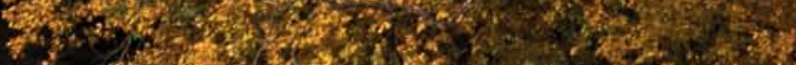
7.7. 


\section{THE POTENTIAL FOR ADAPTATION TO OFFSET THE CROSS-SECTORAL IMPACTS OF CLIMATE CHANGE ON EUROPEAN NATURAL RESOURCE SECTORS}

Paula A. Harrison, Ian Holman, Pam Berry \& CLIMSAVE Partners,

Environmental Change Institute, University of Oxford, UK

\section{ABSTRACT}

Climate change is anticipated to pose a multitude of direct and indirect pressures on European natural resources, such as water, food and biodiversity, even without the additional stresses of future socio-economic change. Understanding the potential of adaptation to counter-act these impacts within uncertain futures is an important need for decision-makers. This paper will provide examples of how the CLIMSAVE participatory Integrated Assessment Platform (IAP; Harrison et al. 2012) can explore choices which inform the integration of adaptation actions and policies across a range of sectors (including agriculture, forests, biodiversity, coasts, water resources and urban development). The CLIMSAVE IAP is a user-friendly, interactive web-based tool which enables stakeholders to explore and understand the interactions between climate change impacts and adaptation across different sectors, rather than viewing their own sector in isolation. This helps ensure that unintentional adaptation resulting from actions in one sector does not reduce the effectiveness of purposeful adaptation in another sector. This paper will illustrate such interactions for a range of sectoral and ecosystem service indicators covered by the platform. It will also demonstrate how the platform can be used to identify robust adaptation strategies for reducing climate change vulnerability which are scenario-independent or no regret strategies (i.e. adaptation responses which will be beneficial for all future climate and socio-economic scenarios). The CLIMSAVE IAP will form part of the tools provided by the European Climate Adaptation Platform (CLIMATE-ADAPT) to support adaptation decision-making in Europe.

\section{REFERENCES}

Harrison, P.A., Holman, I.P., Cojocaru, G., Kok, K., Kontogianni, A., Metzger, M. \& Gramberger, M. (2012). Combining qualitative and quantitative understanding for exploring cross-sectoral climate change impacts, adaptation and vulnerability in Europe. Regional Environmental Change. DOI 10.1007/s10113012-0361-y.

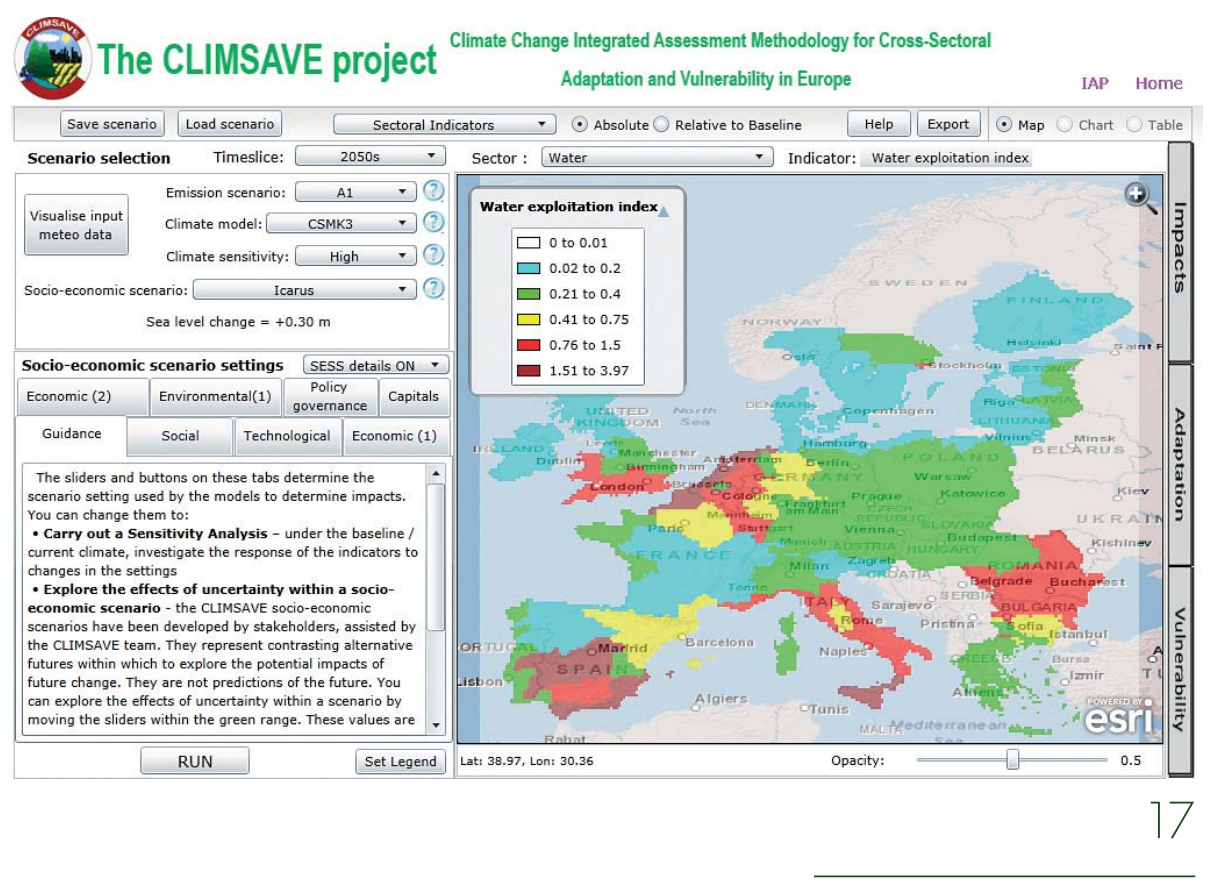




\section{IDENTIFYING KEY CHALLENGES TO DEVELOPING CLIMATE ADAPTATION STRATEGIES IN EUROPE}

Francesco Bosello', Benjamin Boteler ${ }^{2}$, Inês Campos ${ }^{3}$, Alessio Capriolo4, Mikael Hilden ${ }^{5}$, Ad Jeuken ${ }^{6}$, Gil Penha-Lopes ${ }^{3} \&$ Andrew Reid ${ }^{2}$

'Euro-Mediterranean Center on Climate Change (CMCC), ${ }^{2}$ Ecologic Institute, Berlin, ${ }^{3}$ Fundacao da Faculdade de Ciencias da Universidade de Lisboa (FFCUL), ${ }^{4}$ talian National Institute for Environmental Protection and Research (ISPRA), ${ }^{5}$ Finnish

Environment Institute (SYKE), ${ }^{\circ}$ Deltares

\section{ABSTRACT}

There is broad consensus that climate change impacts can lead to serious ecological, economic and social impacts across Europe. Appropriate adaptation can reduce these impacts and, in some cases, yield benefits and opportunities, but this often involves a multi-scalar and multi-sectoral exercise in complex decision-making across different levels of government. Decision makers at all levels in Europe currently face a number of significant challenges when devising appropriate and sustainable adaptation strategies. Broadly speaking, these challenges can be divided into: Uncertainty and insufficient knowledge on the spatial and temporal patterns of the physical impacts of climate change; Uncertainty as relates to current and future socioeconomic trends and processes (and their interactions with climate change); the need to increase coherence between 'top-down' and 'bottom-up' assessments of adaptation strategies, measures and other activities; and the need to ensure synergies and trade-offs with existing policies are identified and exploited, including through enhanced use of participatory processes. Based on literature review and expert opinion, this paper summarises these key challenges, highlighting their implications for adaptation strategies and measures and pointing to avenues of research that could facilitate enhanced decision making for climate change adaptation. This paper builds on the work of the EU funded research project 'Bottom-up Climate Adaptation Strategies Towards a Sustainable Europe' (BASE).

\section{REFERENCES}

Bosello, F. \& Chen, C. (2010). Adapting and mitigating to climate change, Balancing the choices under uncertainty. FEEM Note di Lavoro 2010.59

Hildén, M. (2011). The evolution of climate policies-the role of learning and evaluations. Journal of Cleaner Production, Vol. 19, No. 16:1798-1811. 


\section{TOWARDS A MARGINAL ADAPTATION COST CURVE FOR HEALTH: A CRITICAL SYNTHESIS}

Tim Taylor', Aline Chiabai, Philip Staddon', Anil Markandya² \& Francesco Bosello ${ }^{3}$

'European Centre for Environment and Human Health, University of Exeter Medical School, Truro, UK, ${ }^{2}$ Basque Centre for Climate Change (BC3), Bilbao, Spain, ${ }^{3}$ Fondazione Eni Enrico Mattei, Venice, Italy

\begin{abstract}
The inclusion of health impacts in top down models requires estimation of the adaptation cost curve. To date such curves have been based largely on ad-hoc assumptions as to the costs of adaptation based on parameterisation within models. Here we attempt to synthesise the existing literature on adaptation to the health impacts of climate change in Europe, including a wider range of impacts, such as heat impacts, food and water borne
\end{abstract}

disease, flooding risks to health, mental health impacts and allergies. The objective is to extend the coverage of empirical work on adaptation in health to be included in the models. The potential to develop marginal adaptation cost curves in this context is discussed, as are potential difficulties for integration of such "bottom-up" data into global models, building on the example of AD-WITCH. 


\section{DECISION SUPPORT FOR CLIMATE CHANGE ADAPTATION UNDER UNCERTAINTY}

Oliver Gebhardt, Miriam Brenck \& Volker Meyer

Helmholtz-Centre for Environmental Research - UFZ, Department of Economics, Leipzig, Germany

\section{ABSTRACT}

The need to adapt to the primarily adverse effects of climate change presents decision makers with the challenge to determine which measures are appropriate and efficient to deal with these consequences. This is of particular importance as adaptation measures might be costly and resulting benefits hard to estimate due to the high level of uncertainty related to the changing climate conditions, resulting impacts and the effectiveness of adaptation measures. Under the condition of restricted resources and time an easy to apply technique is required to inform such decisions.

The Helmholtz-Centre for Environmental Research-UFZ has developed such a decision support tool, which not only facilitates the comparison of such measures on the basis of various criteria but also takes account of data uncertainties as well as different stakeholder preferences.

This tool includes a guideline proposing an appropriate assessment approach and a software for Probabilistic Multi-Attribute evaluation (PRIMATE), which is based on the multi-criteria analysis approach (stochastic) PROMETHEE. This method is particularly capable of dealing with uncertain, incomplete, heterogeneously scaled and inconsistent data. Uncertainties in criteria values are accounted for by using a Monte Carlo simulation. Furthermore, different criteria weighting sets reflecting varying preferences of distinct stakeholder-groups are considered simultaneously. The effects of these uncertainties are documented in the final results.

This comprehensive approach has been developed and tested in several projects dealing with various aspects of climate change adaptation at the regional and local level, e.g. water scarcity management, flood protection, rainwater percolation, heat stress reduction and soil erosion control.

The assessment approach and the methodological bases of PRIMATE are introduced. An in-depth case study is presented showing how practitioners can deal successfully with such complex climate adaptation decisions. 


\section{CHALLENGES FOR STORMWATER INFILTRATION IN URBAN AREAS}

Britta Bockhorn, Knud Erik S. Klint \& Marina Bergen Jensen

Department of Geosciences and Natural Resource Managenemt, Copenhagen University, Denmark

\begin{abstract}
Urban densification leads to a constant growth of sealed surfaces in cities. This causes an increase of stormwater runoff compared to natural, vegetated areas where water would infiltrate directly into the soil. Due to Climate Change extreme rain events are expected to happen more frequently in the future which will intensify the amount of stormwater runoff that is generated and exert a great pressure on the sewer systems (1).
\end{abstract}

Providing sustainable urban drainage systems (SUDS) in the cities can stand as an economical alternative to an enlargement of the existing sewer system. Not only do SUDS provide an efficient on site management of stormwater runoff but also do they have the potential to increase the biodiversity and to add a recreational value for the inhabitants (2).

Whether or not an area is suitable for stormwater infiltration depends on various factors like the depth to the groundwater table and the hydraulic conductivity of the soil. In Denmark most cities are located on heterogeneous clay rich deposits with a general low hydraulic conductivity. However various high permeable structures such as fractures, sand lenses and biopores may facilitate hydraulic avenues for infiltration of stormwater $(3 ; 4)$.
The Danish innovation consortium "Cities in Water balance" is investigating the potential for stormwater infiltration in clayey soils. Our hypothesis is that infiltration rates can be enhanced by the exploitation of the site specific geological variability in order to identify optimal locations for stormwater infiltration, and by the development of more advanced technologies to stimulate the hydraulic performance of the subsurface. In that way the work-efficiency of SUDS may increase significantly. First experiments returned up to eight times higher hydraulic conductivities in infiltration designs installed based on geological knowledge.

\section{REFERENCES}

(1) Backhaus, A., Dam, T. \& Jensen, M.B. (2012). Stormwater management challenges as revealed through a design experiment with professional landscape architects. Urban Water Journal 9 (1): $29-43$

(2) Ahern, J. (2007). Green Infrastructure for Cities: the Spatial Dimension. In: Novotny, V. \& Brown, P. (eds.). Cities for the Future: Towards Integrated Sustainable Water and Landscape Management. IWA Publishers; London, pp. 267-283.

(3) Klint, K.E. \& Gravesen, P. (1999). Fractures and biopores in Weichselian clayey till aquitards at Flakkebjerg, Denmark. Nord Hydrol 30 (4/5): 267-284.

(4) Kessler, T., Klint, K.E.S., Nilsson, B. \& Bjerg, P.L. (2012). Characterization of sand lenses embedded in tills. In: Quarternary Science Reviews 53: 55-71. 


\section{EFFECTS OF A VERY LOW ENERGY BUILDING SCENARIO IN EUROPE ON HEALTH}

Jakob Hjort Bønløkke, Gitte Juel Holst, Torben Sigsgaard, Ulrik Korsholm \& Jens Havskov Sørensen Institute of Public Health, Aarhus University, Denmark

\section{ABSTRACT}

The share of energy that is used for domestic heating and cooling is substantial. Accordingly building insulation has significant impact on air pollution. We investigated the effects of a very low energy building scenario with an annual retrofit rate of $2 \%$ in 25 European states on air pollution and resulting benefits to health and economy.

Energy savings from 2005 to 2020 due to insulation were calculated by comparing a business as usual with the insulation scenario based on existing building data on thermal conductivity. The resulting changes in emissions were entered in a Comprehensive Air-Quality Model with extensions, using meteorology for 2009 from which annual changes in the main air pollutants were derived for each country. Data on populations and on impacts of pollutants came from $\mathrm{WHO} / \mathrm{EU}$ reports and databases.
Effects on the mean annual change in fine particles varied greatly from $-0.008 \mu \mathrm{g} / \mathrm{m}^{3}$ (Finland) to $-0.538 \mu \mathrm{g} / \mathrm{m}^{3}$ (Belgium). The annual number of life-years (LY) gained per 100,000 adults varied from $0.9 \mathrm{LY}$ in Finland to 54.5 LY in Belgium - the mean being 24.3 LY. The total number of LY gained annually varied from 31 in Finland to 22,524 in Germany, totalling 78,678 LY in Europe. A total of 7,173 cases of persistent chronic bronchitis were avoided annually. Several other health outcomes improved similarly. The saved societal costs totalled 6.64 billion $€$ annually.

In conclusion, in addition to carbon emission reductions not assessed in this study, a very low energy building scenario in Europe would have substantial benefits on health through improvements in air pollution. Health effects and resulting societal cost savings may significantly counterbalance investment costs and should be taken into account when evaluating strategies for mitigation of global warming 


\section{CALCULATING POTENTIAL FOR EMISSION'S REDUCTION VIA SUPPLY CHAIN CONTRACTS}

Katerina Peterkova

Department of Law, Aarhus University, Denmark

\begin{abstract}
Climate change remains an urgent problem of the global society despite various efforts to regulate its negative effects. Negotiations of internationally binding rules for climate change mitigation fail. National regulation among states is unequal and allows for carbon leakage from jurisdictions with stricter to jurisdictions with weaker laws. Private initiatives are criticized for weak legitimacy, effectiveness and enforcement. Market based regulation proved by the recent carbon's price drop below a bearable limit to be highly sensitive to market failures. Therefore we must seek other regulatory solutions to the climate change issue.
\end{abstract}

The paper presents a hypothesis that supply chain contracts may help to overcome this regulatory gap. It connects theoretical and empirical knowledge. Firstly, applying the legal dogmatic method, the article discusses the role of supply chain contracting in the climate change regulatory matrix. The dogmatic method is extended to all type of law, including various types of state-made/ non-state, soft/hard and public/private law. Secondly, the paper demonstrates the extent of possible $\mathrm{CO}_{2}$ reductions via supply chain contracting on a simple quantitative model built by using the empirical desk research. In relation to four selected industries, the model calculates how much carbon emissions would be saved if companies achieved their publicly proclaimed goals for emissions' reductions in their international supply chains.

The findings show that the possible reduction of $\mathrm{CO}_{2}$ emissions among international supply chains amounts to multiple yearly emissions of developed countries. Despite this huge potential, supply chain contracting has only recently experienced increasing attention of regulators and business community. If we manage to trigger the latent potential of supply chain contracts, they may be successful where other regulatory efforts fail. The author concludes that the potential of private contracting in its full extent could be activated by adequate regulation and calls for future research in this direction. 


\section{GREENHOUSE GAS EMISSIONS FROM A DANISH RIPARIAN WETLAND BEFORE AND AFTER RESTORATION}

Joachim Audet, Lars Elsgaard, Charlotte Kjaergaard, Søren E. Larsen \& Carl C. Hoffmann

Department of Bioscience, Aarhus University, Silkeborg, Denmark

\section{ABSTRACT}

Restoration of riparian wetlands often aims at increasing the removal of nitrogen and phosphorus by re-establishing the hydrological connectivity between the stream and the surrounding floodplain. However, the geochemically reduced soil conditions in the newly restored area may favor the emission of greenhouse gases (GHG) such as nitrous oxide $\left(\mathrm{N}_{2} \mathrm{O}\right)$ and methane $\left(\mathrm{CH}_{4}\right)$. To evaluate this risk the fluxes of $\mathrm{N}_{2} \mathrm{O}, \mathrm{CH}_{4}$ and carbon dioxide from ecosystem respiration $\left(R_{\text {eco }}\right)$ were determined prior to and after restoration of a stream and its adjacent riparian areas. The data collected during the first year after restoration revealed spatially and seasonally variable $\mathrm{N}_{2} \mathrm{O}$ emissions ranging from 0.1 to $3.1 \mathrm{~g} \mathrm{~N} \mathrm{~m}^{-2} \mathrm{y}^{-1}$, but no statistically significant effect of the restoration on $\mathrm{N}_{2} \mathrm{O}$ emission was observed as tested for comparable 8-month periods before and after restoration. The re-establishment of a high groundwater level $(\mathrm{GWL})$ induced a significant increase in $\mathrm{CH}_{4}$ emissions ( $\mathrm{p}<0.001$ ), from -0.04 to $31.7 \mathrm{~g} \mathrm{C} \mathrm{m}^{-2}$ at a permanently flooded, restored area during comparable 8-month periods before and after restoration. Ecosystem respiration at the restored sites decreased or remained stable after the restoration, but a decrease in $R_{\text {eco }}$ was also observed at a control site. According to mixed model statistical analyses both the soil temperature at $10 \mathrm{~cm}$ depth $\left(T(-10 \mathrm{~cm})\right.$ ) and $\mathrm{GWL}$ were apparent controllers of $\mathrm{CH}_{4}$ and $\mathrm{R}_{\text {eco. }}$. Nitrous oxide emissions were related to $\mathrm{N}$ content in the top soil. Annual $\mathrm{CH}_{4}$ emissions the first year after restoration were comparable to those of natural riparian wetland sites and the increased $\mathrm{CH}_{4}$ emission appeared to be compensated for by a decrease in $\mathrm{R}_{\text {eco, }}$, while the effect of the restoration on $\mathrm{N}_{2} \mathrm{O}$ was more uncertain - not least because of large spatial variation. 


\section{SUSTAINABILITY AND ROAD TRANSPORT IN NORWAY}

Henrik Kofoed Nielsen, Karl Sigurd Fredriksen, Rein Terje Thorstensen \& Ivana Janickova

Faculty of engineering and science, University of Agder, Norway

\begin{abstract}
Road transport of goods and people is still increasing in Norway despite initiatives on improving systems for public transportation, walking and cycling. Most frequently sustainability of road transport is limited to direct energy use and accompanying emissions from the vehicles [1, 2]. In this study initiated by Norwegian Public Roads Administration the sustainability of road construction is evaluated for two highways.
\end{abstract}

The study evaluates energy usage and greenhouse gas emissions during construction (including the climate impacts of purchased materials), operation, maintenance, and end-of-life (recycling and final disposal) phases of the road infrastructure (known as the indirect phases). The change of carbon sequestration on the road area is included, and construction work on secondary roads necessitated by the motorway is included in in this study. Data on energy consumption during the construction was collected from the contractors on a voluntary basis. The reports from the contractors cover diesel and electricity consumption for all internal work such as rock and soil excavation and transport. Energy data for materials was derived by help of the ICE database [3], the most important materials as concrete and asphalt also were discussed with the contractors.
The greenhouse gas emissions measured as $\mathrm{CO}_{2}$ equivalents during the construction of the two highways was quite even and in average:

- Main road asphalt area 0.24 tonnes $\mathrm{CO}_{2} \mathrm{~m}^{-2}$

- Main road length (4 - lane) 5,200 tonnes $\mathrm{CO}_{2} \mathrm{~km}^{-1}$

A comparison between a $30 \mathrm{~km}$ old road replaced with a new $26 \mathrm{~km}$ parallel motorway shows that road building causes heavy energy consumption, and it will take decennials to balance even nice energy savings for medium size traffic, in the scale 10-15000 cars pr. day.

\section{REFERENCES}

Chester M.V., Horvath A. (2009): Environmental assessment of passenger transportation should include infrastructure and supply chains. Environmental Research Letters 4, IOP Publishing. 8 pp.

Miliutenko S. (2010): Assessment of energy use and greenhouse gas emissions generated by transport infrastructure, Literature review. Royal institute of technology, Stockholm, Sweden: 42 pp. Retrieved 2013-04-30 from http://www.infra.kth.se/fms/pdf/ TRITA_INFRA_FMS_2009_8.pdf

Hammond G, Jones C. (2011): Inventory of Carbon and Energy (ICE) Version 2.0, University of Bath, UK. 


\section{A GLOBAL $\mathbf{C O}_{2}$ TAX FOR SUSTAINABLE DEVELOPMENT? CARBON LEAKAGE, RENEWABLE ENERGY AND COALITIONS}

Urs Steiner Brandt* \& Gert Tinggaard Svendsen**

*Associate professor, PhD, Department of Environmental and Business Economics, University of Southern Denmark, ${ }^{* *}$ Professor, PhD, Department of Political Science and Government, Aarhus University, Denmark

\section{ABSTRACT}

Can a global $\mathrm{CO} 2$ tax assist in achieving the twin goal from Rio+20 of promoting green economies and improving the quality of institutions? Based on public choice and environmental economics, the answer given is yes when focusing on the possibilities of new political coalitions, renewable energy incentives, the avoidance of carbon leakage and proper investment of tax revenues in better institutions. In perspective, a green climate fund is discussed. 


\section{GROUND SOURCE HEATING AND COOLING - ELEMENTS IN A SUSTAINABLE ENERGY SUPPLY}

Claus Ditlefsen', Ingelise Møller’, Inga Sørensen², Henrik Bjørn², Anker Lajer Højberg' \& Thomas Vangilde-Pedersen' 'Geological Survey of Denmark and Greenland, ${ }^{2}$ VIA University College, Denmark

\begin{abstract}
Shallow geothermal energy is a renewable energy source, where the low enthalpy heat in the shallow subsurface can be exploited using borehole heat exchangers in a combination with heat pumps. Despite the energy saving and $\mathrm{CO}_{2}$ emission reduction potential of the technology, the utilisation of shallow geothermal energy in Denmark is relatively limited compared to e.g. Sweden and Germany. Today, the total number of ground source heat pumps in Denmark is around 27,000 , currently increasing by 5,000 per year. By far, most of the existing installations are horizontal closed loop systems, while four to five hundred are borehole heat exchangers, (Mahler et al. 2013).
\end{abstract}

In contrast to our neighbouring countries, the main part of Denmark is situated in a sedimentary basin dominated by soft sediments and variable depth to the water table. Until now only few investigations of the thermal properties of Danish sediments have been carried out, but preliminary results indicate that the energy extraction may be up to $40 \%$ lower for unfavourable geological scenarios compared to more favourable geological conditions, (Vangkilde-Pedersen et al. 2012). The 3-year project "GeoEnergy" supported by the EUDP program of Danish Energy Agency aims at paving the way for a better understanding of the geological and environmental aspects of heat extraction from shallow geological layers thereby enhancing and optimising the possibilities for using borehole heat exchangers, (Ditlefsen et al. 2013). The purpose is to develop tools and best practice for the design and installation of systems under typical Danish conditions. Results and recommendations from the project will be presented and discussed.

\section{REFERENCES}

Ditlefsen, C., Vangkilde-Pedersen, T., Sørensen, I., Bjørn, H., Højbjerg, A.L. \& Møller, I. (2013). GeoEnergy - a national shallow geothermal research project, Proceedings of the European Geothermal Congress 2013.

Mahler, A., Røgen, B., Ditlefsen, C., Nielsen, L.H. \& VangkildePedersen, T. (2013). Geothermal Energy Use, Country Update for Denmark. Proceedings of the European Geothermal Congress 2013.

Vangkilde-Pedersen, T., Ditlefsen, C. \& Højberg, A.L. (2012). Shallow geothermal energy in Denmark. Geological Survey of Denmark and Greenland Bulletin 26. GEUS 2012, 37-40. 


\section{ADDRESSING EQUITY IN LAND USE DECISIONS: A CASE STUDY IN THE OIL AND GAS SECTOR}

Lydia Lamorgese \& Davide Geneletti

Dept. Civil Environmental and Mechanical Engineering (DICAM), University of Trento, Italy

\section{ABSTRACT}

Equity in the distribution of the expected effects of decisions on present and future generations plays a key role in the sustainability debate. Sustainability requires development paths to meet "fundamental human needs while preserving the life-support systems of planet Earth" (Kates et al. 2001). These paths should enhance ways of taking advantage of wide-spread and long-term opportunities and reversing the undesirable trends in the economic, social and ecological domains.

This paper aims at contributing to address intergenerational and intragenerational equity concerns in impact assessment, focusing specifically on decisions concerning the use of land. Firstly, a framework for conceptualizing equity implications at different scale in space and time is proposed. This framework consists of a set of question-based criteria and related indicators, which can be used as metrics for measuring intra- and inter- genera- tional equity in land use decisions, by comparing present state against future trends. The framework is then applied to a case study related to oil and gas development in the Basilicata region (Southern Italy). The case study is used to test how different decisions involving the future use of land will affect the distribution of benefits at intra- and inter- generational level. Scenario storylines, representing interactions among environmental, social and economic concerns, are drawn and tested against the framework. Trade-offs between human and environmental systems under the different scenarios are examined and compared by multi-criteria analysis. Finally, suggestions are provided on how to include in a more comprehensive way intra- and inter- generational equity considerations to support decision-making processes in land use planning.

\section{REFERENCES}

Kates, R.W. et al. (2001). Sustainability science. Science 292: 641-642. 


\section{ENERGY POLICY, FOOD, AND CLIMATE CHANGE - A NUMERICAL SIMULATION

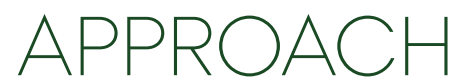

Thomas Kuhn, Michael Pickhardt \& Frauke Voosholz

University of Münster, Germany

\begin{abstract}
Growth orientated policy schemes as well as future energy policy must be, to a large extent, concerned with transportation fuel issues. In particular, sustainable growth rates require, among other things, a substantial substitution process, in which biofuels, hydrogen, or environmentally friendly generated electricity substitute for fossil fuels continuously. In this paper we model this substitution process by incorporating both, a non-renewable resource and a renewable resource, which can both serve for producing transport
\end{abstract}

fuels, into a conventional Romer-type endogenous growth model. Moreover, as a prominent feature of the modeling we also capture the fact that biofuels production may compete with food production for arable land. The main results of the paper, the Keynes-Ramsey rule, the modified Hotelling rules for the renewable and non-renewable resource, and the fuel versus food trade-off are discussed in some detail. Numerical simulations of the model are illustrating the main results. 


\section{ANALYSING (IN)EFFICIENCIES IN THE USE OF RAW MATERIALS AND UNDERLYING DRIVERS - WHAT ARE EXISTING KNOWLEDGE GAPS AND RESEARCH NEEDS?}

Adrian R. Tan, Shailendra Mudgal, Martin Hirschnitz-Garbers, Tanja Srebotnjak \& Albrecht Gradmann BIO Intelligence Service, France

\begin{abstract}
Current projections of population growth and income indicate that we run a high risk of causing irreversible damage to the planet's natural environment and thus also its ability to provide sufficient resources for us all. This is why the concept of absolute decoupling is so important - it aims to break the link between economic prosperity and associated resource use and environmental impacts. To achieve absolute decoupling, we must use resources more efficiently. This requires diverse strategies, such as sustainable resource extraction or shifting to more sustainable consumption and production patterns. But what are the areas where resource efficiency has most potential to achieve absolute decoupling?
\end{abstract}

In order to answer this question, we first conducted an extensive literature review and material flow analyses for selected resources to identify the main areas of resource use that can currently be deemed inefficient and to highlight the magnitude of some inefficient uses.

Secondly, we undertook a meta-analysis of scientific articles to identify and synthesize relevant drivers as this knowledge appears fragmented.
In general there seems to be significant potential to increase resource efficiency across all resources and sectors considered. However, the potentials identified are often theoretical (technical) estimates that seldom consider whether to realise them would be economically feasible and socially acceptable. In order to achieve absolute decoupling, research is therefore needed to inform us on:

What are (economically and socially) optimal investments to be made in resource efficiency and how should we prioritise them?

How should we address inefficiencies related to use and consumption behaviours such as choice of diets, use of products and overconsumption? Here, preferences and the question of 'sufficiency' need to be addressed.

What are promising pathways to achieve global resource use that remains within resource limits and sustainability thresholds?

The research is part of the research project DYNAMIX which receives funding from the European Union Seventh Framework Programme (FP7/2007- 2013) under grant agreement $n^{\circ} 308674$. 


\section{CLIMATE CHANGE AND WATER. IDENTIFICATION OF THE RESEARCH NEEDS IN EUROPE}

Monica Garnier, Géza Jolankai \& David Harper

Water Research Institute - National Research Council, Italy

\begin{abstract}
Global temperature is rising and is very likely that will continue to raise throughout Europe during this century. There is a growing consensus among scientists that one of the causes of the occurring climate change are human activities and one of the consequences is that areas with limited water resources will increase. Population growth and the competing needs of water uses are likely to result in an increase of global water demand, estimated around $35-60 \%$ by 2025 (E.C., 2012), that could further worsen the situation. This, in turn, will probably determine a growing imbalance between water demand (including natural ecosystem needs) and supply.
\end{abstract}

These issues have been dealt with by the FP7 founded project ClimateWater (Bridging the gap between adaptation strategies of climate change impacts and European water policies), which aims at the study of adaptation strategies to tackle the consequences of climate change, at the assessment of how these strategies are taken into account by European water policies and at investigating how they respond to the identified needs.
The present work reports the results of ClimateWater concerning the research needs still existing on the above mentioned topics, that represent one of the main outputs and synthesizing efforts of the whole project. In particular, the work deals with knowledge gaps still existing regarding the direct effects of climate change on water bodies, the indirect impacts on productive areas that, like agriculture and some industrial sectors, use massive amounts of water. The research needs in some sector that, like alternative sewage treatment, could constitute powerful tools to mitigate or to adapt to climate change impacts, are also taken into consideration.The analysis carried out, highlighting knowledge gaps in various fields concerning the relationships between climate change and water, also represents a potentially helpful tool for the EU to orient the themes to be included in the future calls of the Horizon 2020 framework programme.

\section{REFERENCES}

E.C. 2012. A Blueprint to Safeguard Europe's Water Resources. Communication from the Commission to the European Parliament, the Council, the European Economic and Social Committee and the Committee of the Regions. COM(2012) 673 final. 


\section{INVESTIGATION OF TEXTILE WASTEWATER TREATMENT, USING A SYSTEM OF SUB SURFACE CONSTRUCTED WETLAND}

Niloufar Tabesh \& Nasser Taleb Beydokhti

Msc Student of Civil and Environmental Engineering, Shiraz University, Iran

\begin{abstract}
Apart from scarcity of water which is considered a global problem, in some developing countries like Iran, the quality of available water is also deteriorating due to pollution of water bodies, hence intensifying the shortage. Following lack of investment in Textile wastewater treatment and high investment and maintenance costs, conventional treatment systems have not been widely used. Therefore a cost effective and easily maintained and operated method like using a system of constructed wetlands seems to be of interest for treatment of textile wastewater. In order to investigate the effect of hydraulic residence time (HRT) and plant density on the performance of horizontal subsurface flow (HSSF) constructed wetlands, treating industrial wastewaters, three pilot-scale units of dimensions $1.5 \mathrm{~m}$ in length, $0.5 \mathrm{~m}$ in depth and $0.5 \mathrm{~m}$ in width were operated continuously in parallel experiments. The three units with fine gravel were planted, first one with 80 percent and second one with 25 percent plant density covered by Cortaderia selloana, the third was kept unplanted. Synthetic wastewater which was specifically produced
\end{abstract}

and modified to imitate textile wastewater was introduced in the units during the operation period. Four different HRTs (i.e., 1,2,3 and 5 days) were used. The removal performance of the constructed wetland units was very good since it reached an average of 88,74 and 76 for COD, Turbidity and color respectively. All pollutant removal efficiencies showed dependence on plant density and the results show 3 days HRT was adequate for acceptable pollutant removal.

\section{REFERENCES}

Kadlec, R.H. (1955). Treatment Wetlands by CRC. Press LLC.

Crites, R.W. (1994). Dsigin criteria and practice for constructed wetlands. Water Science Technology 29, pp. 1-5.

Amelia, K. (2001). The potential for constructed wetland for wastewater treatment and reuse in developing contries: a review. Ecological Engineering 16, pp. 545-560.

Vaymazal, J. (2009). The use of constructed wetlands with horizontal sub-surface flow for various types of wastewater. Ecological Engineering 35, pp.1-17. 


\section{MULTIPURPOSE WILDLIFE: FOOD. RECREATION AND BIODIVERSITY COMBINED}

Carl-Gustaf Thulin, Göran Ericsson, Jana Pickova, Ivar Vågsholm \& Johan Schnürer

Department of Wildlife, Fish and Environmental Studies, Swedish University of Agricultural Sciences, Sweden

\begin{abstract}
Sustainable utilization of wildlife populations is a form of multipurpose land-use that could deliver food and recreation in combination with rich biodiversity. An increased harvests of game animals for food result in more sustainable animal products. A landscape with abundant wildlife offers also possibilities for recreation, tourism and a general perception of wilderness. Finally, wildlife species such as the larger herbivores have important ecosystem functions that may even increase biological diversity. In addition, a partial shift to more wildlife-directed feed crop production such as kale, maize and sunflower on arable land may generate opportunities for managing the habitats used by wildlife and, thus, minimize damages to conventional farming and forestry.
\end{abstract}

However, large wildlife populations may also become reservoirs for diseases, for example wild boars can carry classical swine fever (CSF). Therefore it is important to develop a surveillance system for game food chain to guarantee both food quality and safety, including slaughter plants, small local enterprises and restaurants. Other questions to be considered are the interactions between wildlife and infrastructure, animal welfare issues, ethics and, most importantly, public perception of an increased game meat consumption. Thus, there is a need for a research program directed towards the potential of game for food production.

The consequences of a transition to a multipurpose landuse that focus on wildlife populations need scientific evaluation. Such a transition offers a potential for sustainable production of high quality animal proteins in combination with agriculture, forestry and biological diversity. This will make available arable land for production of cereals and vegetables directly for human consumption, thereby opening up a possibility for providing food to larger human population in year 2050, while maintaining the environment and the biological diversity. 


\section{BIOGAS FROM BEET PULP AND SOURCE SEPARATED HOUSEHOLD WASTE - ENERGY PRODUCTION AND GREENHOUSE GAS REDUCTION}

Sommer S.G., Astrup T., Boldrin A., Bruun S., Jensen L.S., Petersen S.O. \& Triolo J.M.

Biotechnology and Environmental Tech., Inst. of Chemical Eng., Faculty of Engineering, University of Southern Denmark

\section{ABSTRACT}

If properly used, biogas production is a clean technology converting plant residues and bio-wastes to energy carriers and organic fertilisers. In the Danish energy strategy, biogas production is intended to expand to allow treatment of $50 \%$ of livestock wastes by 2020 . At present, low profitability is a barrier to this development. The BioChain project intends to improve the effectiveness of biomass management, from harvest and transport through gas production till end use of the digestate as a fertilizer, thereby boosting biogas production from, e.g., animal manure and organic household waste, and ultimately improving the economic viability. This article exemplifies the approach of this project through mass and energy balances for beet root and source separated house hold waste used for biogas production. Included is the change in energy production as affected by changes in storage of the untreated biomass and optimisation of retention time for anaerobic digestion. Greenhouse gas (GHG) emissions, carbon sequestration and mineral fertilizer efficiencies associated with each management strategy are included in the calculations. 


\section{MODELS FOR MULTI-CRITERIA SUSTAINABILITY} ASSESSMENT OF A NEW MORE BIOBASED
AND CIRCULAR ECONOMY

Tommy Dalgaard

Department of Agroecology, Aarhus University, Denmark

\section{ABSTRACT}

The aim of this study is to present new approaches to model potentials for an increased and more resource efficient biomass harvest in Denmark, and multi-criteria sustainability assessments of the socio-economic and environmental effects of different scenarios for such production.

Empirical results from a case study of large scale conversion to biorefenery technologies, aiming to increase the total Danish harvest of biomass by 10 million tonnes via the conversion to new types of crop production and land management, is used as an example, and a so called "Traffic-light" multi-criteria sustainability assessment scheme is introduced and exemplified. The aim is to con- textualize how the problems in relation to the concrete scenario results can be considered, and used as input for a discussion of innovative models for future farming systems development, research and management.

Knowledge gaps for the Climate Action and Resource Efficiency Challenge in Horizon 2020 are discussed, and potentials for further research are identified based on experiences from the ongoing research project www.fremtidenslandbrug.dk, the recently initialized Www.dNmark.dk strategic research alliance, and the BIO-VALUE Strategic Platform for Innovation and Research (SPIR) sustainability assessment workpackage. 


\section{EMAS REGULATION IN ITALIAN CLUSTERS: INVESTIGATING THE INVOLVEMENT OF LOCAL STAKEHOLDERS}

Merli R., D’Amico M., Preziosi M. \& Massa I.

Department of Business Studies, Roma Tre University, Italy

\begin{abstract}
Ever since its first version, the EMAS Regulation has represented a point of reference for enterprises seeking to continuously improve their environmental performances. The literature on this topic is quite abundant but has concentrated, until now, mostly on the determination of the effectiveness of the scheme, leaving out other aspects as the involvement of the different categories of stakeholder in developing local solution for sustainable development. Our research activity, conducted by the Department of Business Studies of "Roma Tre" University and ISPRA (High Institute for Environmental Protection and Research), intends to partially fill this gap by investigating the Italian cluster approach for EMAS, characterized by the creation of a cluster Managing Committee (MC) - which has received a dedicated EMAS certificate - that coordinates the implementation of the scheme.
\end{abstract}

If in a first phase we investigated the effectiveness of support given to registered EMAS organizations inside the cluster by the MCs that possess an EMAS certificate, the main objective of the second step here presented has been to verify the impact on different stakeholders categories of the actions taken by the various MCs in 11 Italian clusters.

In this paper we present the results of a survey conducted through the distribution of a specifically designed questionnaire on different categories of stakeholders (public local authorities as Cities and provinces, Trade Association and non-registered firms), with two main goals:

- to determine the impacts of the action put in place by the Managing Committee inside the clusters, in terms of environmental performance enhancements and network creations to improve the cluster competitiveness;

- to evaluate how the tools offered to cluster organizations have effectively contributed to a widespread knowledge of EMAS and environmental concerns.

\section{REFERENCES}

Emilsson, S., \& Hjelm, O. (2002). Implementation of Standardised Environmental Management Systems in Swedish Local Authorities: Reasons, Expectations and Some Outcomes. Environmental Science \& Policy 5 (6) (December): 443-448. doi:10.1016/ S1462-9011(02)00090-4.

Hillary, R. \& Thorsen, N. (1999). Regulatory and Self-regulatory Measures as Routes to Promote Cleaner Production. Journal of Cleaner Production 7 (1) (February): 1-11. doi:10.1016/S09596526(98)00030-4

Iraldo, F., Testa, F. \& Frey, M. (2009). Is an Environmental Management System Able to Influence Environmental and Competitive Performance? The Case of the Eco-management and Audit Scheme (EMAS) in the European Union. Journal of Cleaner Production 17 (16) (November): 1444-1452. doi:10.1016/j.jclepro.2009.05.013.

Merli, R., Ippolito C. \& Lucchetti, M.C. (2011). Promoting Sustainability in Europe Through the Eco-Management and Audit Scheme (EMAS): Final Results of a Survey on Italian Organizations. In Proceedings of the $17^{\text {th }}$ Annual Conference of the International Sustainable Development Research Society. Columbia University, New York.

Milieu Ltd., RPA Ltd., Ganzleben, C., Vernon, J., Peacock, M., Belin, A. \& Candell, M. (2009). Study on the Costs and Benefits of EMAS to Registered Organisations.

Morrow, D., \& Rondinelli, D. (2002). Adopting Corporate Environmental Management Systems: Motivations and Results of ISO 14001 and EMAS Certification. European Management Journal 20 (2) (April): 159-171. doi:10.1016/S0263-2373(02)00026-9.

Pedersen, E.R. (2007). Perceptions of Performance: How European Organizations Experience EMAS Registration. Corporate Social Responsibility and Environmental Management 14 (2) (May 1): 61-73. doi:10.1002/csr.118.

Zutshi, A. \& Sohal, A. (2004). Environmental Management System Adoption by Australasian Organisations: Part 1: Reasons, Benefits and Impediments. Technovation 24 (4) (April): 335-357. doi:10.1016/S0166-4972(02)00053-6. 


\section{BASE: MODELS AND CASE STUDIES IN SUPPORT OF ADAPTATION POLICY DEVELOPMENT IN EUROPE}

Chair: Hans Sanderson

Aarhus University, Denmark

The session will present the methodological point of departure and identification of research gaps and needs of the EU FP7 project Bottom-up Climate Adaptation Strategies towards a Sustainable Europe (BASE). The session will, focus on the key problems of adaptation strategies. It will do this by examining simultaneously the general policy at the EU and national level and actual activities at local and regional levels and provide an outlook on the current status of adaptation in the EU.

The session will also investigate baseline estimates of costs that can be avoided through adaptation, as well as analyses of no- or low-regrets costs for adaptation at sectorial, national, and EU level and investigate how to upscale from case studies to higher levels of organization. Replicable case studies are critically important to be able to generalize across sectors and countries, and to provide tailored data input to the economic models need to support policy making.
The session will explore the case study design process adopted in BASE. Case studies will be clustered and made comparable across countries and in order to provide new empirical data that can be used and reanalysed in integrated assessment modelling. The aim is to test and analyse ways of bridging the gap between top-down and bottom-up approaches in evaluating adaptation policies and measures. BASE will explore the nature of these processes in order to understand how awareness raising and transparency of governmental plans and actions (e.g. through participatory actions) can contribute to making climate change adaptation strategies truly adaptive to changing conditions at a bottom-up level - hence the session will present the consideration and experiences the BASE team has in relation to the on the ground challenges of case study implementation. The quantitative and qualitative output of the case studies and modeling will be modeled using various approaches, e.g. adaptation pathway development in support of adaptation policy making. These methods will be outlined and reviewed in session drawing lines back to the current status of the adaptation in the EU and thereby qualify future research needs to fulfill the adaptation needs and aims of the European Union. 


\section{A BASE PROJECT ANALYSIS OF EU MEMBER STATE CLIMATE CHANGE ADAPTATION STRATEGIES: COMPARING APPROACHES AND DRAWING LESSONS}

Duncan Russel, Andres Pederson, Helle $\varnothing$. Nielsen, Anne Jensen, Silke Beck, Sabine Weiland, Kirsi Mäkinen, Sergio Castellari, Eleni Karali, Katriona Mcglade \& Jenny Troeltzsch College of Social Sciences and International Studies, University of Exeter, UK

\section{ABSTRACT}

It is widely acknowledged that national climate change adaptation strategies require the existence and development of administrative structures and capacity to facilitate policy integration between affected sectors and governance levels (i.e. measures for the identification of cross-sectoral and cross-scale synergies and tradeoffs). The extant literature on policy integration suggests that public bodies can pursue a number of different approaches to achieve these ends, yet there are surprisingly few comparative studies seeking to evaluate how integration measures operate in different contexts and why. This paper aims to address this research gap through comparing the policy integration approaches followed by a selection of EU Member States in their climate change adaptation strategies. . It does so through drawing on drawing on concepts from the policy integration and coordination literatures and data derived from policy documents, parliamentary reports and other relevant literature coupled with some interview data. Considering the differences in institutional configurations, climate change impacts and political, economic and cultural contexts, this paper seeks to better understand: 1) why different nations employ different approaches in their climate adaptation strategies; 2) the extent to which different climate change adaptation policy integration measures and strategies have been operationalized, especially in relation to their reach into other sectors; and 3) the lessons that can be learnt for climate change adaptation policy integration from the varied experiences of the Member States. 


\section{INTEGRATING TOP-DOWN AND BOTTOM-UP PERSPECTIVES IN ADAPTATION ASSESSMENT}

Francesco Bosello, Fabio Eboli \& Ana Iglesias, CIP division Euro-Mediterranean Center on Climate Change, Italy

\begin{abstract}
GHG emissions generate a global externality, however climate change impacts, mitigation, and adaptation effects, are highly differentiated locally. Accordingly, also the economic assessment of adaptation costs and benefits needs to integrate different investigation scopes. A country/regional perspective is needed to define strategic priorities for adaptation investments; a regional, spatially-explicit detail is necessary for the assessment of environmental impacts and cost/effectiveness of adaptation measures. A solid topdown/bottom-up integration is thus crucial in adaptation research (Pat et al. 2010). However, current top-down models analyzing adaptation (see e.g. Agrawala et al. 2010, Banh et al. 2010, de Bruin et al. 2009, Hof et al 2009), albeit remaining useful in highlighting trends and rough "orders of magnitude", are still too aggregated to offer really informative quantitative insights on the opportunities offered by adaptation strategies, and by their combination. Conversely, bottom up analysis of adaptation, which is rapidly expanding, is still largely scattered and incomplete (Agrawala et al. 2011). Notwithstanding interesting attempts to organize the evidence gathered so far (e.g.: Agrawala and Fankhauser 2008, Parry et al. 2009), much more can be done to systematize the already rich information available.
\end{abstract}

In summary: bottom-up studies should be collected and then consistently integrated to define adaptation costs and effectiveness per domain in order to develop better top-down estimates of adaptation costs and effectiveness at the country, European and possibly world level. This requires appropriate integration and scaling methodologies for adaptation across different areas and geographical scopes. On the other hand it would be necessary to expand the portfolio of adaptation options that top-down approaches can consider.
This paper discusses challenges, opportunities, limits and some possible methodologies to accomplish these desired outcomes.

\section{REFERENCES}

Agrawala, S., Bosello, F., Carraro, C., De Cian, E., Lanzi, E., de Bruin, K. \& Dellink, R. (2010). PLAN or REACT? Analysis of adaptation costs and benefits Using Integrated Assessment Models. OECD Environment Working Papers, No. 23, OECD Publishing.

Agrawala, S. \& Fankhauser, S. (2008). Economics aspects of adaptation to climate change. Costs, benefits and policy instrument. OECD, Paris.

Bahn, O., Chesney, M. \& Gheyssens, J. (2010). The Effect of Adaptation Measures on the Adoption of Clean Technologies. Paper presented at the WCERE Congress, Montréal, 2010. Viewed on December 22, 2010.

de Bruin, K.C., Dellink, R.B. \& Tol., R.S.J. (2009). AD-DICE: An Implementation of Adaptation in the DICE Model" Climatic Change, 95:63-81.

Hof, A.F., de Bruin, K.C., Dellink, R., den Elzen, M.G.J. \& van Vuuren, D.P. (2009). The Effect of Different Mitigation Strategies on International Financing of Adaptation. Environmental Science and Policy 12:832-843.

Parry M., Arnell, N., Berry, P., Dodman, D., Fankhauser, S., Hope, C., Kovats, S. \& Nicholls, R. (2009). Assessing the costs of adaptation to climate change. Imperial College, London.

Patt A.G., van Vuuren, D.P., Berkhout, F., Aaheim, A., Hof, A.F., Isaac, M. \& Mechler, R. (2010). Adaptation in integrated assessment modeling:where do we stand?. Climatic Change, 99:383-402 


\section{BASE: A ROBUST STRATEGY FOR ADAPTATION CASE STUDY RESEARCH}

Xin Li, Dabo Guan, Jouni Paavola, Gil Penha Lopez, Nigel Wright \& others

School of Earth \& Environment, University of Leeds, UK

\section{ABSTRACT}

To date, research on adaptation strategies and measures has mostly used a top-down and sectoral approach to generate estimates of the costs and benefits of adaptation or more general lessons for adaptation planning and policy. While these studies are of value for national policy and decision makers, they are less useful for local governments, businesses and non-governmental organisations who will deliver adaptation on the ground and will need to plan for it. Costs, benefits, opportunities and barriers of adaptation are also highly contextual, which means that coordinated European efforts would need to acknowledge and accommodate variations in them between the member states.

BASE has developed a bottom-up strategy for assessing adaptation needs and their costs, benefits and effectiveness from the viewpoint of those who will plan for and deliver adaptation. Such research strategy faces several challenges. On one hand, in-depth case studies are re- source intensive and, therefore, their number will remain limited. This constrains the traditional solution for improving data quality - increasing the sample size. On the other hand, even cases exploring adaptation in the same sector to same climate change impacts can be quite different because of different contexts.

Furthermore, deploying teams with local knowledge to understand the contextuality of adaptation can lead to differences in the expertise of case study teams, which requires flexibility in how the research is conducted whilst guiding what it produces in terms of results. In this paper we outline how BASE will seek to coordinate case study research and to ensure its usefulness to top-down modelling efforts by using common starting points, methodological transparency and core questions as key instruments. We also highlight how research with limited number of case studies is best placed to map the range of possible outcomes rather than expected values. 


\section{CASE-STUDIES - THEIR POTENTIAL AND CHALLENGES WITHIN BASE PROJECT}

Gil Penha-Lopes, Jouni Paavola, Bjorn Bedsted \& BASE Team CCIAM-SIM - Climate Change Research group, Faculdade de Ciências da Universidade de Lisboa (FCUL) Campo Grande, Portugal

\section{ABSTRACT}

Case studies are nowadays considered in research as more real and necessary "objects of study" to better build an integral and holistic perspective of the complex world we live in as well as included to better co-design future pathways to achieve multi-level and sectorial sustainability.

In BASE project ("Bottom-Up Climate Adaptation Strategies for a Sustainable Europe") cases were chosen because they have (are, or will have) implemented adaptation strategies and/or actions. BASE case studies will provide and co-create local and regional data \& information (within the economic, social, ecological and technological fields) that will feed and improve macroscale models and decision making tools, providing policy/ decision-makers advice with regards to the improvement of adaptation management. These cases include cities to rural areas, coastal to water basin zones, energy to health sectors as well as including agriculture to ecosystem services and biodiversity.

This presentation will mainly on focus on: i) the several degrees of research on/with case studies; and ii) its potentials and challenges. This presentation will finalize with the framework developed within BASE FP7 project on how to standardize methods for better replicability and comparability between cases as well as what (and how) needs to be allowed and adapted to particular case study. 


\section{BASE: INTEGRATED ADAPTATION PATHWAYS AT EU LEVEL - HOW TO COMBINE CASE DATA WITH MODELS}

Ad Jeuken, Marjolijn Haasnoot, Maaike van Aalst \& Harm Duel

Deltares, Scenario and Policy analysis, Netherlands

\begin{abstract}
There have been many studies done before to estimate the costs of adaptation against climate change. Main observations derived from the Climate Cost Study (Watkiss and Hunt, 2012): The coverage of adaptation cost estimates is limited; of all studies done, there is an uneven distribution of sectors, the majority of studies have been done for the coastal zone sector on flooding. The assessments vary heavily in methodology and approaches; the use of different metrics, time periods, assumptions with regards to changing socio-economic conditions etc. which makes it challenging to compare. Studies take place at different scales. Estimations based on global models, such as integrated assessment Models (IAM) represent impacts and adaptation only coarsely, lack technical detail, do not consider uncertainty or behavioural change and provide insufficient detail for national or sub-national adaptation planning. On the other hand national and local level studies imply large adaptation costs, mainly for flood protection, are difficult to scale up; the generally estimated adaptation costs are much higher than the adaptation costs as estimated by IAM studies because a.o.the marginal additional costs for climate change are rarely split from those induced by socio-economic change.
\end{abstract}

The BASE project is aiming at overcoming these shortcomings in two ways. 1) By carrying out both gridded sectoral and IAM model studies at European level and a large number of national to local case using a 'common grid' e.g. similar basic assumptions, definitions and scenarios results at different levels may benefit from each other and local case data might be upscaled using the EU wide models. 2) By applying the method of adaptation pathways (Haasnoot et al., 2012) uncertainty is made explicit, biases in preferences for certain strategies may be removed and cost and benefits are split into short term investments and optional long term costs and benefits.

The paper will elaborate on the methods BASE will use to evaluate the case studies, strengthen the models by groundbased evidence and integrate results into pathways at EU-scale.

\section{REFERENCES}

Watkiss, P. \& Hunt, A. (2012). Scoping Study: Reviewing the Coverage of Economic Impacts in the CCRA.

Haasnoot, M., Middelkoop, H., Offermans, A., van Beek, E. \& Van Deursen, W.P.A. (2012). Exploring pathways for sustainable water management in river deltas in a changing environment. Climatic Change, doi: 10.1007/s10584-012-0444-2. 


\section{LIAISE - FP7 NOE FOR AN IMPROVED USE OF IMPACT ASSESSMENT IN POLICY DEVELOPMENT}

Co-chairs: Sander Janssen and Jacgues Janssen

Alterra - Wageningen UR, Wageningen, The Netherlands.

The FP7 Network of Excellence LIAISE (November 2009 April 2014, www.liaise-noe.eu) is designed to identify the causes for not using IA tools which have been developed in research projects and to bridge the gaps between researchers and practitioners. LIAISE aims at integration of the IA research community with the following objectives:

- A better understanding of the policy process and the resulting needs for IA knowledge and IA tools;

- Description of IA tools and scientific IA expertise in a standardised way;

- A shared IA toolbox targeted at the needs of both researchers and practitioners;
- The development of formats for an effective interaction between IA researchers and users based on an improved understanding of the needs for scientific IA knowledge in the policy process;

- A shared IA research agenda - to be developed in an open process with inputs from partners within and outside LIAISE - that integrates scientific knowledge gaps and the priorities for the development of new IA knowledge arising from the future policy agenda;

- Safeguarding the project results beyond the period of project funding, by developing an institutional setting and a business plan for the future extension towards a broad centre of IA expertise with researchers from the present consortium partners as well as additional members.

Table 1. LIAISE network.

\section{Consortium partners}

Alterra Alterra (coordinator) Netherlands

FUB Freie Universität Berlin (co-coordinator) Germany

AU Aarhus University Denmark

AUTH Aristotle University of Thessaloniki Greece

CEH NERC - Centre for Ecology \& Hydrology UK

FEEM Fondazione Eni Enrico Mattei Italy

SEIT Stockholm Environment Institute Tallinn Centre Estonia

SYKE Suomen Ymparistokeskus Finland

TECNALIA Tecnalia Corporación Tecnológica Spain

UBO Rheinische Friedrich-Wilhelms-Universität Bonn Germany

UEA University of East Anglia UK

UFZ HELMHOLTZ - Zentrum Für Umweltforschung Germany

WU Wageningen University Netherlands

ZALF LEIBNIZ - Zentrum für Agrarwirtschaftforschung Germany

ZEW Zentrum für Europaeische Wirtschaftsforschung Germany

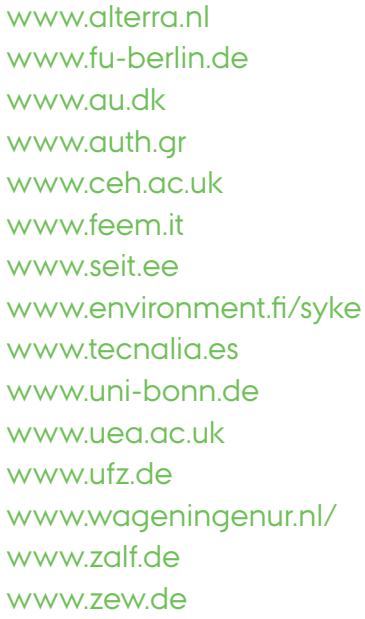

www.alterra.nl

www.fu-berlin.de

www.au.dk

www.auth.gr

www.ceh.ac.uk

www.feem.it

www.seit.ee

www.environment.fi/syke

www.tecnalia.es

www.uni-bonn.de

www.uea.ac.uk

www.ufz.de

www.wageningenur.nl/

www.zalf.de

www.zew.de

\section{Associated partners}

IOM Institute of Occupational Medicine UK

IZA Institute for the Study of Labor Germany

External evaluation: Ecologic www.iom-world.org/

www.iza.org/

www.ecologic.eu

44 
The LIAISE consortium (Table 1) started with researchers from 15 institutes in 9 European countries with a background in policy analysis, ecosystem and land-use modelling, environmental economic modelling, higher education and communication. It unites the multi-disciplinary competences of a core of large European institutes, that in turn consolidate the expertise from large FP6 projects such as SEAMLESS, SENSOR, MATISSE, Sustainability A Test, IQ Tools and EVIA. The team has extensive experience in both the development of models and methods for IA, as well as the analysis of their application in the policy process. The collaboration between the sciences and social sciences is an essential characteristic of the LIAISE approach and is also reflected in the joint coordination by Alterra and the Freie Universität Berlin. Ecologic, a think tank for applied environmental research, policy analysis and consultancy has been contracted as external party to support the LIAISE process with an on-going evaluation of its performance.

A major motivation for organising this LIAISE session in the Science for the Environment Conference 2013 is the ambition to make the project results 'sustainable' by building a broad centre of IA expertise with a structural permanence. This means broadening the network and getting new partners involved. LIAISE has developed an associated partnership concept for extending the network. Here the first priority was to extend the scope with expertise in the field of social sciences. In 2012 two associated partners joined LIAISE: the Institute of Occupational Medicine (IOM) and the Institute for the Study of Labor (IZA). Activities to engage in relations with additional associate partners are under way and will contribute to further broadening the scientific scope.

As LIAISE is entering its final year of gathering evidence on impact assessment (IA) for sustainable development, a future vision on IA for sustainable development - and in particular in relation to tool use in the process - is gradually taking shape. Guidance on how to effectively shape the collaboration and interaction between IA researchers and IA users can be filled in on an operational and on a strategic level. On the operational level 'Knowledge Brokerage' must ensure that the existing scientific knowledge reservoir is effectively used in a specific IA process. On the strategic level the question is how to programme the research that is needed in order to increase and expand the existing knowledge reservoir in a way that enhances its usability in IA for sustainable development. Three keywords emerge to improve the contribution of the research community to the process of IA for sustain- able development. First, it must be truly transdisciplinary, in involving stakeholders in a participative fashion in the whole process, instead of consultative in only involving them for legitimation. Second, it must be integrative in drawing knowledge and perspectives from all dimensions of sustainability and from across scientific disciplines directly from the start, instead of focussing across a limited set of disciplines that are within easy reach. Third, it must be both short and long term, with a slight emphasis on the latter. This implies that long term benefits and adverse impacts must have a similar weight and importance as those visible on the short term such as division of resources and geographical issues.

Currently research has yet to develop a mechanism for strategic reflection on the methodological issues with respect to impact assessment for sustainable development and to develop an IA research agenda that reflects both the scientific interests from a broad range of research groups, and the priorities from a policy-maker's perspective. This is where LIAISE sees a future role for itself. The final year of LIAISE will thus focus on describing the overall evidence base as best as possible, on strengthening the vision as sketched here and on creating a future entity that is appropriate to consolidating the activities and achievements. The LIAISE team hopes that the Science for the Environment Conference 2013 will result in new contacts with IA researchers and IA practitioners that are interested to become engaged in building a broad centre of IA excellence.

\section{The LIAISE session will be structured as follows:}

1. Presentation and discussion of four papers:

- The LIAISE approach to co-designing knowledge on impact assessment (Tarja Söderman)

- The shared IA toolbox (Onno Roosenschoon)

- Impact assessment of soil protection policies in Europe (Nadia Glœsner)

- Impact assessment for Sustainable development: a vision for future development (Sander Janssen)

2. A roundtable discussion on how to conduct research in a meaningful way that addresses the pressing issues of our societies and supports policy makers in their strive for sustainable development? What is needed to solve the issue of the "Policy orientation vs. research orientation" as described in section 2? And how can we secure that science makes an impact on real-world processes? 


\section{THE LIAISE APPROACH TO CO-DESIGNING KNOWLEDGE ON IMPACT ASSESSMENT}

Tarja Söderman, Sanna-Riikka Saarela, Sabine Weiland \& Jacques Jansen Built Environment Unit, Finnish Environment Institute (SYKE), Helsinki, Finland

\begin{abstract}
Impact Assessment (IA) intends to collect evidence on the likely impacts of new policies and thereby minimize unwanted side-effects and maximize the benefits to society. Although it is a requirement in the EC and all OECD countries, the scope and methods vary considerably. Governments have invested considerably in research to support the evidence basis of policy making for sustainable development. However, the general picture shows a gap between the proliferation of IA tools and information from the scientific community and their actual use in the policy process and a need for a more effective knowledge exchange in science-policy interface. The FP7 network of excellence LIAISE (Linking Impact Assessment Instruments to Sustainability Expertise, www.liaise-noe.eu) is designed to explore the causes for limited use of IA tools and bridge the gaps between researchers with a generally strong orientation towards their (disciplinary) peers, and practitioners who tend to focus on their policy domain and current policy
\end{abstract}

problems. LIAISE aims at: 1) understanding of the policy process and the resulting needs for IA knowledge, IA tools and approaches; 2) description of IA tools and scientific IA expertise in a standardised way; 3) a shared IA toolbox targeted at the needs of both researchers and practitioners; 4) a shared IA research agenda integrating scientific knowledge gaps and the priorities for new IA knowledge arising from the future policy agenda; and 5) safeguarding the project results beyond the period of project funding, by developing an institutional setting and business plan that facilitates the extension of the present consortium towards a broad centre of IA expertise with a structural permanence. The presentation will outline the overall approach of LIAISE and focus on the lessons learned from the test cases about transdisciplinary integration of knowledge, knowledge brokerage techniques, factors influencing case-specific brokering activities and recommendations for a more successful use of IA tools in policy processes. 


\section{THE SHARED IA TOOLBOX}

Onno Roosenschoon, Stefan Reis, Rob Knapen, Klaus Jacob, Thomas Huesing, Dirk Wascher \& Yke van Randen Alterra - Wageningen UR, Wageningen, The Netherlands

\begin{abstract}
A key ambition in the development and use of models and software in impact assessment (IA) is to support the policy process with tools to evaluate the impacts of policy options on the three dimensions of sustainability: economic, environmental and social. To achieve this, IA tools need to be scientifically and technically sound, reliable, relevant to users, and widely applicable in a societally accepted participatory process. Various examples exist of complex and sophisticated models being applied in IA for policy making. However, in many cases, a gap persist between the currently realized and potential use of models in IA. Here, we will discuss causes and possible solutions for this.
\end{abstract}

We discuss how a lack of demonstrated robustness of model results, scarcity of documentation and usability of tools present barriers for uptake by potential users. This includes, but is not limited to, information about reliability, robustness, uncertainty as a lack of transparency, resulting in a 'black-box' perception of tools. IT may result in evidence for IA not being deemed trustworthy. To overcome these problems, the LIAISE network of excellence developed a common reference framework and guiding structure (the Reference Model for Impact Assessment Tools, RM-IAT), which provides a starting point for developing a shared toolbox, bringing together information about tools, experts, best practices and related documents to support policy impact assessments.

Describing IA tools consistently following this framework gives users more information about the tools, scale of use complexity, data requirements and application area, existing applications in IA, amongst many other parameters. The toolbox provides guidance to tool users for a better selection of tools for their specific purposes, which in turn may improve tool use in IAs. In addition, the toolbox is utilises taxonomies to classify not only tools, but also experts and best practices in a consistent fashion. The LIAISE Toolbox thus aims to serve as a central platform for the community of IA practitioners and researchers. 


\section{IMPACT ASSESSMENT OF SOIL PROTECTION POLICIES IN EUROPE}

Nadia Glcesner, Katharina Helming, Luca Montanarella \& Wim de Vries Leibniz-Zentrum für Agrarlandschaftsforschung (ZALF), Muencheberg, Germany

\section{ABSTRACT}

Soil protection plays an evident role for grand societal challenges, such as food security, climate change mitigation, and increased resource efficiency. Despite this, a common legally binding framework for soil protection does not exist at European level. In 2006, the "Thematic strategy for soil protection" [COM(2006)231] was proposed by the European Commission, including a proposal for a legally binding soil framework directive [COM(2006)232]. The final adoption of the proposed directive was opposed by a minority of EU member states with arguments of excessive administrative burden and alleged violation of the subsidiarity principles. Furthermore, the scientific evidence was not convincing to decision makers at that time, and particularly monetary information related to soil degradation was not sufficient. At present, ongoing activities within awareness raising, research and policy integration of the EU Soil Thematic Strategy are taking place [COM(2012)46].
We believe that action at European level is necessary for meeting upcoming grand societal challenges. Our study aims at revisiting the 2006 impact assessment [SEC(2006)620] with new insights in view of i) focusing on soil functions in relation to grand societal challenges instead of soil threats, ii) new role of soil issues in other environmental policies, iii) analysis of soil related policies since 2006, using new tools for impact assessment which allows new insight through different integration of existing knowledge. The review will aid in developing stronger science evident base for the proposed soil protection framework directive.

An important reason for a revisited impact assessment is that soil degradation is now much more prominent on the awareness list than it was in 2006. It has been stressed in many policy related documents in the last decade that soils are fundamental pillars of sustainable development [COM(2013)92]. 


\section{IMPACT ASSESSMENT FOR SUSTAINABLE DEVELOPMENT: A VISION FOR FUTURE DEVELOPMENT}

Sander Janssen, Klaus Jacob \& Jacques Jansen, Team Earth Informatics Alterra - Wageningen UR, Wageningen, The Netherlands

\begin{abstract}
Demonstrating the evidence for the needs and the benefits of planned policies is increasingly core in decision making in Europe, Member States, business and among stakeholders. In particular, the consideration of impacts on the different dimensions of sustainable development in decision making requires a comprehensive evidence base. In our paper, we elaborate on the basis of the activities and findings of the Network of Excellence LIAISE a number of criteria to improve the evidence base of policy making.
\end{abstract}

Based on a number of cases, the development of tools and a toolbox to facilitate impact assessment of policies we demonstrate that research and the IA process firstly must be truly transdisciplinary, in involving stakeholders in a participative fashion in the whole process, instead of consultative and only involving them for legitimation. Second, it must be integrative in drawing knowledge and perspectives from all dimensions of sustainability and from across scientific disciplines directly from the start. Third, it must demonstrate the impacts of policies on the creation/depletion of stocks of capital (economic, social and natural). This implies that long term benefits and adverse impacts must have a similar weight and importance as those visible on the short term such as division of resources and geographical issues. Knowledge Brokerage is key to facilitate between the spheres of research and decision making - in particular in understanding the contexts of decision making. We showcase how knowledge brokerage can be shaped.

Finally, the requirements for policy and SD relevant research can translate into quality attributes. This should guide future research and in particular the development of models and help to develop a durable and excellent research community. 


\section{CIRCULAR RESOURCE FLOWS FROM ALGAE PRODUCTION}

Michele Seghetta', Kaisa Manninen², Kristian Spilling, Berit Hasler', Annette Bruhn³, Jacob Carstensen³ \& Marianne Thomsen' ${ }^{7}$ Aarhus University, Dep. of Environmental Science, ${ }^{2}$ Finnish Environment Institut, Centre for Sustainable Consumption and Production, ${ }^{3}$ Aarhus University, Dep. of Bioscience

\section{ABSTRACT}

Algal biomass has been identified as a promising substrate for energy production. Several lab scale experiments have been performed on different species of both macroalgae and microalgae. The high content of carbohydrates makes both macroalgae and microalgae appealing feedstock for bioethanol and biogas production. Unfortunately, so far no industrial scale plant has been set up. This is a demonstration that there are still constraints to be overcome. This study will tackle the first obstacle for the development of this technology: the feedstock supply to a potential biorefinery. This study evaluates difficulties and constraints in the macroalgae and microalgae growth process though the utilization of the Life Cycle Assessment and an economic evaluation. In particular a case study of Saccharina latissima cultivation site in Limfjorden (Denmark) and a microalgae cultivation site in Finland will be compared and presented. Minimum feedstock requirement for a biorefinery, minimum selling price and influence of transport of the raw material, provide useful information for system design. 


\section{MUSSEL PRODUCTION TO UTILIZE EXCESS NUTRIENTS IN FJORDS - IS IT COST-EFFECTIVE AS MITIGATION MEASURE?}

Jens Kjerulf Petersen', Berit Hasler ${ }^{2 *}$, Karen Timmerman ${ }^{3}$, Pernille Nielsen ${ }^{1,4}$, Ditte Tørring', Martin Mørk Larsen ${ }^{3}$, Marianne Holmer ${ }^{5}$, Marianne Zandersen ${ }^{2}$, Hans Frost $^{6} \&$ Jens Erik Ørum ${ }^{6}$

'Danish Shellfish Centre, ${ }^{2}$ Aarhus University, Dep. of Environmental Science, ${ }^{3}$ Aarhus University, Dep. of Bioscience, ${ }^{4}$ University of Copenhagen, Marine Biological Laboratory, ${ }^{5}$ University of Southern Denmark, ${ }^{6}$ Department of Food and Resource Economics,

University of Copenhagen

\begin{abstract}
Mussel production is an alternative measure to reduce excess nutrients in fjords causing unwanted eutrophication and negative impact on ecosystem services, and hereby improving the utilisation of the nutrients. The basic principle of mussel farming as a mitigation tool is that by harvesting cultured mussels, the unidirectional flow of mineral nutrients from land to sea is returned by bringing back the nutrients bound in the mussels from sea to land, and hence regarding the emitted nutrients as a resource that can be recycled. Further, as the production of nitrogen fertilizer is an energy demanding process with negative climate impact and phosphorus is a limited resource on a global scale, there are several environmental interests in using mussels as a mitigation tool. Mitigation mussel
\end{abstract}

production can be carried out at lower costs compared to consumption mussel production, and our study has demonstrated that using mussels to remove nutrients from the coastal environment can be a cost-effective means of mitigation of excess load of nutrients. Many land based measures are partly already in use and thus have a restricted capacity for additional reduction of nutrient load to the marine environment, and the costs of implementing land based abatement measures for nutrient load reductions are thus increasing at the margin. Compared to the most expensive land-based measures mitigation mussel production is a cost-effective measure to obtain the nutrient load reductions required in order to obtain set environmental goals. 


\section{ECO-EFFICIENT POST TREATMENT OF DIGESTATE FROM FARM AND COLLECTIVE BIOGAS PLANTS TO IMPROVE NUTRIENTS (N\&P) RECYCLING}

Anne Trémier', Fabrice Béline', Claire Déchaux', Lynda Aissani', Mette Hjort Mikkelsen² \& Marianne Thomsen²* 'IRSTEA - National Research Institute of Science and Technology for Environment and Agriculture

${ }^{2}$ Aarhus University, Faculty of Science and Technology, Dep. of Environmental Science, *Corresponding author

\section{ABSTRACT}

Anaerobic digestion (AD) of organic waste from agriculture and others sectors is a widely used technology which shows increasing implementation due to its capacity to produce renewable energy and also to reduce greenhouse gas emissions from waste management. The development of $A D$ is also an opportunity to improve nutrient recycling from organic waste through the development of an eco-efficient post-treatment system. In this context, LCA was applied to evaluate the sustainability of different raw digestate post-treatment technologies regarding recycling of nutrients from agricultural and organic waste to agricultural soils for decreased resource depletion and climate mitigation. Substitution of the use of $\mathrm{N}$ and $\mathrm{P}$ mineral fertilizers with recycled soil health improver or organic fertilizers products as function of five different post-treatment technologies and raw digestate characteristics was evaluated. A particular attention was carried to (1) the gaseous emissions $\left(\mathrm{NH}_{3}\right.$ and $\left.\mathrm{N}_{2} \mathrm{O}\right)$ from process (post-treatment) but also after land spreading and (2) the carbon cycle considering the $\mathrm{CO}_{2}$ carbon costs of fertiliser production and the soil carbon sequestration benefit. 


\section{THE POTENTIAL OF USING ALGAE AS FEEDSTOCK FOR BIOFUEL, A NORDIC PERSPECTIVE}

Kristian Spilling, Jukka Seppälä, Kaisa Manninen \& Timo Tamminen Finnish Environment Institute, P.O. Box 140, 00251 Helsinki, Finland

\begin{abstract}
At first glance, areas in the high latitudes, like the Nordic Region, seem suboptimal for large-scale outdoors phytoplankton cultivation. It is obvious that dark winter season is not suitable for growing any photosynthetic organism. However, beyond winter months, the supply of solar energy is sufficient for phytoplankton growth. In this presentation, theoretical and realised phytoplankton productivities at various latitudes are compared. Temperature is considered another limiting factor for phytoplankton growth at high latitudes. Some phytoplankton species are, however, adapted to temperatures close to the freezing point. We show that they may have high growth rates and accumulate large
\end{abstract}

amount of lipids, thus being potential candidates for biofuel production.

Fertilizers and $\mathrm{CO}_{2}$ is a major cost when growing phytoplankton at large scale. Using waste streams as nutrient source for cultivation may thus reduce both the production cost, and also provide additional societal services by reducing nutrient fluxes to the sea. We present estimates for how much phytoplankton biomass may be produced using municipal waste waters. As a conclusion of this analysis, nutrient recycling becomes crucial for large-scale, cost-efficient production of phytoplankton biomass. 


\section{GETTING VALUE OUT OF BIOMASS. HIGH VALUE CHEMICALS FROM LIGNOCELLULOSIS}

Ib Johannsen

Department of Chemistry, Aarhus University, Denmark

\section{ABSTRACT}

In the conversion of fossil oil, $77 \%$ is converted to fuel and only $3 \%$ is converted to chemicals, however in terms of value, these two product groups contribute to approximately $50 \%$ each. In order to get value out of biomass a similar development must be undertaken. In this presentation an overview of the chemical conversion activities in the Danish bio refinery program, BioValue, is given alongside with initial results from work. 


\section{REBOUND EFFECTS - NEW PERSPECTIVES ON A PHENOMENON KNOWN FOR ALMOST 150 YEARS}

Co-chairs: Martin Soland' \& Anja Peters ${ }^{2}$

Universität Zürich, ${ }^{2}$ Fraunhofer ISI

Reducing the use of energetic and non-energetic resources is typically considered to be a key strategy towards achieving sustainable development goals. While new technologies and environmental policies have led to significant improvements in energy and resource efficiency, progress in the reduction of energy and resource consumption and environmental impacts has been less than expected. To some extent, this is also due to socalled rebound effects, a phenomenon which has first been described in 1865 by the economist W. S. Jevons. Accordingly, efficiency improvements can induce increased demand for services or products which at least partially compensates the expected reduction of energy or resource consumption.

Three types of rebound effects are usually differentiated in the literature. The term direct rebound effect relates to an increase in demand for or usage of a product or service after the product or service has become more efficient. The term indirect re-bound effect denotes the phenomenon that, after an improvement in efficiency, the demand for other resource consuming products or services may increase. A third type of rebound effects, the economy-wide or macro rebound effect, refers to increases in resource consumption of a whole economy due to changes in demand, production, relative prices and distribution patterns.

While scientists generally agree on the existence of rebound effects for energetic resources, magnitude and relevance in different areas of energy consumption as well as explanations and drivers of such effects are controversially discussed. So far, mainly financial drivers have been taken into account and research has just begun to consider socio-psychological and regulatory drivers. With regard to consumption of non-energetic resources, hardly any studies exist on potential rebound effects. However, knowledge about the relevant areas and drivers of rebound effects is crucial in order to take such effects into account when designing environmental policies and estimating their impacts.

This session presents and discusses relevance and drivers of rebound effects from various perspectives and for various areas and sectors in order to identify specific need for action. Martin Soland (University of Zurich) introduces greentech optimism as a socio-psychological driver of rebound effects and presents empirical results which illustrate how and under what conditions greentech optimism can negatively influence environmentally responsible behaviour. Anja Peters et al. (Fraunhofer ISI) introduce a psychological model for the explanation of rebound effects and present results of qualitative and quantitative methods to empirically study rebound effects related to lighting in the residential sector in Germany. Matthias Pfaff and Christian Sartorius (Fraunhofer ISI) use an input/output table based tool to quantitatively assess indirect and economy-wide rebound effects of efficiency improvements in resource intensive industrial sectors. Hans Jakob Walnum (Western Norway Research Institute and Aal-borg University) aims at an interdisciplinary understanding of macro rebound effects. Hans Marth and Anja Peters (Fraunhofer ISI) present a conceptual framework to clas-sify, identify and explain rebound effects and to discuss guidelines for policies to address rebound effects in different fields of environmental policy. Based on the various presentations, recommendations for policy and for further research shall be discussed. 


\section{ENVIRONMENTAL RESPONSIBILITY DENIAL DUE TO OPTIMISM IN GREEN TECHNOLOGY}

Martin Soland

Psychology Department, University of Zurich, Switzerland

\begin{abstract}
Rebound effects are generally suggested to originate from cost savings per unit of use (Sorrell, 2009). Additionally, de Haan (2009) suggested reductions of moral load as cause for rebound effects. Both, savings of monetary costs as well as reductions of moral load, are generated intraindividually through the utilisation of green technology. However, drawing on qualitative research findings (Lorenzoni, Nicholson-Cole, \& Whitmarsh, 2007) and referring to the concept of vicarious moral licensing (Kouchaki, 2011), we suggested that an individual's moral load can be reduced as well through optimistic beliefs regarding the problem-solving capacity of green technology in a society as a whole. Hence, we hypothesized that optimism in green technology weakens the individual's felt responsibility to act pro-environmentally.
\end{abstract}

We developed a scale to measure greentech optimism in order to test quantitative models of the suggested responsibility denial mechanism. In two studies ( $N=642, N=$ 169) the scale was then integrated into a prediction model for environmentally responsible behaviour based on the Norm activation model (Schwartz, 1977). Results from structural equation modelling suggest that greentech optimism weakens the individual's feelings of moral obligation to act pro-environmentally via the mediators problem awareness and awareness of consequences. However, the results further suggest that the hypothesized model only holds true for situations in which pro-environmental behaviour is related to high behavioural costs.

The findings make an important contribution to research on psychological explanations for rebound effects. Implications for sustainability policy as well as paths for future research are discussed.

\section{REFERENCES}

de Haan, P. (2009). Energie-Effizienz und Rebound-Effekte: Entstehung, Ausmass, Eindämmung. Schlussbericht. Bern: Bundesamt für Energie.

Kouchaki, M. (2011). Vicarious moral licensing: The influence of others' past moral actions on moral behavior. Journal of Personality and Social Psychology, 101(4): 702-715.

Lorenzoni, I., Nicholson-Cole, S. \& Whitmarsh, L. (2007). Barriers perceived to engaging with climate change among the uk public and their policy implications. Global Environmental Change 17: 445-459.

Schwartz, S. (1977). Normative influence on altruism. In: L. Berkowitz (Ed.), Advances in experimental social psychology (p. 189-211). New York: Academic Press.

Sorrell, S. (2009). The rebound effect: definition and estimation. In: J. Evans \& L.C. Hunt (Eds.), International handbook on the economics of energy (p. 199- 233). Cheltenham: Edward Elgar Publishing. 


\section{INTERDISCIPLINARY UNDERSTANDING OF MACRO-REBOUND EFFECTS}

Hans Jakob Walnum

Western Norway Research Institute Environmental Research and Aalborg University, Department for Planning and Development, Norway and Denmark

\begin{abstract}
Rebound effects have mainly been addressed at the micro-level. However, we must gain a better understanding of rebound effects at the macro-level if we aim to find effective policy strategies to meet key environmental goals. Macro-rebound effects (also called economic-wide) are discussed within energy economics. Where there is a disagreement in connection to prevails on detail questions, such as the scope of the output elasticity of energy (namely, how energy as a factor of production leverages overall economic growth), the degree of substitutability of all factors of production, or the relationship between efficiency increases and product/service innovation. It is difficult to prove or disapprove how the dynamics between energy efficiency and growth is based on macro-economic growth models. The results of the models depend on underlying assumptions. While energy economist's deals with how increases in energy efficiency influence
\end{abstract}

economic growth are other researchers more concerned of how economic growth combined with technological and sociological structures outstrips the efficiency gains. In the workshop "Interdisciplinary understanding of macro rebound effects. How can we understand and mitigate them?", arranged by Aalborg University at the $15^{\text {th }}$ of August, we will dive into some of the core controversies in understanding of macro rebound effects, addressing the importance of interdisciplinary understanding of rebound effects. Thus we will attempt broadening the perspective and more comprehensively investigate why the current environmental and sustainability policies fails, by further discussing the interrelationship between efficiency, energy, and related environmental problems, and the current and dominating growth policy. In our presentation we will address main findings from the workshop. 


\section{DEVELOPING A POLICY GUIDELINE FOR REBOUND EFFECTS}

Hans Marth \& Anja Peters

Fraunhofer Institute for Systems and Innovation Research ISI, Competence Center Energy Policy and Energy Markets, Germany

\begin{abstract}
Improving efficiency of products or services is generally regarded as an effective strategy to reduce energy and resource demand. However, changes in behaviour may render observed energy savings lower than expected based on engineering-economic analyses. While there is wide-spread consensus that energetic rebound effects exist, their magnitude is disputed. A large part of the discussion of rebound effects is centred on different explanations and their implications for environmental policy (Sorrell 2007; Sorrell and Dimitropoulos 2008; Maxwell et al. 2011). For non-energetic resources (e.g. water, raw materials) hardly any study on rebound effect exists and data to analyze rebound effects is difficult to obtain. Moreover, various scholars have called for a systematization of the debate on rebound effects (e.g. Turner 2013).
\end{abstract}

The aim of our study is to evaluate relevance of rebound effects in various areas of energy and resource consumption as well as for different consumer groups (households, commercial consumers), to analyze their drivers and to derive need as well as options for policy measures to contain them. Therefore, a comprehensive literature review and a categorization and evaluation of drivers for rebound effects in various areas were conducted. Based on this identification of relevant drivers of rebound effects, conclusions by analogy were drawn for areas with insufficient empirical evidence. The procedure, results and conclusions were discussed in an expert workshop in order to develop a guideline for stakeholders to support decisions about policy measures. In our presentation, findings and conclusions of our study will be outlined and discussed in detail.

\section{REFERENCES}

Maxwell, D., Owen, P., McAndrew, L., Muehmel, K. \& Neubauer, A. (2011). Addressing the Rebound Effect. A report for the European Commission DG Environment. Available online at http://ec.europa.eu/environment/eussd/pdf/rebound_effect_ report.pdf

Sorrell, S. \& Dimitropoulos, J. (2008). The rebound effect: Microeconomic definitions, limitations and extensions. In: Ecological Economics 65 (3): 636-649.

Sorrell, S. (2007). The Rebound Effect: an assessment of the evidence for economy-wide energy savings from improved energy efficiency. UK Energy Research Centre.

Turner, K. (2013). 'Rebound' effects from increased energy efficiency: a time to pause and reflect, Energy Journal: forthcoming. 


\section{MEASURING MACROECONOMIC REBOUND EFFECTS FOR NON-ENERGETIC RESOURCES}

Christian Sartorius \& Matthias Pfaff

Fraunhofer Institute for Systems and Innovation Research, Competence Center Sustainabililty and Infrastructure Systems, Germany

\begin{abstract}
The existence and nature of rebound effects have been widely discussed in the literature (e.g., see Dimitripoulos (2007), Maxwell and McAndrew (2011) and Sorrell and Dimitripoulos (2008) for surveys). This discussion has mainly taken place on the microeconomic level and in the context of energy efficiency improvements. Rebound effects for non-energetic resources as well as on the macroeconomic level have barely been covered so far. Our contribution aims to provide one potential approach to estimating rebound effects on the macro level for a variety of resources.

While there is no common typology of the rebound effect, the division into direct, indirect and economy-wide has been broadly accepted. Barker et al. (2009) additionally define the macroeconomic rebound as the sum of indirect and economy-wide effects. We follow this definition in our analysis. In a research project on resource efficiency potentials of innovative technologies in resource intensive production processes across Germany, an input/output table based assessment tool is used to estimate rebound effects. The analysis is based on 16 case studies for different production sectors.
\end{abstract}

For each case, specific resource efficiency measures are quantified and used to calculate a shift in the structure of the demand emanating from the respective sector. Following this, two types of rebound effects are analyzed.
First, demand increases for goods from connected sectors resulting from the efficiency improvement are assessed. Mutual demand relationships in turn lead to an increase in the demand for goods from the original sector. This can be regarded as the indirect rebound effect. Second, the sum of these increases in demand equates to an increase in aggregate demand. By nature of the structure of the economy, this leads to secondary increases in the demand for products of the original sector. This can be considered the economy-wide rebound effect. Together, both effects make up the macroeconomic rebound effect.

\section{REFERENCES}

Barker, T., Dagoumas, A. \& Rubin, J. (2009). The macroeconomic rebound effect und the world economy. In: Energy Efficiency, 2:411-427.

Dimitropoulos, J. (2007). Energy productivity improvements and the rebound effect: An overview of the state of knowledge. In Energy Policy 35 (12):6354-6363.

Maxwell, D. \& McAndrew, L. (2011). Adressing the rebound effect. Final report to European Commission DG ENV framework contract ENV.G.4/FRA/2008/0112

Sorell, S. \& Dimitropoulos, J. (2008). The rebound effect: Microeconomic definitions, limitations and extensions. In: Ecological Economics 65 (3):636-649. 


\section{EXPLORING AND ANALYZING RELEVANCE AND PSYCHOLOGICAL DRIVERS OF REBOUND EFFECTS}

Anja Peters, Elisabeth Dütschke \& Joachim Schleich

Fraunhofer Institute for Systems and Innovation Research, Competence Center Sustainability and Infrastructure Systems, Germany

\section{ABSTRACT}

Adopting energy efficient products or services is generally regarded as an effective strategy to reduce energy demand. Rebound effects due to changes in behaviour, however, may render observed energy savings lower than those expected from engineering-economic analyses. Scientists generally agree that such rebound effects exist, but their size, relevance and explanation are controversially discussed (Maxwell et al., 2011; Sorrell 2007). While economists point to price and income effects, social or psychological factors have largely been neglected. In this paper, we look at the case of residential lighting. First we identify possible psychological drivers drawing on psychological action theories (Peters et al., 2012). We then combine qualitative and quantitative methods to empirically study the factors driving rebound effects related to lighting in the residential sector in Germany. That is, we first carry out focus-group discussions and then conduct a representative survey $(n=6409)$. In the second study we conceptually and empirically distinguish between rebound effects due to higher brightness and longer burning time of more efficient bulbs. Limiting our analyses for reasons of homogeneity to the replacement of the main bulb in the dining/living room, we find that if the new bulb is more efficient than the old bulb, $57 \%$ of respondents chose a brighter bulb and $35 \%$ report to have increased burning time. With regard to psychological factors, the focus groups provide a detailed view of the possible role of attitudes, personal and social as drivers of rebound behaviour. The analyses of the survey data support that re-evaluations as part of attitudinal processes might play a role, however they do not support the influence of norms.

\section{REFERENCES}

Maxwell, D., Owen, P., McAndrew, L., Muehemel, K. \& Neubauer, A. (2011). Addressing the rebound effect. A report for the European Commission DG Environment, Ivry-sur-Seine, 26 April 2011.

Peters, A., Sonnberger, M., Dütschke, E. \& Deuschle, J. (2012). Theoretical perspective on rebound effects from a social science point of view - Working Paper to prepare empirical psychological and sociological studies in the REBOUND project. Working Paper Sustainability and Innovation No. S 2/2012. Karlsruhe: Fraunhofer ISI.

Sorrell, S. (2007). The rebound effect: An assessment of the evidence for economy-wide energy savings from improved energy efficiency. A report produced by the Sussex Energy Group for the technology and policy assessment function of the UK Energy Research Centre. Sussex: UK Energy Research Centre. 


\section{FP7 AFROMAISON: HOW TO PLAN. PLAY \& PROMPT MESO-INSTITUTIONS FOR INRM}

Session chair: Nils Ferrand

Irstea, France

The FP7 Afromaison project (2011-2014) aims to propose and validate concrete strategies for integrated natural resources management in Africa in order to adapt to the consequences of climate change. The challenge is to get to efficient integrated natural resource management (INRM) plans actually engaging all stakeholders and supported by the existing or emerging institutions, under the critical constraints of coherency and implementation.

A common operational framework has been implemented in 5 countries (TN, SA, ET, UG, ML) by local partners. It intensively and directly engages the communities (farmers, inhabitants) and all-level stakeholders in assessing the situation (resources, well-being, drivers) and the envisioned evolutions in front of global change, in proposing and specifying various actions (natural resource use and management, regulation instruments, information, organization...), and structuring them in coherent multi-sectorial multi-level strategies. These plans are explored and tested through dedicated role-playing games locally designed by actors to represent their issues and complex linkages between society and the environment. These games lead to strategy improvement and appropriation, and ultimately to the emergence of new meso-scale insti- tutions implementing these plans. A continuous monitoring and evaluation protocol provides information about the process and its outcomes.

This session proposes to introduce this complex but operational action-research project through the following sub-topics:

1. Bringing to efficient and engaging INRM strategies : how to combine multi-level participatory planning and role playing games to bring communities and other stakeholders to effectively co-design, adapt and adopt complex multi-sectorial action plans.

2. The Rwenzori Mountain case (UG) : a pilot for large scale social extension, exploration and institutionalization of a change strategy from many villages to a whole region under pressure.

3. Restoration and adaptation for ecosystems goods and services in the case studies: knowledge mobilization, innovation and integration.

4. Comparing conditions and results of a joint monitoring and evaluation protocol in 5 countries: success, failures and lessons.

5. Conclusions and proposals for natural resource management research in Horizon2020. 


\section{PARTICIPATORY PLANNING AND ROLE PLAYING GAMES FOR MULTILEVEL INRM IN AFRICA}

Ferrand, N., Ducrot, R., Abrami, G., Morardet, S., Hassenforder, E., Gumpinger, E., Kabaseke, C., Muhumuza, M., Lemmens, R., Lemenih, M., Cullen, B., Diallo, M., Waldron, S. \& Ghazouani, I. UMR Gestion Eau Acteurs Usages (G-EAU), IRSTEA, France

\section{ABSTRACT}

In FP7 Afromaison project, a common operational framework has been designed and implemented in the 5 pilot countries. It shapes an innovative participatory process which ultimately should deliver some regional strategies for natural resource use and management, coherent and acknowledged at all levels from end-users (farmers, households) to meso-scale policy makers and NGOs, tuned to the overarching political and economic context. The procedure has to accommodate the complexity of the socio-environmental conditions, the diversity of knowledge sources and legitimacy (lay, political, scientific), combine technical and non technical options, organize regulation, actually engage all stakeholders, check implementation conditions and foster the emergence or adaptation of the related institutions. It's applied in case studies with various size ( 300 to $30000 \mathrm{~km}^{2}$ ), population (up to 1 million) and issues. The time frame of the action (max 2 years) imposes a virtual test approach.

\section{Agreement on the general process}

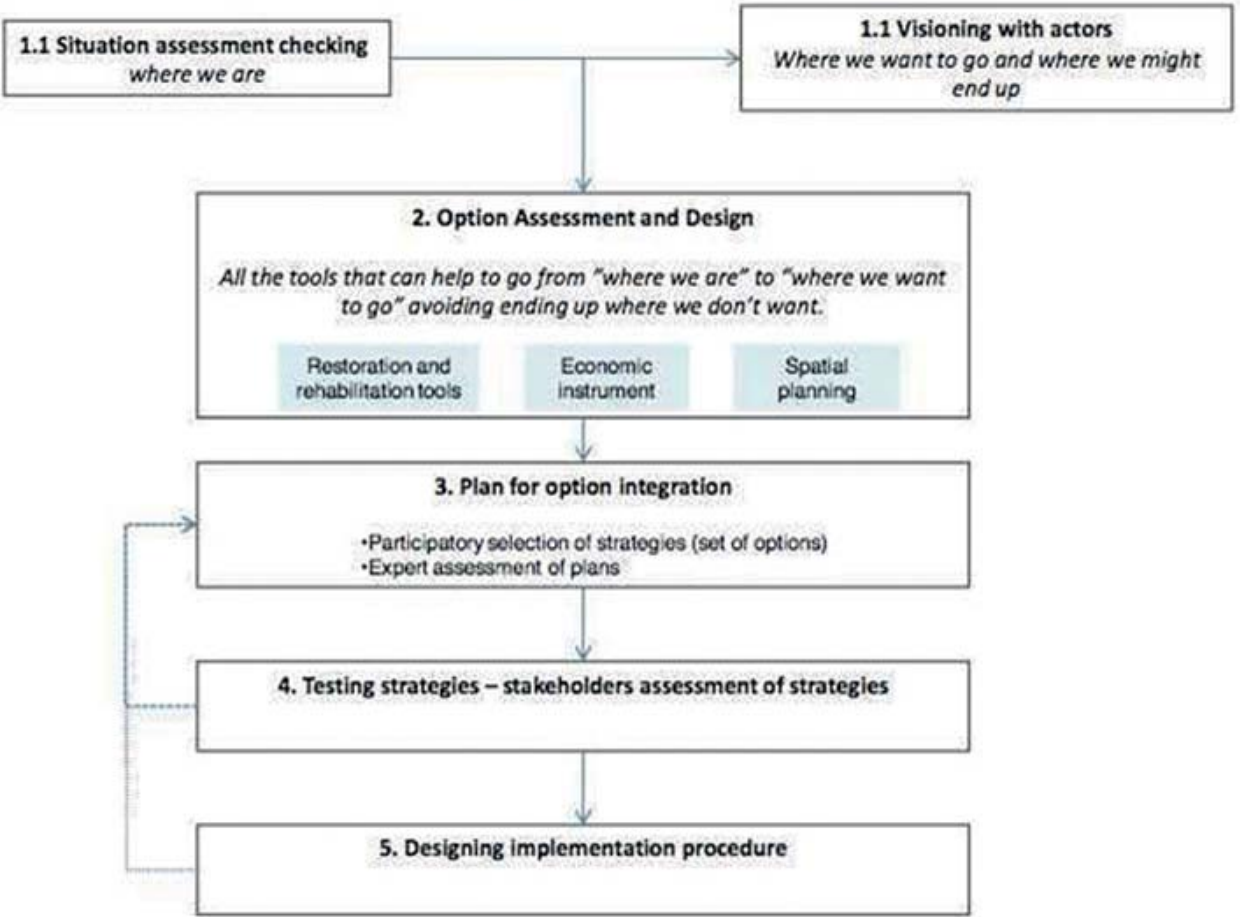


The framework (adapted from the FP6 Aquastress IP) has 6 phases: 0 . procedural agreement 1. initial assessment and visioning 2 . actions' proposals 3 . actions' selection and integration in strategies (planning) 4.strategy testing using role playing games 5 . implementation procedure. It's based on a sequence of participatory sessions, including lay people and all upper stakeholders, together or in parallel. The key methodological tools are: 1. a generic "action model" used by all actors (in paper form) to voice their wishes, and specify the required resources (natural, human, social, immaterial) and the expected impacts on pre-agreed common goals 2 . an integration protocol and a matrix to combine the actions in multi-level plans and discuss their coherency, feasibility and efficiency 3. a local role-playing game design process using the Wat-A-Game toolkit (Ferrand, Farolfi, 2009; Abrami, Ferrand, 2012) 4. a protocol combining the planning and the game to explore, test and improve the strategies. This paper will detail these procedure, method and tools. Progress and results are detailed in another slot of the same session.

\section{5 tools for INRM change}

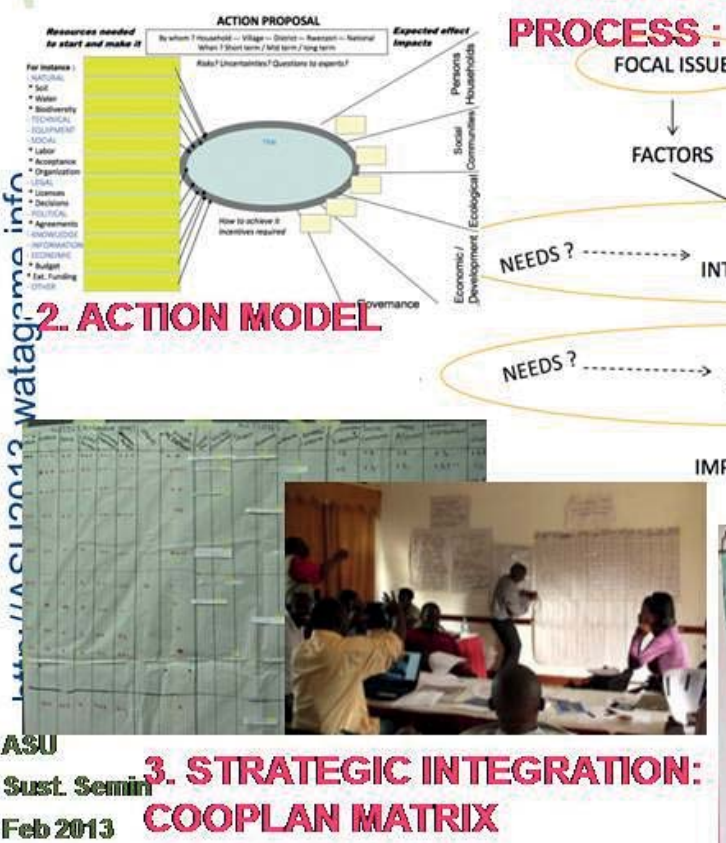

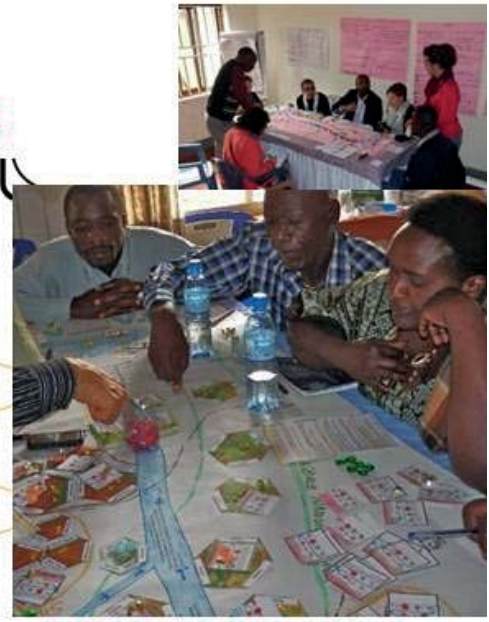

4. PARTICIIPATORY SIMULATION (Game)

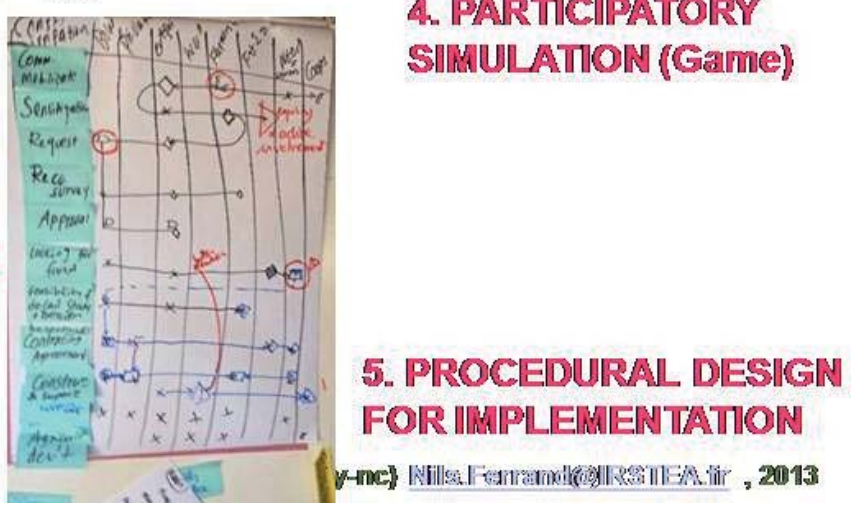




\section{CONDITIONS AND RESULTS OF A JOINT MONITORING AND EVALUATION PROTOCOL IN 5 COUNTRIES}

Ducrot, R., Ferrand, N., Hassenforder, E. \& Gumpinger, E. UMR Gestion Eau Acteurs Usages, CIRAD

\begin{abstract}
In FP7 Afromaison project, complex research and stakeholders engagement processes take place in 5 African countries, following a common operational framework. Aiming at the design and viability of new INRM strategies and its related institutions, the project has not only to monitor its own progress and outcomes, but also to finely analyze the different external conditions which foster or hinder these results, and attempt to decipher causes. The main aim is not so much to assess the "external" environmental conditions and changes, but rather to deeply look at the action-research process itself, at the stakeholders evolution and finally at social learning and changes in practices and organizations of the natural resource users. Therefore a common protocol for monitoring and evaluation has been specified, looking at different possible changes, considered either as factors or effects. Initially based on the ENCORE framework (Ferrand, Le Bars, 2004), which considers External/Normative/Cognitive/Operational/ Relational/Equity dimensions, it's been adapted to local requirements to organize and provide an open model for
\end{abstract}

monitoring activities and results. This monitoring and evaluation must be autonomously made by the local process holders, with all the risk of self-assessment. This has been addressed by systematizing records and structuring information. Dealing with an embedded research intervention, the key instrument is a logbook mechanism, supposed to record all interventions and interactions, participatory events, external sudden drivers (e.g. crisis). Additional tool record stakeholders engagement by listing participants and tracking their inclusion in steps. When possible, specific additional interviews or questionnaires are made on the way. All meetings normally include an ex-post questionnaire and a structured debriefing. For the wide scale Ugandan process, 5 evaluators have been recruited to monitor the $30+$ facilitators, using electronic pads and an internet data recording infrastructure, adapted to the low-tech local context. This paper will detail this process, discuss the different implementation in the countries, the observed discrepancies, and discuss some of the procedural results. 


\section{LARGE SCALE INRM STRATEGY DEVELOPMENT IN THE RWENZORI MOUNTAINS (UGANDA) THE RWENZORI MOUNTAIN CASE: A PILOT FOR LARGE SCALE SOCIAL EXTENSION, EXPLORATION AND INSTI- TUTIONALIZATION OF A CHANGE STRATEGY FOR INTEGRATED NATURAL RESOURCE MANAGEMENT FROM GRASS ROOT TO REGIONAL LEVEL}

Kabaseke, Muhumuza, Semana, Lemmens, Tibasima, Birungi, Kusemererwa, Hassenforder, Gumpinger, Ferrand, Abrami, Ducrot, Morardet \& Baha

Mountains of the Moon University, Uganda

\begin{abstract}
Natural resources in the Rwenzori region just like elsewhere in Uganda are under intense anthropogenic pressure. Despite the availability of policies on natural resource management and implementation of various interventions, the pressure has intensified. The Afromaison project has designed a number of innovative participatory tools involving stakeholders from the micro to the meso scale to reflect and come up with a strategy for sustainable integrated natural resource management. The focus of this paper is on the process of development and use of one of the tools (the Mpa'game) in natural resource planning and strategy development in the Rwenzori region. From the onset, the development of the tool involved stakeholders who tested it and suggested improvements to make it context specific and as a way of enhancing its ownership among end users. Pilot sessions involving the tool were conducted in villages in the Rwenzori region and stakeholders such as farmers, leaders, politicians, civil society organizations and the private sector participated. Results
\end{abstract}

from the sessions indicate that a reflective and exploratory process has been going on in the villages resulting into commitments for sustainable use of resources by stakeholders, consensus on concrete options for Integrated Natural Resource Management, and in some instances actual positive chance in practices. Evidently, the main strength of the Mpa'game is its ability to create synergies in interests among natural resource users from different locations, tribes, political affiliations, religions, economic status, and levels of education. Using a dedicated protocol, the Mpa'game session managers and rapporteurs have documented the results from each session for scientific analysis and integration into the existing development framework of the Rwenzori region. This process provides a unique example of a participatory large scale social extension, exploration and institutionalization of a strategy for Integrated Natural Resource Management from grass root to regional level. This process can be replicated in other regions in Africa where a similar situation prevails. 


\section{A WAY TO PLAN, PLAY, ASSESS AND MONITOR A PARTICIPATIVE INTEGRATED NATURAL RESOURCE MANAGEMENT (INRM) IN INNER NIGER DELTA (IND) IN GENERAL AND THREE (3) MUNICIPALITIES LEVEL IN PARTICULAR IN THE FRAME OF FP7 AFROMAISON}

Diallo Mori

Mali

\section{ABSTRACT}

The challenge is to get an efficient INRM plan actually engaging all stakeholders. In the frame of decentralization, this INRM is supported by existing institutions as well as emerging ones.

In a particular context of IND, where more than 1,5 millions of people are fully depending on ecosystem services, different kind of drivers are intensively impacting the management issues.

In AFROMAISON implementation process, a common operational frame work has been developed in 5 basins in Africa among which IND. This implementation is led by Wetlands International and his partners both at national and international level meets a long term vision of Sustainable management Plan of IND called in French PDD-DIN.

\section{Description}

During the implementation of the operational frame work, we have identified in visioning with stakeholders various actions related to natural resources use and management, tools, local practices and traditional knowledge. Lists of options for restoration, economic incentives and spatial planning tools have been identified with different work packages and Institutions involved in IND case namely 2iE and A\&W.

Promising options have been integrated into strategies with stakeholders including the robustness of these options under different scenarios. The plans are explored and tested through dedicated role playing game at local level designed by actors to represent their issues and complex linkage between society and environment.

The game leads to strategy improvement and its appropriation at meso scale and even higher level due to many similarities of landscape management issues in IND. Based on the monitoring and evaluation protocol on one hand and engagement of stakeholders on other hand, the outcome are better appreciated through provided information. 


\section{A FRAMEWORK FOR NORDIC ACTOR-ORIENTED CLIMATE ADAPTATION RESEARCH}

Richard J.T. Klein \& Sirkku Juhola

Stockholm Environment Institute, Sweden

\begin{abstract}
The past ten years have seen a substantial increase in research on climate change adaptation, but a large gap remains between adaptation research and action. Adaptation researchers have failed to demonstrate the relevance of their findings to practitioners and policymakers, forcing stakeholders to base their views and decisions on other kinds of information. In addition, in sectors such as agriculture, forestry, nature conservation, urban planning, water management and energy supply, adaptation has been studied separately from mitigation, which contradicts the reality of many practitioners. This paper identifies five bottlenecks to the use of adaptation research in adaptation practice and policy. These bottlenecks have gone unnoticed because the traditional framing of adaptation does not adequately consider the
\end{abstract}

notion of agency, often rendering stakeholder interactions ineffective. Knowledge and use of actor-oriented theory when analysing and discussing adaptation needs and options could serve to find ways to overcome the bottlenecks and narrow the gap between research and action. The paper presents a novel framework for actor-oriented adaptation research that is being conducted within the Nordic Centre of Excellence for Strategic Adaptation Research (NORD-STAR). It frames climate adaptation as addressing both the impacts of climate change and the consequences of climate policy. Two methodological approaches - modelling and visualisation, and policy analysis - are applied to three thematic issues: land-use change, energy transitions, and insurance and finance. 


\section{A BASE-ANALYSIS OF ADAPTATION IN COASTAL AREAS - WHAT CAN EU POLICIES DO?}

Mikael Hildén, Duncan Russel, Benjamin Boteler \& Katriona McGlade

Finnish Environment Institute, Climate Change Programme, Finland

\begin{abstract}
The EU Strategy on Adaptation to Climate Change (COM(2013) 216 final) recognizes coastal areas as vulnerable. The strategy identifies coastal flooding and erosion as key issues of concern. The strategy envisions funding through the Life+ instrument to support trans-boundary coastal management, emphasizing densely populated deltas and coastal cities, and stresses climate proofing through policy integration. For coastal regions, this means e.g. an explicit recognition of climate change in the proposal for a directive on Maritime Spatial Planning and Integrated Coastal Management (COM(2013) 133 final) and in planned guidelines on adaptation and coastal zone management (2014). This paper analyses the conditions for policy integration in coastal areas based on documentary analysis of relevant policy documents and reflection on selected cases. It specifically examines the most important challenges to adaptation and asks to what extent current and envisioned European legislation
\end{abstract}

is able to deal with the key vulnerabilities and adaptation needs. Does the European legislation provide regulatory instruments that can effectively address the most pressing questions that the strategy has identified, or is the role of European policies mainly to raise awareness? Awareness raising supports risk assessment and management, but in addition we suggest that coastal adaptation is critically dependent on integrated land use planning, a matter for which EU does not have competence. Progress therefore depends heavily on Member States' actions and policies. To be effective, EU legislation has two main options: either develop various ways of indirect regulation of land use or provide incentives for Member States to adopt sustainable land use. The approach of the adaptation strategy is a combination of the two. Its success is likely to depend on the ability to achieve synergistic effects, which in turn requires flexibility to deal with the diversity of the conditions along Europe's coasts. 


\section{THE EU CLIMATE ADAPTATION STRATEGY: AN EVALUATION OF ITS 'PROGRAMME THEORY'}

Sabine Weiland, Silke Beck, Alessio Capriolo, Sergio Castellari, Mikael Hildén, Kirsi Mäkinen, Helle Nielsen \& Duncan Russel Helmholtz Centre for Environmental Research - UFZ, Germany

\begin{abstract}
The European Commission adopted an EU Strategy on Adaptation to Climate Change in April 2013. The Strategy aims to contribute to a more climate-resilient Europe by ensuring that adaptation considerations are addressed in all relevant EU policies. It also promotes greater coordination and information-sharing among Member States and thus complements their own activities. Such coordination of climate change adaptation measures require the vertical integration of different levels of governance (European, national, regional, local) alongside horizontal integration between different sectors of the economy and society. Integration means the EU has to 'mainstream' climate change adaptation by including adaptation measures in its sectoral policies or strengthening already existing ones. This will also offer potential for synergies if adaptation policies are successfully coordinated.
\end{abstract}

This paper analyses how policy integration is conceptualised in the EU Strategy. What particular integration and coherence does the EU Strategy wish to achieve? What are the stated or implicit rationales for the choice of policy areas that have been included in the strategy for integration of climate change adaptation objectives? Does the strategy aim to radically change the thinking in the target sectors? We are particularly interested in the underlying 'programme theory' of integrating and mainstreaming climate goals into different policy sectors and across governance levels.

The paper develops an analytical framework to assess policy integration and coherence in the EU Strategy. The policy integration perspective appears as a useful starting point as the Strategy is strongly built around the idea that other policy sectors pick up the ball. At the same time this is expected to happen purely through Commission staff interaction as the strategy itself does not include any strong commitments. The paper analyses which institutional mechanisms and processes are contained in the Strategy to promote policy integration, and discusses the feasibility of achieving this goal in light of the literature on policy integration and coordination. Thereby, it goes beyond the Commission's impact assessment of the Strategy. 


\section{HOW WILL THE EU CLIMATE ADAPTATION STRATEGY AFFECT EU AGRICULTURAL POLICIES?}

Helle Ørsted Nielsen, Eleni Karali, Anders Branth Pedersen \& Sergio Castellari

Department of Environmental Science, Aarhus University, Denmark

\begin{abstract}
A key objective in the EU Strategy on adaptation to climate change (COM (2013) 216 final) is to ensure mainstreaming of adaptation measures into European sectoral policies. The Common Agricultural Policy (CAP) is one such sectoral policy, which is prioritized in the strategy. The CAP will be reformed for the $2014-2020$ period with the explicit objectives of strengthening the competitiveness and the sustainability of agriculture (EC). Climate change adaptation objectives are included in the proposal for a greening of the single payment scheme (2011/0280 (COD)). Also the proposal for the Rural Development Program specifically sets out climate change adaptation as an objective to which funding must contribute (2011/0282 (COD). This paper therefore examines the most important challenges to adaptation in agriculture and analyses to what extent the reformed CAP will provide the tools to deal with the key vulnerabilities and adaptation needs. Specifically, the paper analyses the policy instruments
\end{abstract}

available in the CAP and assesses their suitability for addressing climate change adaptation, given the knowledge available in the literature and policy analyses on effective adaptation measures. At the same time, the CAP and not least the Rural Development Program are to contribute to and integrate multiple policy objectives, including other environmental objectives as well as fostering innovation and ensuring viable rural areas. This raises the second and related question, which the paper will seek to address, as to the strength of the mainstreaming mandate laid out in the climate change adaptation strategy, particularly when policy objectives conflict or when they simply compete for attention. The paper is based on analysis of key EU climate adaptation and agricultural policy documents and compares the policy instruments and the institutional mechanisms laid out against the academic and policy relevant literatures on policy integration and coordination as well as on policy instruments. 


\section{WATER FOR PEOPLE AND FOR THE ENVIRONMENT: LINKING MODELLING AND PARTICIPATORY APPROACHES TO DEFINE ADAPTATION IN THE TAGUS BASIN, IBERIAN PENINSULA}

Ana Iglesias, Aline Chiabiai, Pedro Iglesias, Marc Newman \& Luis Garrote CEIGRAM, Universidad Politécnica de Madrid, Spain

\begin{abstract}
In the beginning of the $21^{\text {st }}$ century water to support ecosystems, cities and culture seems to stand at a crucial juncture. Projections of water availability remain complex and uncertain, not least due to changes in population, consumption patterns and environmental policy. Research and technology have been unusually vigorous and have shed light on many possible innovations. In southern Europe of this transformation is due to the pressure of agricultural practices and policies to face climate change, especially in relation to water for agricultural production.
\end{abstract}

The climate change challenge has forced research and policy to look at the interactions of urban and rural areas and environment with a longer term perspective. Exploring policy choices for future water management in the Tagus basin - a transboundary basin in the Iberian Penin- sula - need to consider climate change projections and need to be successfully balanced to achieve sustainability. In this case study we explore some aspects of water management through a combined participatory and modelling approach designed to stimulate discussion and debate. In our work, models assist in providing evidence of changes in patterns of water supply and demand under a range of scenarios. The participatory approach aims to understand resilience and adaptive capacity. We then design the adaptation strategies organized around the idea that understanding (1) resilience, (2) policy trade-offs, and (3) flexible mechanisms. We recognise major limitations in our assessment of adaptation policy due to the difficulties in forecasting water needs and supply. The strength in our approach is the science-policy interface. 


\section{JOINT PROGRAMMING INITIATIVE ON CLIMATE: PROVIDING SCIENTIFIC KNOWLEDGE FOR THE BENEFIT OF SOCIETY}

Session Chair; Eva Banos de Guisasola

CMCC, Italy

The concept of Joint Programming was introduced by the European Commission in July 2008 in order to implement the European Research Area (ERA). There is a need of a strategic approach in coordinating European research activities to address societal challenges of common interest on a European or even global scale. The aim of Joint Programming is to increase the value of relevant national and EU R\&D funding by concerted and joint planning, implementation and evaluation of national research programmes, including common financing of transnational research projects or other joint research activities.

Some member states have taken up this approach and presented a proposal for a new Joint Programming Initiative "Connecting Climate Knowledge for Europe (JPI Climate)" in April 2010. After its formal launch in November 2012 in Brussels, JPI Climate is now well-established, with 13 participating countries, an agreed governance structure and Strategic Research Agenda (SRA). With support of an FP7 Coordination and Support Action and a number of so-called fast track activities, the member countries are now working on the implementation plan and updating the SRA. the research agenda and develop an implementation plan. With a first pilot call scheduled for later in 2013, JPI Climate is now setting its research agenda in 4 interrelated areas: decadal and seasonal projections, climate services, decision support methods and tools, and societal transformation.

We understand 'climate knowledge' in a rather broad sense, including all kinds of scientific knowledge on causes and consequences, on cost, risks and benefits of climate change as well as possible responses. JPI Climate intends to contribute to a highly coordinated knowledge development by not only improving the scientific expertise on climate change risks and adaptation options, but also by connecting that knowledge with decision-making on safety and major investments in climate-vulnerable sectors in Europe. JPI Climate research should be well coordi- nated with other environmental research at the European and member state level, and hence liaison with appropriate partners is essential and can be enhanced during the Aarhus conference.

\section{DESCRIPTION OF THE SESSION:}

1. Discussion of questions such as:

- Is sufficient knowledge available to decision-makers for them to make properly informed choices to meet climate policy goals?

- Are current research programmes adequately addressing the gaps in policy-relevant knowledge?

- Does international collaboration enhance project quality and relevance, or does it make research more complicated?

- Are current or planned research budget sufficient to meet society's demands?

\section{A general presentation of the JPI climate (Panel with} fours speakers explaining the four modules + brief questions and answers:

a Moving towards Reliable Decadal Climate Predictions: Sylvie Joussaume and Sanna Sorvari

b Researching Climate Service Development and Deployment: Dagmar Bley

c Sustainable Transformations of Society in the Face of Climate Change: Lisa Almesjö, Sebastian Helgenberger

d Decision-support methods and tools for Climate Change: Gregor Laumann

e Integrating the JPI climate: Roger Street

3. The session will close with an action from the audience identifying what is the information and knowledge they are missing and the JPI panelists will respond to them. We will use yellow stick notes, flipchart, a board, so everyone can see what is being produced. The session will be dealt with by a facilitator. 


\section{CONSEQUENCES OF EU ENVIRONMENTAL POLICIES FOR ECOSYSTEM SERVICE PROVISION ELSEWHERE}

Rob Alkemade \& Tanya Lazarova

PBL Netherlands Environmental Assessment Agency, Bilthoven, The Netherlands

\begin{abstract}
The European Union is strongly committed to preserving Europe's ecosystems and biodiversity and has concentrated efforts into developing strong environmental policies. For instance, the new EU biodiversity strategy sets ambitious targets towards halting the loss of biodiversity and ethe degradation of ecosystem services in Europe by the year 2020. Moreover, the strategy commits to working towards averting global biodiversity loss. Despite of its good intentions, by implementing environmental and other policies that explicitly or implicitly relate to the concepts of ecosystem services and natural capital, the EU could be causing substantial impacts on biodiversity and the provision of ESS outside of Europe. As a part of the EU OpenNESS project (Operationalization of Natural Capital and Ecosystem Services), PBL works towards understanding the effects of European Union policy frameworks on a global scale. For that reason, a methodology for assessing the impact of EU policies on ecosystem services outside of
\end{abstract}

Europe was developed, based on the IMAGE framework and GLOBIO model of PBL. The provision of a diverse set of ecosystem services in different regions outside Europe was evaluated based on assessments of ecosystem service supply and demand. As an example, the methodology was applied to assess the impact of the 2020 targets of the EU Renewable Energy Directive (RED) on ecosystem service provision in Africa and South America. The preliminary results reveal that the increased demand for biofuel import for outside of Europe, following the 10\% target of $\mathrm{RED}$, could have considerable negative impact on the provision of each of the assessed ecosystem services (food \& water provision, climate regulation and erosion protection) in the regions assessed. The methodology will contribute towards the objectives of OpenNESS, as a tool for operationalizing the concept of ecosystem services to support the development and evaluation of EU policies and practices. 


\section{THE ECOSYSTEM SERVICES CONCEPT IN EU POLICIES: A REVIEW OF REGULATORY FRAMEWORIKS}

Christian Schleyer \& Jennifer Hauck

Helmholtz Centre for Environmental Research (UFZ), Department of Environmental Politics, Germany

\begin{abstract}
This contribution will present the results of a first review and preliminary analysis of policies and regulations at EU level (e.g., CAP and Cohesion Policy, including their emerging reforms) which are expected to have the greatest impact (either direct or indirect) on ecosystem services. Particular attention will be given to initiatives where the concept of ecosystem services plays an important role, such as the EU Biodiversity Strategy to 2020 , including the forthcoming Green Infrastructure Strategy and the No Net Loss Initiative 2015; but also the Water Frame-
\end{abstract}

work Directive and Renewable Energy Strategy will be focused on. Emphasis will also be placed on identifying potential synergies and trade-offs - in particular across sectors - between those regulatory frameworks. Based on a document analysis and literature review on selected regulatory frameworks we will focus on the degree of policy integration of the different ecosystem-services-related frameworks and the tensions or trade-offs between them. Finally, the role of those and other regulatory frameworks for driving ecosystem change is addressed. 


\section{HOW DOES GOVERNANCE CONTRIBUTE TO CONSERVATION OF BIODIVERSITY AND ECOSYSTEM SERVICES: A CONCEPTUAL MODEL OF KNOWLEDGE USE AND THE EFFECTS OF ARGUMENTS AND POLICIES}

Eeva Primmer, David Barton \& Rob Bugter

Finnish Environment Institute, Finland

\begin{abstract}
Biodiversity and ecosystem services are dominantly viewed as spatially defined units whose functions are vital and beneficial to humans either directly or indirectly. The recognition, and even monetary valuation, of the benefits is often taken to be a precondition for designing sustainable governance of biodiversity and ecosystem services. In other words, decisions are assumed to be based on a calculation of benefits and costs, and once there is accurate information, the decisions should generate the planned effects. However, instead of waiting for the accurate information about ecosystem service interdependencies, authorities, businesses, land-owners and managers are developing strategies and practices to enhance conservation and sustainable governance already in their current practice.
\end{abstract}

The conservation and sustainable management decisions of our time rely on diverse knowledge sources and combine them in deliberations and negotiations, drawing on multiple value domains. These decisions generate intended (and unintended) effects on the status of biodiversity and ecosystems. Whilst developing ever more elaborate ways of analyzing ecosystem services and their values, the research community should ambitiously advance also the understanding of governance and how it generates effects in the social-ecological system. This endeavor should make use of the abundant literature on policy analysis, evaluation and implementation as well as adaptiver governance and multi-level governance.

To feed into the analysis and development of ecosystem service governance, the chains of impacts; from knowledge to practice through arguments and policies, need to be conceptualized. This paper develops the conceptual model of ecosystem service governance by drawing on research on knowledge use and the effects of arguments and policies 


\section{DEVELOPING REGULATORY FRAMEWORKS FOR GREEN INFRASTRUCTURE: ISSUES TO BE ADDRESSED}

Suvi Borgström (researcher) and Jukka Similä (division manager)

Finnish Environment Institute, Environmental Policy Center/Environmental Governance Studies Unit

\begin{abstract}
Ecosystems are under a great pressure from intensive human use, habitat fragmentation and climate change. As a result, biodiversity and associated ecosystem services are declining. Green infrastructure (GI) is an emerging policy response to these challenges. The central idea behind the concept is the understanding of the natural environment as an infrastructure resource capable of delivering variety of ecological, economic and social benefits (Frischmann 2012). Just as "traditional" infrastructure such as road systems and mobile networks requires investment and management, so does $\mathrm{Gl}$. Investing in $\mathrm{Gl}$ can make significant contribution towards number of policy objectives including protecting natural capital, helping species and people adapt to and mitigate climate change, increasing human health and well-being as well as facilitating sustainable growth (COM (2013)249).
\end{abstract}

In order to maximize GI benefits, comprehensive policies and actions are needed at different scales. At the EU level GI strategy will provide an enabling framework for promoting $\mathrm{Gl}$ initiatives and policies within the context of existing legislation, policy instruments and funding mechanisms (COM(2013)249). However, new policy instruments and changes in existing regulatory frameworks may be needed at the national, regional and local level. Development of GI policies and initializing effective and cost-efficient initiatives and projects at different scales requires further investigation in scientific paradigms behind the concept and development of new planning and measuring tools. Furthermore, research is needed to assess the role of existing regulatory frameworks in sustaining and enhancing $\mathrm{Gl}$. The potential regulatory gabs to be filled and legal barriers to be removed need to be identified. Also the potentiality of different policy instruments for mobilizing green infrastructure investments should be assessed. This paper discusses the challenges and possibilities for green infrastructure governance and aims to develop a tool for assessing regulatory frameworks for $\mathrm{Gl}$. The tool provides means for identifying relevant policy measures and instruments for GI and criteria for their assessment.

\section{REFERENCES}

COM(2013)249. Communication from the Commission to the European Parliament, council, the European Economic and Social Committee and the Committee of the Regions. Green Infrastructure (GI) - Enhancing Europe's Natural Capital.

Frischmann, B. (2012). Infrastructure. The Social Value of Shared Recourses. Oxford University Press. 


\section{MAPPING AND ASSESSMENT OF ECOSYSTEMS AND THEIR SERVICES: DEVELOPING A KNOWLEDGE BASE FOR MAINSTREAMING ECOSYSTEM SERVICES INTO EU POLICIES}

Joachim Maes

European Commission, Joint Research Centre, Ispra, Italy

\section{ABSTRACT}

The concept of ecosystem services is integrated in current biodiversity policies at global and European level. In particular, the EU Biodiversity Strategy to 2020 integrates the sustainable use of ecosystem services as underpinning element of human economies to complement the non-utilitarian conservation approach to biodiversity, thus contributing to the Europe 2020 target, in particular through the resource efficiency flagship. The Europe 2020 strategy aims at building smart, sustainable and inclusive growth for the European Union. It establishes resource efficiency as the guiding principle for other EU policies. For environmental policy, it requires demonstrating that protecting the health, vitality, resilience and productivity of natural ecosystems and securing the services they provide is good for economic growth as well as for the environment.

Action 5 of the EU Biodiversity strategy, in particular, addresses some of the knowledge gaps with respect to natural capital and ecosystem services and calls the EU Member States to map and assess the state of ecosystems and their services in their national territory by 2014 , assess the economic value of such services, and promote the integration of these values into accounting and reporting systems at EU and national level by 2020 . This ambitious action requires innovative use of data and models and is of crucial importance for setting priorities to restore ecosystems, promote the use of green infrastructure and ensure the no net loss of biodiversity and ecosystem services across the EU.

Much of the ambition incorporated in the biodiversity targets is dependent on mainstreaming biodiversity and ecosystem services into other policies that affect the use of natural resources. At the EU policy level, this is most notably the agriculture policy (including forestry), but also regional and environmental policies should be the target for incorporating ES in their decisions. Achieving biodiversity targets requires demonstrating that changes in these policies are beneficial to human well-being through the enhanced flow of ecosystem services. It also requires prioritizing investments and making them cost effective based on a sound knowledge base and assessment methods. This paper will help exploring how such assessments might be developed under Horizon 2020. 


\section{ADVANCING RESEARCH \& PRACTICE IN GENDER, ENERGY AND CLIMATE CHANGE ACROSS AND BEYOND EUROPE}

Co-chairs: Susan Buckingham, Leader SubWorking Group Energy and Climate Change, genderSTE Inés Sánchez de Madariaga, Chair, COST policy-driven network Gender, Science, Technology and Environment, genderSTE

It is evident that the causes of climate change are gendered, as are the effects.

- Women feature disproportionately amongst the poor in all countries, so, by virtue of income alone, they consume less energy, and contribute less to climate change. However, there is also evidence that women have different consumption habits, which are less damaging environmentally. This is reflected in opinion polls, which consistently demonstrate that women are more concerned about, and more likely to take action to mitigate, climate change. Worldwide, evidence suggests that money paid to women is more likely to be spent on food and clothing for the family. Where money paid to men it is more likely to be spent on energy intensive and polluting consumer goods. Women's prudence with money has been demonstrated with micro-credit schemes, increasingly used by development banks.

- Extreme weather conditions, many of which are related to climate change, have clear gendered impacts. The after effects of extreme climate change induced (and other) weather events also have gendered impacts which range from physical and sexual abuse of women and girls in refugee camps, to women providing support for and cleaning up of devastated communities. Worldwide, gendered income differentials mean that women are more likely than men to be poor, and so to experience more environmental injustice than men. This can result in women being less likely to escape climate change related disaster. Gendered social and economic roles lead to women and men experiencing the effects of climate change in different ways, which relate to the gendering of everyday lives. The effects of climate change are overlain on existing social and economic inequalities. Gendered poverty also makes females more likely to suffer environmental injustices such as fuel poverty. The failure to invest in clean energy alternatives to burning biomass have a gendered impact on mortality.

- Of the 70 countries the UNDP ranked as most developed in 2007, only 18 reduced or stabilized their overall carbon emissions between 1990 and 2004 (UNDP, 2007). Fourteen of these had a greater than average percentage of female elected representatives. Professions dominating climate change and energy are heavily male dominated. According to Eurostat, female participation in the energy sector is low: only $22 \%$ of those employed in electricity, gas, steam and air-conditioning supply activities in $\mathbf{2 0 1 0}$ were women. The numbers of women in high-level positions related to climate change in the EU are substantially lower than those of men. In environment positions there are 121 women to 236 men; for energy, 35 women to 167 men.

This round table discussion proposes to address the following issues:

- How are attitudes towards, and thinking about energy and climate change affected by gender, as well as by other vectors of disadvantage (such as income, age, disability, race/ethnicity, parenthood?) 
- What are the links between gender-balanced decisionmaking and more effective policies to mitigate climate change and provide climate-neutral energy options?

- How can policy making in these areas at the local, national, and international become more gender sensitive?

- How do gendered experiences of energy use and climate change vary between countries, cultures and world regions?

- What and where are the gaps in research into gender, energy and climate change?
This roundtable is part of a broader inquiry into the 'state of the art' of research into gender, energy and climate change, which will inform the development of a major research initiative to influence national and international policy. This is an initiative of the genderSTE COST Action to advance the state of the art in knowledge and policy implementation on gender, science, technology and environment through creating a network of policy-makers and experts on gender, science and technology. Further details at: http://www.cost.eu/about_cost/governance/genderste

\section{Roundtable Discussion Agenda}

09.00-09.10 Ines Sanchez de Madariaga, "Objectives of COST policy driven network Gender, Science, Technology and Environment, genderSTE"

Susan Buckingham, "Mapping the state of the art, Working Group on Energy and Climate Change"

09.10-10.40 Mapping the state of the art of gender and climate change 1 (15' each).

09.10: Karen Morrow, "Women's Participation in Climate Change Governance; why we need it, how we can reduce barriers"

09.25: Hilda Rohmer, "Impact of gender differences in transport on energy consumption and climate change"

09.40: Sherilyn MacGregor, "The politics of energy consumption in the North: feminist challenges to dominant discourses"

09.55: Berit Aasen, "A gendered view from the South: access to energy and impact of climate change" 


\section{INCLUDING THE HUMAN FACTOR IN ADAPTATIVE ACTIONS TO FACE CLIMATE CHANGE}

Maria J. Polo \& Miguel A. Losada

Interuniversity Institute for Research on Earth System, University of Cordoba, Spain

\begin{abstract}
Predicted scenarios for the current climate change foresee a general sea level rise and significant changes in precipitation and evaporation/transpiration regimes associated to the global temperature increase. Extreme events of flood and drought will very likely be more frequent, and will bring significant damages in areas with high water and soil demands and in many others that will undergo further urbanization and economic development. Protection against both flood and drought consequences is usually carried out by means of reservoir/ dam networks and improving supply systems (urban/ irrigation), to decrease the vulnerability of floodplains or the water scarcity during dry years. This action decreases the frequency of such events, by increasing the threshold values associated. The indirect effect is an enhaced perception of "safety" in such areas, since occurrence is significantly lower, and a further occupation of the territory takes place unless additional actions are taken to
\end{abstract}

avoid it. This call-effect brings as a consequence a high increase of the damages associated to extreme floods or droughts, which fall out of the control capacity of the existing protection network, since more people and more activities are affected after the occupation of these now "safer" areas. This work presents a methodology to include the call-effect in the simulation of the impact of the actions to be taken, in the framework of a decision-making process based on risk analysis. Two examples from the Guadalquivir River Basin (Southern Spain) show this approach: the increase in olive crop areas following the modernisation of irrigation systems, which brought an increase in the global water demand for irrigation despite the significant reduction in unitary water use efficiency, and the occupation of coastal/fluvial areas associated to the development of protection structures. The results highlight the need for including the human factor in the design of adaptative actions facing climate change. 

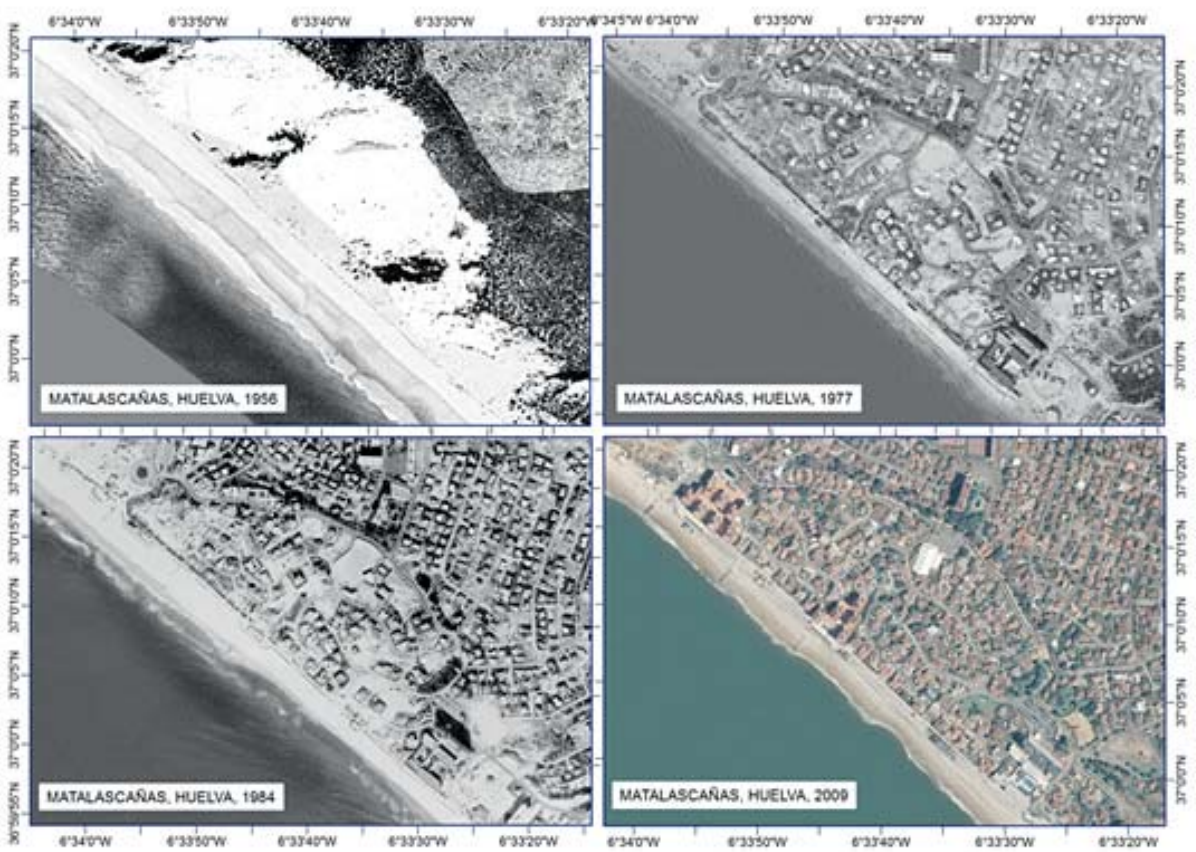

Urban development in the littoral zone in Matalascañas (Huelva, Southern Spain).
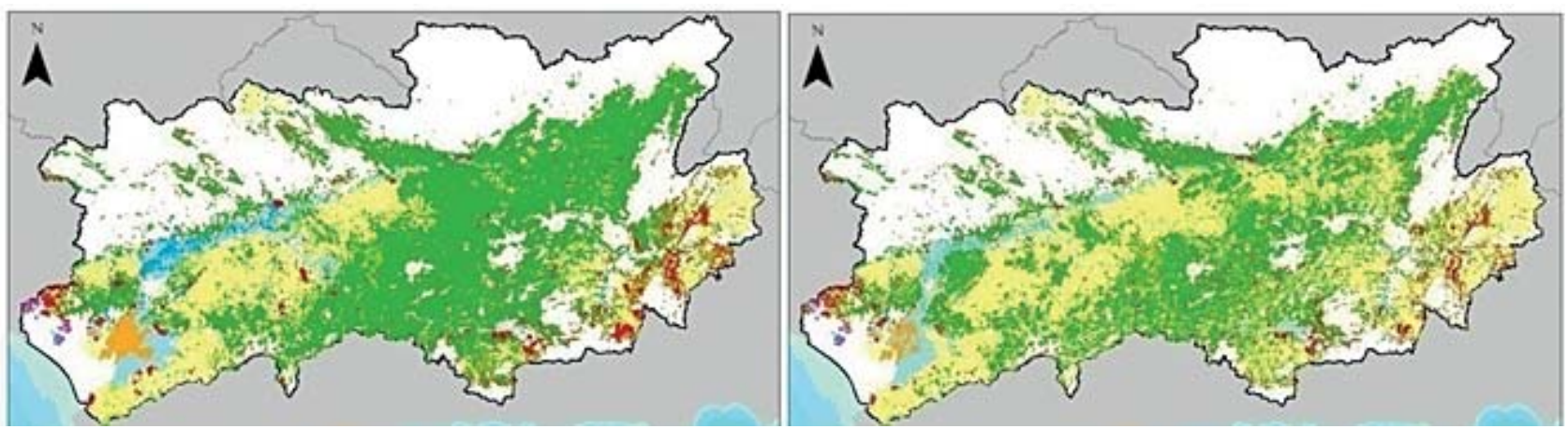

Olive crop distribution (green area) in the Guadalquivir River Basin in 1956 (left) and 2003 (right). 


\section{SOCIO-ECONOMIC AND CULTURAL CONTINGENCIES IN THE PLANNING. IMPLEMENTATION AND TRANSFER OF CLIMATE ADAPTATION ACTION}

Grit Martinez, Fanny Frick \& Kira Gee Ecologic Institute, Germany

\begin{abstract}
Culture and tradition are an undervalued part of climate adaptation action research. Research tends to either focus on the actual extent of climate change (modelling impacts), or the technical feasibility of adaptation measures. Comparatively little effort is spent on understanding perceptions of climate change, or the cultural prerequisites for developing successful strategies for adaptation.

Through such cultural dynamics motivations in society for climate action e.g. acceptance of adaptation measures and cooperation in a given context can be uncovered. This can provide new perspectives on branding, categories and the wider cultural environment. And in doing so, it offers access to otherwise hidden knowledge and helps building socio-ecological networks and systems for climate adaptation action.
\end{abstract}

The presentation deals with the perception of climate risks and different resulting measures for adaptation to climate change developed in selected coastal municipalities. We attempt to trace the reasons behind these differences based on empirical work such as interviews with political decision-makers and residents as well as document analysis. The contribution examines the respective cultural traditions in selected communities. This particularly focuses on images of nature, people's relationships to the sea, economic development and past approaches and attitudes to coastal defense. It sets out the specific constellation of social-cultural, ecologic and economic driving forces that led communities to adopt a different approach, with particular focus on different factors of success. It is argued that cultural traditions and historical development are undervalued but significant determinant in the selection of local adaptation strategies and that greater account needs to be taken of such local specificities (and mentalities) to create a bottom-up drive for adaptation strategies.

The study forms part of the FP7- research project BASE (Bottom-up Climate Adaptation Strategies towards a sustainable Europe).

\section{REFERENCES}

Adger, W.N., Barnett, J., Brown, K., Marshall, N. \& O'Brien, K. (2012). Cultural dimensions of climate change and adaptation. Nature Climate Change 2012.

Döring, M., Settekorn, W. \& Storch von (Eds) (2005). Küstenbilder, Bilder der Küste. Interdisziplinäre Ansichten, Ansätze und Konzepte, Hamburg University Press, Hamburg.

Fische, L. (2011). Maritime Gedächtniskultur an der Nordseeküste: Adaptionen der Katastrophe. In: Fischer, L. \& Reise, K. (Eds). Küstenmentalität und Klimawandel. Küstenwandel als kulturelle soziale Herausforderung. Oekom Verlag, München.

Kempton, W. (1999). Cultural Models of Nature. In: Boster, J., Kempton, W. \& Hartley, J. (Eds). Environmental Values in American Culture. MIT Press, Massachusetts.

Shackley, S. \& Deanwood, R. (2009). Stakeholder Perceptions of Climate Change Impacts at the Regional Scale: Implications for the Effectiveness of Regional and Local Responses. Environmental Planning and Management, 45 (3): 381-402. 


\section{GENERAL AND PARTICULAR SOCIAL VULNERABILITY TO NATURAL HAZARDS IN POLAND}

Piotr A. Werner

University of Warsaw, Faculty of Geography and Regional Studies Poland

\begin{abstract}
The concept of a natural hazard can be clearly distinguished from a natural disaster (Lisowski, 1993). The latter can be described in terms of systems theory as 'irreversible change in the (...) of the system, compared to the situation prior to ...' (ibid.). Natural disasters are often identified with the extreme natural phenomena. Donald Rumsfeld's (2002) words that there are: (i) known knows, (ii) known unknowns and (iii) unknown unknowns might be applied to natural hazards and disasters and supplemented with the (iv) unknown knows which means that people sometimes knowingly ignore the hazard or disaster (Kundzewicz et al., 2011).
\end{abstract}

Usually approach to assessment of risk of extreme natural phenomena involves convolution of natural hazards and vulnerability (Bankoff 2004). Multi-dimensionality of the vulnerability rise from the exposure (environmental), susceptibility (socio-economic) and coping capacity (organizational or system) conditions (Villagran, 2006). Studies of vulnerability to defined natural hazards describe usually the specific conditions of natural phenomena and socio-economic characteristics of the defined regions, taking the form of hardly comparable for different hazards. complex geographical indices.

The scientific aims of the studies are the measurement and evaluation of social vulnerability to chosen environmental hazards in Poland i.e. construction and estimation of spatial differentiation of the indices of society vulnerability to identified environmental hazards in Poland using the unified methodology. The results encompasses assessment of the spatial inconsistency of identified, potential environmental hazards in Poland and spatial differentiation and conformity of (locations) of vulnerable people and digital division areas and increased vulnerability to identified, potential environmental hazards in Poland.

The project: 'Spatial Differentiation of Information Society Vulnerability to Defined Environmental Hazards in Poland' is supported by Polish National Science Centre (2012-2015).

\section{REFERENCES}

Bankoff, G., Frerks, G. \& Hilhorst, D. (2004). Mapping vulnerability disasters, development, and people. Earthscan Publications, London; Sterling, VA.

Kundzewicz, Z.W., Matczak, P. \& Sadowski, Z. (2010).

Wprowadzenie do raportu o zagrożeniach. Nauka 4

http://www.portalwiedzy.pan.pl

Lisowski, A. (1993). Skutki występowania wybranych zagrożeń naturalnych i ich percepcja w Polsce, Wyd. Uniwersytet Warszawski, Wydz. Geografii i Studiów Regionalnych, Warszawa.

Rumsfeld, D. (2002). http://en.wikipedia.org/wiki/There_are_ known_knowns

Villagrán de León, J.C. (2006). Vulnerability: a conceptual and methodological review. United Nations University, Institute for Environment and Human Security, Bonn, Germany. 


\section{TOWARDS AN APPLIED SCIENCE OF PAST DISASTERS}

Felix Riede LaPaDiS - Laboratory for Past Disaster Science, Department of Culture \& Society (Materials, Culture \& Heritage), Aarhus University, Denmark

\begin{abstract}
Extreme climatic events are forecast to become more frequent in the future. This contribution argues that the past may hold clues to efficient, cost-effective, and culturally sensitive adaptations to and relief measures following such events. It is widely recognised that disasters emerge in the interplay between extreme geophysical events and the human communities affected by them. Whilst detailed knowledge of a given event is critical in understanding its impacts, an equally thorough understanding of the affected communities, their economies, ecologies, religious structures, and how all of these have developed over time is arguably as important. Many extreme events leave methodologically convenient traces in the geological and archaeological records. This contribution focuses on two volcanic eruptions that have significantly affected Europe: the eruption of the Laacher See volcano (Germany) in the 13th millennium BCE and the eruption of Vulcán llopango (El Salvador) in the $6^{\text {th }}$ century CE - to illustrate the power of the case-control comparative method for examining European vulnerability and impacts in the near- and far-
\end{abstract}

fields of these eruptions. Although issues of data resolution often plague the study of past disasters, these limitations are counterbalanced by the access to unique long-term information on societies and their material expressions of livelihood, as well as a similarly long-term perspective on the critical magnitude/frequency relationship of the geophysical trigger(s) in question. By drawing together aspects of disasters science, archaeology, volcanology and historical sociology, this contribution offers a programmatic statement and methodological roadmap for a European science of past disasters that can make historically-informed, evidence-based statements on general processes of cultural adaptations to climatic processes and events, and on contemporary vulnerability and impact from a deep time (historical and prehistoric) perspective [1]

\section{REFERENCES}

1. Riede, F. (in prep.) Towards a science of past disasters. Natural Hazards. 


\section{URBAN ADAPTATION TO CLIMATE CHANGE AND DIFFERING CAPACITIES OF CITIES TO ADAPT}

Anne Jensen, Blanka Loučková, Mark Zandvoort, Bjørn Bedsted, Margaretha Breil, Filipe Alves \& X Li Department of Environmental Sciences, Aarhus University, Denmark

\begin{abstract}
Cities are widely recognized as key nodes of economic, social, environmental, cultural and political activities as well as concentrations of diverse people and multiple flows. Being key nodes, with cities' activities affecting adaptation and the amount of people and economic activities that are affected by the impact of a changing climate in the urban, cities hold a crucial position in societal responses to the impacts of climate change. With these impacts becoming increasingly evident, cities face challenges related to complexity and uncertainty in crafting timely and apt responses and implementing these in contexts that are equally marked by a range of other pressing issues for urban policy. However, there are wide
\end{abstract}

differences in how well cities are equipped to manage these challenges. These differences in adaptive capacity of cities and their determinants are not sufficiently covered in urban/climate adaptation literature.

Drawing on theories of urban policy analysis and urban planning, in particular related to the notion of adaptive capacity of cities and building on six European case studies, this paper addresses questions of which (policy) actions cities launch to adjust the urban context to impacts of a changing climate, which factors determine cities' ability to adapt, how the adaptive capacity of cities could be improved, and how such policy actions influence the spatial urban context. 


\section{TRANSFORMATIVE EXPERIMENTS AS STRATEGIC TOOLS IN CLIMATE GOVERNANCE - CASE STUDIES FROM FINLAND}

Annukka Berg, Mikael Hildén \& Jukka Similä

Environmental Policy Centre and Climate Change Programme, Finnish Environment Institute, Finland

\begin{abstract}
This paper discusses the role of experiments in efforts to mitigate climate change. Transformative experiments can be defined as 1) making something new and concrete that is 2) restricted in terms of time, space, scope and/or actors but that 3) aims at having wider societal relevance through various up-scaling mechanisms. Experimenting, taking place at different levels and contexts of society, can be seen as an alternative to policy development based on traditional planning (cf. Lindblom 1959; Mintzberg, Ahlstrand and Lampel 1998). Both planning and experimenting can be applied at an early stage of the policy process (Sutton 1999) with restricted resources and political support. And both are ways to approach a relatively unknown field with the aim to increase understanding, boost discussion and find solutions for challenges at hand. However, they differ fundamentally from one another in that planning aims at systematic progress towards a goal, whereas experimenting is about probing in an unchartered terrain.
\end{abstract}

This study presents the first results of a research project that draws lessons from transformative experiments conducted by public and/or private actors in the context of climate governance in Finland. We discuss how experiments can open new ways to deal with some "wicked problems"
(Rittel and Webber 1973) of climate policy development. We specifically explore the role of experiments in policy development processes. Do they change the framing of issues at hand and in this way support the adoption of climate-friendly policies and practices? Are they able to promote public deliberation and provide specific suggestions on how policies and policy instruments need to be changed in order to transform locked-in regimes? By addressing these questions the paper contributes to indepth understanding about the potential of transformative experiments in addressing complex challenges such as climate change.

\section{REFERENCES}

Lindblom, C.E. (1959). The Science of "Muddling Through". Administration review 19(2): 79-88.

Mintzberg, H., Ahlstrand, B. \& Lampel, J. (1998). Strategy Safari: A Guided Tour Through the Wilds of Strategic Management. New York, NY: The Free Press.

Rittel, H.W.J. \& Webber, M.M. (1973). Dilemmas in a general theory of planning. Policy Sciences 4(2): 155-69.

Sutton, R. (1999). The Policy Process: An Overview. London: Overseas Development Institute. 


\section{LINKING KNOWLEDGE TO ACTION}

María Del Mar Delgado-Serrano, María José Ambrosio-Albalá \& Alice Newton

Department Of Agricultural Economics, University Of Córdoba, Spain

\section{ABSTRACT}

Connecting scientific knowledge and tools to society interests and actions remains an urgent research challenge that must be met to enable the fundamental societal transformations needed to move towards sustainable, low-carbon global societies. Natural and physical aspects have had a leading role in the building of knowledge about Climate Change. However Climate Change societal aspects have attracted less scientific attention (ISCC, 2012). There is a growing body of evidences highlighting that new ways of approaching Climate Change issues need to be considered. To link Knowledge to Action interdisciplinary, transdisciplinary and excellent research is needed on:

1. The factors determining individual and collective perception and behaviour facing climate change. To propose solutions to environmental pressures, an appropriate characterization of the socio-cultural factors shaping Climate Change perception should be undertaken. Knowledge of the sociological factors influencing individuals to internalize, react or deny the reality of Climate Change emerges as a new area of research (Nagel et al., 2010) necessary to fully engage people with the issue and with the relevance of their own actions.

2. The barriers that hinder effective science-society communication and co-responsibility in adaptive and mitigation strategies. New ways of science-society interactions are necessary to display consequences of Climate Change in recognizable and manageable terms for society (Spence et al., 2012), delivering information accessible, understandable and comprehensive (Dilling and Lemos, 2011) and creating usable knowledge in iterative communication processes between scientists and information users.
New efforts and approaches are needed on co-designing and developing research to: 1) society increase knowledge and awareness of the influence of individual and collective behaviour on climate change; 2) scientists increase the effort in delivering society-friendly knowledge and 3) policy-makers delivering sound and acceptable policies and engaging society to adaptation and mitigation strategies.

\section{REFERENCES}

Dilling, L. \& Lemos, M.C. (2011). Creating usable science: Opportunities and constraints for climate knowledge use and their implications for science policy. Special Issue on The Politics and Policy of Carbon Capture and Storage, 21(2), 680-689. doi:10.1016/j.gloenvcha.2010.11.006

International Social Science Council (ISSC) (2012). Transformative Cornerstones of Social Science Research for global Change. Recuperado a partir de http://www.worldsocialscience. org/?p=2871

Nagel, J., Dietz, T. \& Broadbent, J. (2010). Workshop on Sociological Perspectives on Global Climate Change. Arlington, Virgina: National Science Foundation. American Sociological Association. Recuperado a partir de http://ireswb.cc.ku.edu/ crgc/ NSFWorkshop/Readings/NSF_WkspReport_09.pdf

Spence, A., Poortinga, W. \& Pidgeon, N. (2012). The Psychological Distance of Climate Change. Risk Analysis, 32(6), 957-972. doi:10.1111/j.1539-6924.2011.01695.x. 


\section{CLIMATE CHANGE IN DENMARK: MODELS, UNCERTAINTIES. EFFECTS AND ADAPTATION}

Jens Hesselbjerg Christensen' \& the CRES team

'Danish Meteorological Institute

\begin{abstract}
Adapting to climate change requires a common understanding and quantification of how human activities, interacting with natural processes, affect human and natural systems. The Centre for Regional Change in the Earth System (CRES) is a five year funded multidisciplinary climate research platform financed by the Danish Council of Strategic Research. It brings together leading scientists with excellent and long track records of quality research in climate change and key Danish stakeholders and practitioners with a need for improved climate change information.
\end{abstract}

CRES carries out a number of specific research activities, all tied together with a common agenda taking an interdisciplinary approach. The overall objective of CRES is to extend knowledge on and reduce the uncertainties surrounding regional climate change and its impacts and thereby support future climate change adaptation and mitigation policies. While more specific objectives are to: a) reduce uncertainty surrounding regional climate change and its impacts for the period 2020-2050 by improving model formulation and process understanding; b) identify key changes and tipping points in the regional hydrological system, agriculture, freshwater and estuarine ecosystems caused by changes in seasonality, dynamics and extreme events of precipitation, droughts, heat waves and sea level rise; c) quantify confidence and uncertainties in predictions of future regional climate and its im- pacts, by improving the statistical methodology and substance and by integrating interdisciplinary risk analyses; d] interpret these results in relation to Danish, European, and global risk management approaches for climate change adaptation and mitigation.

Since the start of CRES in October 2009, scientific advancement has taken place with respect to each of these specific objectives. A large number of scientific papers have resulted from this and has in many cases substantially lifted the scientific foundation that underpins decision making with respect to climate change adaptation. With CRES, one may argue that advancing the underlying scientific understanding of issues central for decision making particularly in Denmark has gone hand in hand with the need to communicate the state-of-the-art in addressing these issues. An emerging theme already pertinent to CRES activities is to take a risk based approach towards understanding climate change impacts and when considering practical adaptation options and strategies.

This presentation will highlight both some of the scientific achievement as well as how these have been communicated to the users of climate change information needed in adaptation work as well discussing how the remaining efforts within the lifetime of CRES are expected to kick-off the next stage in defining how climate change science meets societal needs related to adaptation. 


\section{ROLE OF CLEAN DEVELOPMENT MECHANISM (CDM) IN TRANSFER OF ENVIRONMENTALLY SOUND TECHNOLOGIES (ESTS) AND ATTAINING SUSTAINABLE DEVELOPMENT GOALS}

Mahatab Uddin

Department of Law, Aarhus University, Denmark

\begin{abstract}
Clean Development Mechanism (CDM), established under UNFCCC regime is a climate change mitigation tool through which the developed countries (Annex 1 countries) can fulfill their carbon emission reduction obligation by purchasing carbon Emission Reduction (CER) units from the CDM-projects located in developing countries (Non-Annex 1 countries) - including the least developed countries (LDCs). CDM is the only mechanism whereby the non-annex 1 countries can involve themselves in external mitigation activities under UNFCCC regime. In addition to fulfilling the emission reduction obligation of the industrialized countries, the basic goals of CDM include promoting sustainable development and transfer of environmentally sound technologies (ESTs) to non-annex 1 countries.

This paper is aimed to show the existing role of CDM projects in transferring ESTs and attaining sustainable development in non-annex 1 countries, especially in the LDCs. The paper will analyze examples of transfer to Bangladesh - one of the most climate change-vulnerable LDCs. The environmental risks and adversities caused by changing
\end{abstract}

climate patterns demand large-scale of transfer of ESTs to Bangladesh to ensure a sustainable future for the society.

\section{REFERENCES}

1. Kasturi, D. Technology Transfer under the Clean Development Mechanism: an empirical study of 1000 CDM projects, The Governance of Clean Development. Working Paper 014 - July 2011, available at http://www.tyndall.ac.uk/sites/default/files/ gcd_workingpaper014.pdf

2. The contribution of the clean development mechanism under the Kyoto Protocol to technology transfer, UNFCCC, 2011, available at https://cdm.unfccc.int/Reference/Reports/TTreport/ TT_2010.pdf

3. Voigt, C. Is the Clean Development Mechanism Sustainable? Some Critical Aspects, Sustainable Development Law \& Policy, Vol. 7, No. 2, pp. 15-21, Winter 2008

4. Voigt, C. The Deadlock of the Clean Development Mechanism: Caught between Sustainability, Environmental Integrity and Economic Efficiency, available at xa.yimg.com/kq/ groups/17397856/2036658714/.../Resumo+-+Voigt.doc 


\section{SCALING UP INCLUSIVE AND SUSTAINABLE DEVELOPMENT THROUGH GREEN FINANCE IN INDIA}

Dr.Vaidehi Daptardar \& Manasi Gore

Visiting Faculty at University of Pune, Department of Economics India

\begin{abstract}
According to Dr. Manmohan Singh, Indian Prime Minister, "Inclusive growth is the centerpiece of our development process. Fast economic growth has little meaning, if it does not lead to the well being of the poor and the disadvantaged, of our farmers, workers, our children, students and women."
\end{abstract}

India being one of the fastest developing countries today is more vulnerable to the climate damages. This is so as generally the faster growth of an economy demands higher energy use, that too with more fossil fuels and then this growth many times becomes unsustainable.

The IPCC has identified developing countries as more vulnerable to climate change damages and that this condition is most extreme among the poorest people. (IPCC 2001: 227) This is due to

High dependence on ecosystem for climate sensitive livelihoods.

Limited access to availability of resources (incidence of poverty).

Disparities on human development (inequalities within country).
Therefore growth from sustainable pathways becomes critical in these countries and inclusive growth comes as a priority. By scaling up the Green finances, both these objectives could be achieved. Any project, that promotes preservation or conservation of natural resources, reduction in Carbon emissions or the absorption of Carbon from environment is generally known as a Green Project. And financing such a project is the Green Finance. The Kyoto Protocol has offered immense opportunities to the developing economies with a 'Surprise' of Clean Development Mechanism (CDM).

The paper throws light on these issues in general and more particularly deals with the CDM and its financing in India as a major step to mitigate the challenge of climate change. The paper evaluates the existing financing framework and also offers some policy suggestions as a future pathway.

\section{REFERENCES}

SIDBI and its Role in Green Financing \& Development. SIDBI Report. OPPORTUNITIES IN GREEN FINANCE (NATIONAL RESOURCE MANAGEMENT CENTRE) NABARD India, 2009

Country Presentation on Green Micro Finance by Debasish Prusty. Ministry of Finance, Government of India.

Various official documents of Government of India, international agencies like UNDP, UNEP, UNFCCC, IPCC. 


\section{THE SOCIO-ECOLOGICAL SCALES OF ECOSYSTEM SERVICE BUNDLES IN DENMARK}

Katrine Grace Turner ${ }^{a, b}$, Peter K. Bøcher ${ }^{b}$, Chris Kjeldsen ${ }^{a}$, Jens-Christian Svenning ${ }^{b} \&$ Tommy Dalgaard $^{a}$ alntegrated Geographical and Social Studies, Department of Agroecology, Aarhus University

${ }^{b}$ Ecoinformatics \& Biodiversity Group, Department of Bioscience, Aarhus University

\begin{abstract}
To better understand the interactions of multiple ecosystem services in the landscape, their modeling, opportunities and restraints, we examine the differences in the composition of multiple ecosystem services at different scales. This addresses the following questions: what are the composition, interaction and distribution of nationwide ecosystem services when aggregated on municipal and managerial boundaries? Furthermore, we study the composition of the services bundles as we aggregate data from fine scale to coarse scale in different ecosystem service-landscape types. The case study of Denmark is particularly relevant for ecosystem service trade-off analysis due to the high human population pressure (128 pers/ $\mathrm{km}^{2}$ ) and large fraction of agricultural land-uses putting pressure and creating demand for a diverse range of ecosystem services. We conduct the analysis at the scale of the municipality, which are approx. $400 \mathrm{~km}^{2}$ in average, to
\end{abstract}

investigate ecosystem services' trade-offs and synergies at a scale relevant to the policy maker. Within selected municipalities we investigate how ecosystem service bundle types are distributed at a finer resolution $(500 \mathrm{~m} \times 500 \mathrm{~m}$; i.e. the land management decision scale). The services aggregated are separated into provisioning services (livestock, crops, and drinking water); cultural services (sense of place, nature appreciation, summer cottages, nature tourism); and the regulating services of carbon storage, wetlands water purification, and soil organic content. Earlier analyses found support for the existence of four distinct bundle types; coastal, agricultural, forested and multifunctional bundle types. We expect these general patterns to be consistent when aggregated to the municipality scale and become more specialized at the higher resolution as the finer detail in the landscape are uncovered. 


\section{CLIMATE REGULATING SERVICE - A SPATIAL ANALYSIS ASSESSING THE EFFECTIVENESS AND ECONOMIC EFFICIENCY OF ECO- SYSTEM SERVICE BASED MANAGEMENT}

Marianne Zandersen, Gregor Levin, Sisse Liv Jørgensen, Doan Nainggolan, Louise Martinsen, Steen Gyldenkœrne \& Mette Termansen

Department of Environmental Science, Aarhus University

\section{ABSTRACT}

Soil organic carbon (SOC) and carbon stored in biomass $(\mathrm{BIOC})$ play a crucial role in the regulation of the global carbon cycle and its feedbacks within the Earth system. Compelling evidence exits that soil carbon stocks have been reduced in many regions of the world, with these reductions often associated with agriculture. In a Danish context research also suggests that carbon stocks are declining. The scope of Payment Ecosystem Service Approaches to effectively and efficiently address climate regulation will depend on the spatial distribution of the carbon assimila- tion capacity, current land use, the value of avoided emissions and land owners objectives and preferences in terms of participating in initiatives to increase SOC and BIOC. The spatial analysis of these factors is conducted at the Danish national scale. We map the carbon sequestration potential under different land use scenarios, value the potential avoided emissions in terms of their marginal abatement costs and compare these to an assessment of costs of achieving these potentials using voluntary agreements with agricultural land managers. 


\section{BIODIVERSITY AND ECOSYSTEM SERVICES IN DANISH FORESTS: OPTIMIZING MULTIPLE OBJECTIVES}

Anders Højgård Petersen, Thomas Hedemark Lundhede, Niels Strange, Bo Jellesmark Thorsen \& Carsten Rahbek

\begin{abstract}
Timber production used to be the main purpose of the Danish forests. However, there is an increasing demand for other ecosystem services such as carbon storage, ground water protection, outdoor recreation and biomass for energy production. Thus, a central question is whether overall gains can be made from a differentiation of functional targets across forest areas relative to the current multifunctional forest policy ideally pursuing several targets simultaneously in the same areas? Answering this question is an important aim of the present project. The results will support the future forest policy and may feed in to the national ecosystem service assessment that Denmark has to compile as part of its EU obligations. Using quantitative analyses we combine biodiversity data on the national distribution of forest species with data or models on $\mathrm{CO}_{2}$ storage, groundwater, rec-
\end{abstract}

reational value and production of timber and biomass. Furthermore knowledge is compiled on the relation between forest management and ecosystem services. Some specific questions to be answered are: Which forests in Denmark constitute together the most cost-efficient network to ensure the preservation of forest biodiversity? Given the optimal solution for biodiversity, what are the trade-offs in terms of other ecosystem services? Are there geographical patterns in how optimization of ecosystem service values for biodiversity and the other services interact in terms of cost and provision? We present the intentions and technical setup of the project as well as initial analyses of the geographical distribution of the Danish forest biodiversity the other ecosystem services and thus where potential conflicts or synergies are most likely to occur. 


\section{VALUING THE BENEFITS AND COSTS OF PROVISION OF ECOSYSTEM SERVICES FROM DANISH FORESTS}

Suzanne Elizabeth Vedel, Jette Bredahl Jacobsen \& Bo Jellesmark Thorsen Department of Food and Resource Economics, Copenhagen University

\begin{abstract}
In the Danish forest policy, and in particular in Natura 2000 areas, there is an increased focus on the ecosystem services provided. On one hand they have a large value for society, e.g. in terms of recreational benefits and biodiversity and groundwater protection, on the other hand, providing these services typically implies a cost for the forest owner, in terms of lost production, but also loses in values from restrictions in future land use options, nuisance from visitors, and other non-monetary disutilities of restrictions on an area. A large part of the conservation effort relies on voluntary contracts, and therefore it is crucial to identify barriers to participation and the required compensation
\end{abstract}

levels. This has to be weighted against which components adds to the benefit side. Therefore this study aims at addressing and comparing the value and the costs for three ecosystem services from forests, 1) recreational possibilities, 2) biodiversity and 3) groundwater production. The novelty in the study lies in the direct comparison of the ecosystem services at attribute level; thereby addressing where the potential welfare gain will be largest and smallest respectively. The analysis is based on two primary studies assessing respectively the welfare economic value obtained by citizens and the compensation requirement among forest owners. 


\section{THE ECOSYSTEM APPROACH: IMPROVING RESOURCE USE \& SUSTAINING ECOSYSTEM SERVICES}

Rob Brooker, Alison Hester \& Kerry Waylen

The James Hutton Institute, Aberdeen, UK

\begin{abstract}
Natural biological processes help deliver a wide range of ecosystem services. However, key drivers have led to declines in biodiversity and a perceived need to replace natural processes with external inputs and mechanisation. In some cases a cycle of increasing dependency on external inputs due to increasing negative impacts on natural systems has arisen, for example the negative feedback loop between the mechanisation of crop production and biodiversity and ecosystem function in crop systems.
\end{abstract}

However, increasing resource (i.e. fuel and agrochemical) costs, unintended consequences of short-term technical fixes, and concerns about food security, are driving a re-evaluation of the way in which we manage ecosystem services and the benefits we derive from them. There is growing realisation that reduced external inputs might be achieved through the conservation of biodiversity and greater appreciation of our dependency on natural processes.

Implementation of an ecosystem approach to land use decision making may be one way by which such changes in land management practice could reflect these ideas. An Ecosystem Approach (as defined by the CBD) implies a holistic and participatory approach to understanding systems. Here we outline research currently underway in Scottish ecosystems on the implementation of an ecosystem approach to land use decision making, and its consequences for ecosystem service delivery and long-term environmental sustainability. We discuss this issue by contrasting patterns and processes in upland and lowland environments in Scotland, and identify key research gaps for supporting implementation of an ecosystem approach. 



\section{BOOSTING OF ECO-INNOVATIONS - POLICY STEPS PROMOTING GREEN ECONOMY}

Riina Antikainen, Teppo Hujala, Per Mickwitz, Jyri Seppälä, Venla Virkamäki, Maija Leppänen, Teppo Hujala, Maria Riala, Tuomas Nummelin, Leena Paavilainen, Hilkka Vihinen, Sirpa Kurppa, Laura Kitti \& Sirpa Thessler The Finnish Environment Institute (SYKE), Finland

\begin{abstract}
Green economy is considered to have significant worldwide potential, which is currently evident particularly in the rapid growth of cleantech demand. Transition to green economy is a long-term process. Along with gradual shifting, the transition requires notable leaps in technology and social practices. Therefore, a wide variety of eco-innovations is needed. The future success stories will be more material- and energy-efficient than their competitors. Eco-innovations require purposeful creative activity and investments on innovators' operational environment. In order to the process be effective, both bottom-up initiatives and top-down policy processes need to aim to the same direction supporting one another. In this presentation, we will take a closer look at forerunner eco-innovation examples in Finland representing e.g. cleantech industries, industrial symbiosis and public-private partnerships (PPP), and analyse the assets that enabled and hastened those. Based on existing case studies and other publicly available documentary, the success factors behind the case innovations were listed, synthesized and finally clustered in
\end{abstract}

economic, social, communicative, and functional assets. As a summary, the role of central, regional and local government appeared essential. Those actors are facilitators in creating the preconditions for green growth enhancing eco-innovations. These results suggest that at least to some extent, eco-innovations may be cultivated, and thus, we will propose six policy steps by which Finland can support eco-innovations and the path to green economy. The steps include decision-makers' commitment, fostering green production and consumption, developing piloting environments, cutting out wasteful systems, and enhancing learning and networking activities.

\section{REFERENCES}

Antikainen, R., Mickwitz, P., Seppälä, J., Virkamäki, V., Leppänen, M., Hujala, T., Riala, M., Nummelin, T., Paavilainen, L., Vihinen, H., Kurppa, S., Kitti, L. \& Thessler, S. (2013). Vihreän kasvun mahdollisuudet [Opportunities for green growth]. Prime Minister's Office Reports 4/2013. 81 p. (In Finnish, abstract in English.) http://vnk.fi/julkaisukansio/2013/r04-vihrean-kasvun/PDF/fi.pdf 


\section{SOCIAL COST BENEFIT ANALYSIS WAY TO EFFICIENT RESOURCE UTILIZATION}

Chow Fah YEE \& Eu Chye TAN

Editoria boad member, Green Economics Institute, Malaysia

\begin{abstract}
Nations have limited resources but many competing uses. These different uses of resources are not the final aim of the allocative process, they are in fact the means by which a country can marshal its resources to pursue its fundamental objectives. Social Cost Benefit Analysis (SCBA) is similar to financial analysis in that both seek to evaluate the profit of a project. However, financial analysis of a project identifies the money profit accruing to the project-operating entity only, while SCBA measures the effect of the project on the fundamental objectives of the whole economy. In the recent global financial crises, we have seen how private sector decisions can have devastating effect on the rest of the economy. If private sector decisions impact the whole society, then perhaps SCBA should be used to evaluate the feasibility and efficiency of these projects. The art of SCBA is to assign social prices to goods and services which do reflect their actual costs to society (when used as inputs) and their real benefits when produced. Using social prices generally produce a systemic bias towards projects that result in higher savings and further growth rather than higher current consumption; thus contribute towards achieving a sustaina-
\end{abstract}

ble balance between limited resources and the needs of a society. Also, SCBA can help a country identify the firms that use resources optimally; thus marshaling its resources on the path to achieving its objectives; whether it may be more job opportunities or efficient resource utilization. The authors have unprecedentedly used SCBA to evaluate a sample of private sector firms; to investigate if liberalization of Malaysia's banking sector, resulted in more efficient utilization of a country's resources. Social prices used incorporated both the country's growth and distributional objectives.

\section{REFERENCES}

Brucato, B. (2012). The Crisis and a Way Forward: What We Can Learn from Occupy Wall Street, Human \& Society, vol 36, pp 76-84.

Boardman, A. et al. (2001). Cost Benefit Analysis: Concepts and Practice, Prentice Hall.

Brent, R.J. (2001). Applied Cost Benefit Analysis.

Colin, Bruce. (1976). Social Cost-Benefit Analysis: A Guide for Country and Project Economists to the Derivation and Application of Economic and Social Accounting Prices, World Bank Staff Working Paper no. 239. 
Curry, S. \& Weiss, J. (1993). Project Analysis in Developing Countries, New York: St. Martin Press.

Demergic-Kunt, A. \& Detragiache, E. (1998). Financial Liberalization and Financial Fragility, IMF Working Paper, International Monetary Fund, Washington.

Dilip, K.D. (2010). Contours of Deepening Financial Globalization in the Emerging Market Economies, Global Journal of Emerging Market Economies, vol 2, pp 45-67.

Dipinder, S. \& Randhawa (2011). Banking and Capital Reforms in Malaysia, ASEAN Economic Bulletin, vol 28. Pp 388-413.

Eitzen, D.S. \& Baca Zinn, M. (2006). Globalization: The Transformation of Social Worlds, Thomson Wadsworth.

Gale de Oliveria, M.S. \& Kennet, M. (2010). The Green Economic Responses to Economic and Environmental Crises in 2010 , Proceedings of the Green Economics Institute $5^{\text {th }}$ Annual Conference at Mansfield College, Oxford University.

Kennet, M. (2008). 'Green Economics', Harvard College Economics Review, vol. 19

Kuala Lumpur Stock Exchange Annual Companies Yearbook, (various issues), Kuala Lumpur: Kuala Lumpur Stock Exchange.

Little, I.M.D. \& Mirrlees (1974). Project Appraisal and Planning for Developing Countries, London: Heinemann Educational Books Ltd.

Little, I.M.D. \& Mirrlees (1968) Manual of Industrial Project Analysis in Developing Countries, Vol. II.
Mitchell \& Joseph (2010). 'Capital Controls, Prime Ministers and Political Connections', Pacific-Basic Finance Journal, vol 18 pp 460-76.

Organization for Economic Cooperation and Development (OECD), (1989). Manual of Industrial Project Analysis in Developing Countries (1), OECD Development Centre.

Organization for Economic Cooperation and Development (OECD), (2001). The Impact of Development Proejcts on Poverty, OECD Development Centre.

Stiglitz, J. (2010) The Stiglitz Report, The New York Press, New York. Tan, T.S. (1994). 'Shadow Prices for Malaysia with an Extended Semi Input-Output Method', PhD thesis, University of Bradford.

United Nations Industrial Development Organization (UNIDO), (1978) Manual for the Preparation of Industrial Feasibility Studies, United Nations.

Veitch, M.D. (1986). National Parameters for Project Appraisal in Malaysia, vol. 1, January.

Weller, C.E. \& Hersch, A. (2006). 'Free Markets and Poverty', in: Eitzen D.S. \& Baca Zinn, M. (Eds.). Globalization: The Transformation of Social Worlds, Thomson Wadsworth

Yee, C.F. (2004). 'Financial Liberalization, Allocative Efiiciency and Financial Instability in Malaysia', PhD Thesis, University of Malaya. Malaysia.

Yellen, J.L. (2007). The Asian Financial Crisis Ten Years Later: Assessing the Past and Looking to the Future. Available: http://www.frbsf.org/news/speeches/2007/0206.html, Last accessed 30 June 2010 


\section{THE LEGAL CONDITIONS FOR WATER UTILITIES ECO-INNOVATION AS ENERGY SMART WATER UTILITIES}

Professor, dr. jur. Ellen Margrethe Basse

School of Business and Social Sciences, Aarhus University, Denmark

\section{ABSTRACT}

Instead of solely collecting, transporting and cleaning wastewater, the energy smart water utilities are also reducing their carbon footprint by energy efficiency, material recovery and energy generation. This paper will give a picture of the complex environment of the political, legal and institutional forces that taken together influences the water utilities' possibility of delivering on green growth as energy smart water utilities. The paper will examine the EU and Danish policy and legislation to answer the question if it is possible for the Danish public owned utilities to deliver more environmental benefits to society by capturing their wastewater solids to electricity methane, and by generating clean renewable energy by use of biogas at their facilities. Innovative market uptake solutions call on such knowledge of the regulatory environment as a successful transformation of the utilities to energy smart water utilities depends on a co-ordination between different policy areas (e.g. water, climate, energy, and competition) at the EU as well as the national levels. The paper will examine the EU and Danish policy and legislation and assess whether the existing rules are well designed to account for multi-media assessment of energy and resource recovery in the wastewater facilities. One of the central features is to avoid counterproductive legal principles, traditions and overlaps of instruments and to design a combination of market-based instruments (pricing, taxes, feed-in tariffs, etc.) and non-market-based instruments (norms, standards, planning, information, etc.).

\section{REFERENCES}

National Association of Clean Water Agencies (www.NACWA.org), Water Environment Research Foundation (www.WERF.org) and Water Environment Federation (www.wef.org), The Water Resources Utility of the Future. A Blueprint for Action, US, 2013.

Barendrecht, M., Raic, D., Janse, R. \& Muller, S. (2012). Trend report. Rulejungling. When lawmaking goes private, international and informal, HiiL innovation justice (www.hiil.org).

E. Darian-Smith (2013). Laws and societies in Global Contexts, Cambridge UP.

H.P. Glenn (2004). Legal Traditions of the World, $2^{\text {n }}$ ed., Oxford UP.

European Commission communication. A Resource-efficient Europe - Flagship under the Europe 2020 Strategy, COM(2011) 21 final.

OECD (2011). Tools for Delivering on Green Growth.

ENVIRONMENTAL REVIEWS AND CASE STUDIES: The Legal Design of Sustainability Criteria on Biofuels Used by the European Union, http://journals.cambridge.org/action/displayAbstract?fromPage $=$ online $\&$ aid $=8868718$ 


\section{COHERENT POLICY INSTRUMENTS FOR CLIMATE CHANGE ADAPTATION?}

Anders Branth Pedersen, Helle Ørsted Nielsen, Kirsi Mäkinen, Jenny Troeltzsch \& Benjamin Boteler

Department of Environmental Science Aarhus University, Denmark

\begin{abstract}
Strategic documents such as the 2009 EU White Paper on Adaptation and the 2010 Cancun Adaptation Framework identify climate adaptation as a necessary complement to mitigation. Cost effective and efficient climate adaptation is of key relevance, together with the enhancement of market opportunities and innovation (Europe 2020 goals; the 2050 Road Map). Climate change adaptation cuts across multiple sectors and therefore requires an integrated policy strategy. Often, procedures for addressing cross-sectoral issues lack coherence (OECD Policy Brief October 2002). Moreover, development of policy strategies to tackle a new problem interacts and may even conflict with existing policies in related policy areas, deepening the problem of coherence. This paper therefore aims to assess policy mixes being implemented to address climate change adaptation in Denmark, Finland and Germany We map and characterize the intervention logic embedded in policy instruments for climate change
\end{abstract}

adaptation implemented in relevant policy areas (see e.g. Vedung 2009). In order to assess the policy mix we apply the framework developed by Howlett and Rayner (2007) examining the coherence of policy objectives and the consistency of policy instruments in the mix as well as with instruments already in place in selected related policy fields. In addition to policy sectors, the analysis will focus on the distinction between instruments aiming to encourage private action versus instruments aiming at public action in order to examine how the border between public and private responsibilities is conceptualized. Finally, we will discuss how the time frame and the intervention logic of the possible adaptive measures affect conclusions concerning the consistency of instruments. The analysis is primarily based on literature review and uses data from the European Union's Climate-Adapt data base supplemented with data gathered by national experts. 


\section{CRITERIA FOR EVALUATING CLIMATE ADAPTATION MEASURES: A META-ANALYSIS}

Sabine Weiland, Silke Beck, Benjamin Boteler, Alessio Capriolo, Francesca Giordano, Mikael Hildén, Duncan Russel \& Jenny Tröltzsch

Helmholtz Centre for Environmental Research - UFZ, Germany

\begin{abstract}
Climate change threatens the countries, regions and economic sectors of Europe in different ways. Adaptation to climate change is therefore carried out through different policies and measures. Monitoring and evaluating these initiatives is important in order to track successes and failures. There already exist a large number of criteria and criteria sets to evaluate the implementation of climate adaptation policies and measures. They can be used to assess the effectiveness of an adaptation intervention, the avoided damage, the economic, environmental and social side effects etc. As climate adaptation mainly is a about integrating climate aspects into other policy fields, criteria that assess the interlinkages between different policy objectives (e.g. co-benefits) are of particular importance.
\end{abstract}

The paper aims to identify which criteria sets for evaluating adaptation policies and measures already exist, and what the advantages or disadvantages of these criteria are. The meta-analysis will include existing evaluation criteria for the EU and international level, Member States level and, where available, regional and local level. We aim at systematising these criteria, by grouping and showing interrelations between them. The criteria sets will be analysed according to, inter alia, their clearness of definition, overlaps between different criteria, transferability and existing experiences with their use. At the same time, we will consider the context specificity of adaptation and also policy coherence in the way it is experienced at the 'street' or actor level. Criteria must be chosen based on the relationship between planned adaptation activities and the socio-economic, political, environmental and climatic context in which they will be implemented. The criteria must also be salient from the point of view of their primary user. The latter may vary from those vulnerable to a particular impact of climate change to local implementers of adaptation measures and developers of policy.

With this meta-analysis of evaluation criteria, we strive to contribute to the attempts of upscaling and generalising the lessons learnt from context-bound (in many cases local and regional) adaptation initiatives. 


\section{ECOSYSTEM-BASED APPROACHES TO CLIMATE ADAPTATION - POSSIBILITIES AND CONFLICTS IN URBAN AREAS}

Marianne Zandersen \& Anne Jensen

Aarhus University, Denmark

\begin{abstract}
Effects of climate change are particularly challenging in urban areas. The high concentration of impervious surfaces significantly modifies energy exchanges and hydrological processes leading to heat islands and a higher rate and volume of surface runoff of rainwater. Meanwhile, humanity is rapidly urbanising and there are significant technical, social and institutional vulnerabilities due to uncertainties and surprises in climate impacts that cannot be avoided.
\end{abstract}

Policymakers and urban adaptation strategies are increasingly accepting and calling for the need to work actively with ecosystem-based adaptation approaches, i.e. nature's capacity to absorb and control impacts of climate change while offering a number of co-benefits such as aesthetics, biodiversity, improved mental welfare and proper-ty/neighbourhood improvements. Using an ecosystem based approach can be more economically, socially as well as ecologically just and efficient compared to focusing ex-clusively on technical solutions, where co-benefits are absent.

In this study, we investigate the prospects and conflicts of systematically applying an ecosystem based approach in the municipality of Copenhagen. We take the case of green roofs as one example of implementing green infrastructure. The project quanti-fies the potential for green roofs in the Municipality of Copenhagen; examines the prospects of integrating ecosystem-based climate change adaptation in urban policies; and analyses areas of potential conflicts between ecosystem-based approaches and other drivers of urban development in cities, such as the increasing urbanisation and expanding built environment.

We combine quantitative and qualitative methods from the fields of environmental economics and environmental sociology. 


\section{EXPLORING ECOSYSTEM-BASED APPROACHES TO CLIMATE CHANGE ADAPTATION}

David Vačkář, Zuzana Harmáčková, Eliška Lorencová \& Blanka Loučková

CzechGlobe - Global Change Research Centre, Academy of Sciences of the Czech Republic

\section{ABSTRACT}

Climate change presents one of the most important drivers influencing natural ecosystems and biodiversity (IPCC 2007). Ecosystem-based approaches to adaptation (EbA) have been recently put forward as a useful approach to buffering the impacts of climate change while sustaining ecosystems and biodiversity (Jones et al. 2012). Although current adaptation strategies tend to focus on technical, structural, social and economic developments, ecosystems and biodiversity can play a significant role in societal adaptation to climate change. A major advantage brought by EbA lies in parallel provision of climate change adaptations and delivery of multiple environmental co-benefits (Munang et al. 2013). In this poster we aim to explore the potential of EbA approaches to be mainstreamed into recent adaptation practices. As ecosystems and biodiversity are threatened by climate change, they likewise pose an option to adapt at the same time, as they provide a wide range of services mitigating the climate impacts, e.g. carbon sequestration, flood protection and prevention of soil erosion (Campbell et al. 2009).

\section{REFERENCES}

IPCC (2007). Climate Change 2007: Impacts, Adaptation and Vulnerability. Contribution of Working Group II to the Fourth Assessment Report of the Intergovernmental Panel on Climate Change, Cambridge, 976 pp.

Campbell, A., Kapos, V., Scharlemann, J.P.W., Bubb, P., Chenery, A., Coad, L., Dickson, B., Doswald, N., Khan, M.S.I., Kershaw, F. \& Rashid, M. (2009). Review of the Literature on the Links between Biodiversity and Climate Change: Impacts, Adaptation and Mitigation. Secretariat of the CBD, Montreal. Technical Series 42, $124 \mathrm{pp}$.

Jones, H.P., Hole, D.G. \& Zavaleta, E.S. (2012). Harnessing nature to help people adapt to climate change. Nature Climate Change 2: 504-509.

Munang, R., Thiaw, I., Alverson, K., Mumba, M., Liu, J. \& Rivington, M. (2013). Climate change and ecosystem-based adaptation: a new pragmatic approach to buffering climate change impacts. Current Opinion on Environmental Sustainability 5: 67-71. 


\section{INSTITUTIONAL BARRIERS AND KNOWLEDGE IN LOCAL POLICIES TO INTEGRATE CLIMATE ADAPTATION}

Anne Jensen, Helle Ørsted Nielsen \& Anders Branth Pedersen

Department of Environmental Sciences, Aarhus University, Denmark

\begin{abstract}
The policy paradigm of sustainable development and the eco-modernistic ideas of win-win have over the past years gained a companion in visions of societal transition as a respond to major environmental challenges. Among these challenges, climate change is prominent and the impacts of a changing climate are experienced at local to global scales, posing fundamental challenges for public policy. In Danish local governance, the position of different forms of knowledge in the framing of policy actions to adapt to climate change have changed, accompanied by a national adaptation strategy, including a national decision that all municipalities must make a climate adaptation strategy to manage impacts, especially flooding.
\end{abstract}

This study examines the institutional barriers and innovative options for adapting to climate change in local governance in Denmark. Using theories of climate policy integration in local level policies and of the role of knowledge in framing adaptive policy actions, questions of knowledge in policy integration and further of institutional conditions for proactive adaptation policies are examined. The study is based on case studies in five coastal areas, supplemented by a survey among all Danish municipalities. The study shows how the level of maturity of local governance networks that involve especially local business and local water companies promotes development of adaptive policies with potential for reaching beyond local environmental policies. Significantly, the ways in which relevant and apt forms of knowledge were included in policy processes across sectors differed across diverse policy environments and influenced the designe and comprehensiveness of local adaptation strategies, with the larger municipalities appearing better equipped to manage the impacts of climate change. (264 words). 


\section{TRANSLOCATIONS FOR CONSERVATION DURING CLIMATE CHANGE: AN ADAPTATION CASE STUDY}

Rob Brooker, Antonia Eastwood, Chris Ellis, David Genney \& Alessandro Gimona The James Hutton Institute, Craigiebuckler, Aberdeen, UK

\begin{abstract}
With increasing evidence of the impacts of climate change on biodiversity, the suite of conservation actions is being re-examined to see whether they will enable species to survive. New strategies are also being considered. Of these, perhaps the most contentious is conservation translocations - the movement of a species from its current location to alternative sites that are expected to provide a refuge. Whilst this approach has provoked substantial and often extremely heated debate in the conservation literature, few practical tests of conservation translocations with the explicit aim of adapting to the threats of climate change have been undertaken.
\end{abstract}

Here we report on the preliminary results of an on-going field trial of translocations in Scottish mountain environments. The study is focussed on the alpine lichen Flavocetraria nivalis. Lichens represent a very substantial percentage of Scottish biodiversity, particularly in upland and mountain environments. However, they can be severely dispersal limited. For example, the target species has a UK distribution restricted to the Cairngorms. Given its limited UK distribution, and restriction to a particular altitudinal zone within the Cairngorms, it may be a species negatively impacted by climate change and the upward expansion of lower altitude competitive vascular species.

With an experimental approach combining field surveying and a trial translocation, we are assessing whether it is possible to predict, using a combination of field data and downscaled GIS-based climate data, the location of suitable habitat for our target lichen species. This presentation will report on the results of this translocation trial, as well as on more recent work which has involved moving the lichen to a site outside of its current distribution. 


\section{UNIVERSIDADE ESTÁCIO DE SÁ - BRAZIL 2020: CONTRIBUTION TO INNOVATIVE ADAPTATION}

Dr. Maria Cecilia Trannin \& Dr. Karina L. Garcia

Post Graduation Environment Department, Universidade Estácio de Sá, Brazil

\begin{abstract}
In face of uncertainties associated with natural disasters, one of the challenges in Climate Change is improving adaptive capacity to environmental change and developing flexibility in response to crises and surprises. Brazil is the largest country in South America and the fifth largest in the world, with $191 \mathrm{M}$ people (IBGE 2010). Due to its generous biodiversity, Brazil is considered a hotspot for ecosystems conservation. Climate change impacts, adaptation and vulnerability studies must be a priority and experiences, exchanged. This paper aims to collect the contribution of Environmental Post Graduated Professors at University Estácio de Sá* - Brazil - on cost effective measures towards biodiversity conservation and climate change adaptation. As published in the Horizon 2020 Thematic Workshops, "... international collaboration is considered vital to improve the EU innovation capacity. In this context incentives for the
\end{abstract}

participation of EU12 and third countries in MCAs should be developed and MCAs need to keep their bottom-up character." In this sense, we believe it would be interesting for "Science for the Environment 2013" to hear our Brazilian ideas, actions and experience. We are conducting a series of interviews with these experts, in order to highlight bottom-up ideas coming from highly upgraded professors for a better and safer world. Ours goals are also identifying gaps and building knowledge bridges that can help to further societal change. We also believe that the ideas suggested by these professionals might also provide guidance for European Finance Aid Projects, so as to help decision makers on which projects to support.

*University Estácio de Sá has a total of 320,000 Students in Brazil and over 78 headquarters across all country states. 


\section{APPLICATIONS OF INTRINSIC CONDUCTING POLYMER FOR WI-FI ELECTROMAGNETIC RADIATION ENVIRONMENT POLLUTION REDUCTION}

Whamid Al-shabib

School of Engineering, ECU, Australia

\section{ABSTRACT}

The rapid increase in the operating frequency that is used in Wi-Fi devices and mobile phones systems to $\mathrm{GHz}$ region poses health and environmental hazards. This increase in the operating frequency will increase the danger of the electromagnetic radiation that is emitted by devices that are operating in the Wi-Fi frequency of $2.5 \mathrm{GHz}$. Current materials that are used in the mobile phone at that region of frequency have more tendency to reflect the electromagnetic radiation rather than absorbing it. The current materials like (Aluminium, Copper, Carbon nanocomposites) that are used in the industry carry from large weight and have a tendency to rust or are difficult to dispose of. The current metal composites cannot be made into thin layers of coating on the devices to shape the radiation of the $\mathrm{WI}-\mathrm{Fl}$ and mobile phone.
In this research the Intrinsic Conducting Polymers (ICP) is a pure polymer material with great potential applications to replace metals, and carbon composites materials to reduce pollution. In this research different ICP materials were used to investigate the reduction of Electromagnetic Radiations (EMR). The choice of ICP materials that were used for this investigation were Polyaniline (Salt) (PAni), Polypyrrole (PPy) and poly(3,4-ethylenedioxythiophene) poly(styrenesulfonate) (PEDOT:PSS). The ICP materials EMR were experimentally compared in an open air laboratory with common metals like Aluminium and Copper materials and micro-composite Carbon materials. Intitial results show that those ICP materials can offer a replacement to the electromagnetic shielding in Wi-Fi frequency and beyond. 


\section{DNMARK: DANISH NITROGEN MITIGATION}

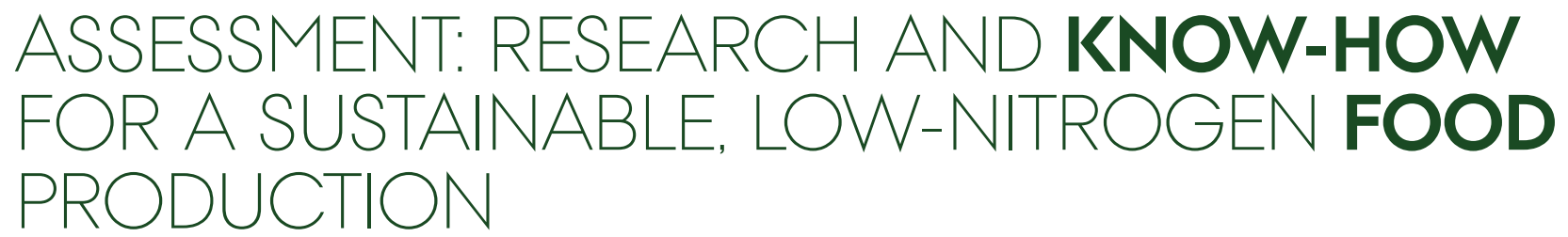

T. Dalgaarda, S. Brock ${ }^{b}$, B. Hansen ${ }^{c}$, B. Hasler ${ }^{d}$, O. Hertel $^{d}$, N. Hutchings ${ }^{a}$, B. Jacobsen ${ }^{e}$, C. Kjeldsen ${ }^{a}$, B. Kronvang', J.E. Olesen ${ }^{a}$, J.K. Schjørring ${ }^{9}$, T. Sigsgaard ${ }^{h}$, L. Stoumann Jensen', H. Vejrei, W. de Vries \& I.A. Wiborgk

${ }^{a}$ Aarhus University, Department of Agroecology, Denmark, barhus University, Department of Culture and Society, Denmark, 'Geological Survey of Denmark \& Greenland - GEUS, Denmark, 'AAarhus University, Department of Environmental Sciences, Denmark, eUniversity of Copenhagen, Department of Food and Resource Economics, Denmark, ${ }^{\dagger}$ Aarhus University, Department of Bioscience, Denmark, ' University of Copenhagen, Department of Plant and Environmental Sciences, Denmark, ${ }^{h}$ Aarhus University, Department of Public Health, Denmark, 'University of Copenhagen, Department Geosciences and Natural Resource Management, Denmark, 'Wageningen University, Alterra, The Netherlands, ${ }^{K}$ Knowledge Centre for Agriculture, Denmark

\begin{abstract}
The aim of this paper is to present the Danish Nitrogen Mitigation Assessment (DNMARK), a recently initiated 5-year multidisciplinary research alliance, focusing on the quantification of $\mathrm{N}$ flows and solutions scenarios for a more sustainable $\mathrm{N}$ use in Denmark. As one of the world's most agriculture intensive countries, with a long $\mathrm{N}$ regulation history, and state of the art monitoring of developments in key indicators for nitrogen losses, -use and -efficiency, Denmark is a case of special interest. Based on the results and recommendations from the European Nitrogen Assessment (http://www.nine-esf.org/ENA), DNMARK focus on all parts of the $\mathrm{N}$ cascade, and demonstrates results
\end{abstract}

both at the landscape scale, and the national scale. Results from the national $\mathrm{N}$-flow and $\mathrm{N}$-balance accounting 1990-2010 are presented, and methods for the downscaling of these results to regional pilot study regions are discussed, together with approaches for the integrated assessment and modeling of the three main types of solution scenarios defined: i) New production chains with a more efficient use and recycling of N, ii) Geographically differentiated $\mathrm{N}$-measures implemented by cost-effective instruments with localized planning and management of agricultural landscapes, and iii) Changed consumption patterns driving land use change and reducing $\mathrm{N}$ use. 


\section{IMPLEMENTATION OF HSE MS IN THE PIPELINE OF SOUTHERN PARS GAS FIELD OF IRAN AND ITS IMPACT ON GREEN EFFICIENCY GROWTH}

Hamid Sarkheil

University of Environment, Karaj, Iran

\begin{abstract}
Iran's natural gas production has increased by over 550 percent over the past two decades, and the consumption has kept pace. As demand growth rates persist, the potential for shortfalls in natural gas supply grows. South Pars gas field is one of the famous gas fields of Iran with several phases, which is one of the major gas fields part is pipelines. The use of HSE MS to avoid wasting condensate gas to protect the resources, safety and the environment is very important. So that it can be effective in increasing efficiency and economic growth, with the preservation of the environment. Implementation of HSE MS provides a detailed framework outlining the roles and responsibilities for managers and employees which can be used to improve health, safety and environmental performance and increase efficiency in organizations
\end{abstract}

and therefore it will bring about sustainable development. In the part of pipeline in southern Pars gas field, HSE MS brings awareness to safety hazards, provides appropriate levels results and Performance indicators and turned on one of its precarious that it is disability equipment is gas pipelines. So that, these factors that could be dangerous to the economy, fire and environmental toxicity is suspected. So that, the full implementation of the integrated HSE MS, efficiency increased by 7 percent and human risks reduced to a minimum value and the environmental pollution caused by condense gas leaks were fully protected and consequently the costs of cleaning up contaminated water and soil in this area is considerably reduced and effective as a step forward towards the green economy and efficiency. 


\section{AQUATIC ECOSYSTEMS SERVICES IN DENMARK - SPATIAL MAPPING OF ECOSYSTEM SERVICES AND CREATION OF GREEN ECONOMIC ACCOUNTING}

Berit Hasler, Flemming Møller, Hans Estrup Andersen, Janus Larsen, Peter Borgen Sørensen, Anne Winding, Marianne Zandersen Department of Environmental Science and Department of Bioscience, Aarhus University

\begin{abstract}
Freshwater, marine- and coastal water ecosystems provide a range of provisioning, regulating, and cultural services, most of which are affected by nutrient loads to the water bodies. At the same time services can be utilized to reduce impacts on other services, e.g. utilizing the regulating services by wetland restoration and river meandering will influence the capacity of nutrient trapping and transformation in watersheds, and hereby improving recreational services. Improvements in ecosystem service provision can also be managed by reducing nutrient loads at source. The aim of this study is to map how the regulating and cultural ecosystem services vary spatially, as well as to model cost-efficient management strategies to maintain and improve these services. The assessment of economic values of the services presently provided by
\end{abstract}

the aquatic ecosystems can also be used as an input to national and international attempts to build up green national accounts. We use a case study from one watershed to demonstrate how existing data and model outputs can be used to define cost-efficient management as well as providing input for the development of a green economic accounting system. Mapping and assessment of these ecosystems services and their values is one of the key actions of the EU Biodiversity Strategy to 2020 and one of the aims of this study is to feed into the development of the Danish assessments. At the same time the spatial mapping will be carried out to identify cost-efficient management of fresh- and marine ecosystems, linked to the needs for cost-efficient implementation of the Water Framework Directive and the Marine Strategy Directive. 


\section{ILLEGAL USE OF POISONED BAITS AND THEIR EFFECTS ON BIODIVERSITY IN CRETE, GREECE}

Probonas, M., Sakellari, M., Baxevani, K. \& Xirouchakis, S.

Natural History Museum of Crete (NHMC), University of Crete, Greece

\section{ABSTRACT}

In the framework of LIFE+ Biodiversity project on "Innovative actions against illegal poisoning in EU Mediterranean pilot areas" [LIFE09 NAT/ES/000533], the Spanish organization "Fundación Gypaetus", acting as coordinating beneficiary, along with the Portuguese partners "Quercus" and "Centro de Estudos da Avifauna Ibérica" (CEAI) and the Greek partners "Arcturos" and "University of Crete - Natural History Museum of Crete" (NHMC), are implementing specific actions on this issue since October 2010 for a 5-years' project.

The illegal use of poisoned baits is a harmful practice for the environment and for the preservation of biodiversity. In addition, it can be a potential source of negative effects for public health. The main goal of the project is to evaluate and spread the effectiveness of several innovative actions based on voluntary agreements with the main rural groups related with the fight against the illegal use of poisoned baits (municipalities, hunters, stockbreeders, etc.)
Thanks to the demonstrative character of the foreseen actions, it is expected to relevantly improve the current anti-illegal poisoning strategies and so diminish the biodiversity loss related with this malpractice at EU level.

In Crete, Greece, the project is being implemented in Eastern Mountains of Crete (pilot area GR-2), more specifically the following NATURA 2000 protected areas: Idi Oros (GR4330005), Asterousia (GR4310005) and Dikti (GR4320002). Among other innovative actions, the establishment of three (3) European networks against illegal use of poisoned baits, i.e. stockbreeders (ENSPAIP), municipalities (ENMAIP) and hunters / hunting associations (ENHAIP), will be under short presentation, as far as their design and operation is of concern. Results and constrains of the operation of these networks will be also under consideration. Finally, a brief description of other innovative actions and actions of public awareness will be briefly presented. 


\section{IMPACT OF DIGESTATES FROM ANAEROBICALLY DIGESTED CATTLE SLURRY AND PLANT MATERIALS ON SOIL MICROBIAL COMMUNITY}

Anders Johansen', Anne-Kristin Løess ${ }^{2}$, Mette S. Carter ${ }^{3}$, Per Ambus ${ }^{3}$ \& Henrik Hauggaard-Nielsen ${ }^{3}$ ${ }^{1}$ Dep. of Environmental Science, Aarhus University, ${ }^{2}$ Organic Food and Farming Division, Bioforsk, Norway, ${ }^{3}$ Ris $\varnothing$ National Laboratory for Sustainable Energy, Technical University, Denmark

\section{ABSTRACT}

Tightening the overall cycle of plant nutrients and organic carbon includes utilization of huge quantities of biogas slurries as fertilizers in arable systems. These digestates differs from traditional fertilizers (e.g. raw animal slurries) with respect to content and quality of organic matter and nutrients like $\mathrm{N}$ and $\mathrm{P}$ and may thus have implication for the soil microflora and soil ecosystem services. This presenta- tion will present data on how application of digestates vs. non-digested slurries and grass-clover material (green manure) affects the structure of the soil microbial communities as well as some of the essential biogeochemical processes they drive (production/emission of $\mathrm{CO}_{2}$ and $\mathrm{N}_{2} \mathrm{O}$, mobilization/immobilization of soil mineral $\mathrm{N}$ ). 


\section{STRATEGIES FOR KNOWLEDGE BASED PROTECTION OF THE DANISH DRINKING WATER RESOURCES}

Lœrke Thorling \& Birgitte Hansen

Department of groundwater and quaternary geological mapping, GEUS, Denmark

\begin{abstract}
All Danish Drinking water is groundwater and usually distributed to consumers after simple treatment at the waterworks (aeration and filtration - no disinfection). To preserve this highly valued resource a national strategy for sustainable abstraction and groundwater protection has developed over the last 50 years.
\end{abstract}

Cost efficient sustainable regulation calls for knowledge on the pressures and response in groundwater systems. In Denmark nitrate and pesticides are the largest causes for groundwater to fail the drinking water standards. Development of scientifically sound conceptual models for the natural protection in aquifers against these agricultural pressures plays an important role when implementing protection. The impact of nitrate leaching on groundwater and surface waters depend on the site specific hydrological pathways and denitrifikation.

There is a growing awareness in the political and agricultural communities that cost efficient measures to reduce the environmental impact of nitrate and pesticides on nature and surface waters in the future should be site specific and not based on national standard regulations. Scientific developments in mapping methods in regard to hydrogeology and geochemistry are a prerequisite before this goal can be realized. The Danish case is a strong example of the potential of the science policy interface to develop better resource efficiency.
Especially a better knowledge of the nitrate reduction in the subsurface and aquifers is required in order to implement site specific measure for protection of nature and surface waters. Since 1999 the National Groundwater Mapping Program has detailed mapped the hydro-geo-chemical settings of about $40 \%$ of Denmark followed by delineation of nitrate vulnerable areas in drinking water abstraction areas. Cost efficient sustainable regulation of agriculture for protection of groundwater, nature and environment calls for a proper monitoring strategy of the efficiency of implemented measures. E.g. agedating of monitored groundwater has proved indispensable while interpreting the collected data.

\section{REFERENCES}

Hansen, B., Thorling, L., Dalgaard, T. \& Erlandsen, M. (2011). Trend Reversal of Nitrate in Danish groundwater - a Reflection of Agricultural Practices and Nitrogen Surpluses since 1950. Environmental Science \& Technology, 45(1): 228-234.

Thomsen, R., Søndergaard, V.H \& Sørensen, K.I. (2004). Hydrogeological mapping as a basis for establishing site-specific groundwater protection zones in Denmark. Hydrogeology Journal 12: 550-562.

Dalgaard, T., Hutchings, N., Børgesen, C., Vinter, F.P. \& Hansen, B. (2011). How can Nitrogen utilisation in farming systems be optimised to minimise losses? Proceedings of th International Fertiliser Society Conference, Cambridge 9. Dec 2011. 26 pp. 


\section{AUTHOR INDEX}

Abrami, G

$9.1,9.3$

Aissani, Lynda

7.3

Alkemade, Rob

12.1

Al-shabib, Whamid ..................................................................... p.8

Alves, Filipe ……………………………………………………… 14.5

Ambrosio-Albalá, María José......................................................... 15.2

Ambus, Per p.13

Andersen, Hans Estrup ..........................................................................

Antikainen, Riina ............................................................................. 17.1

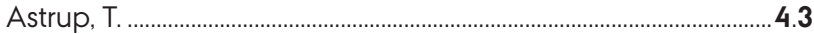

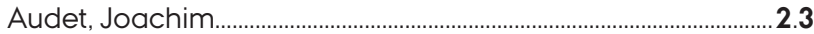

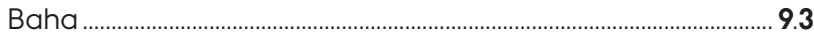

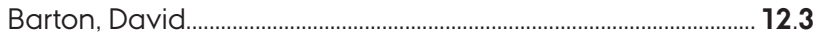

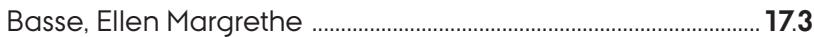

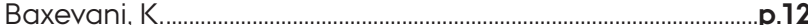

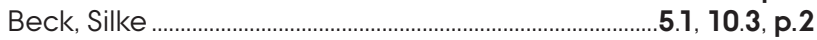

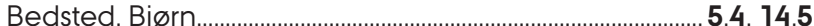

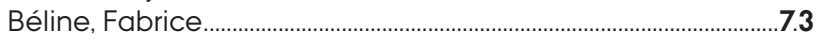

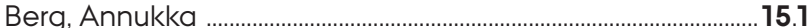

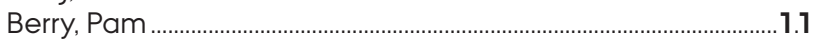

Beydokhti, Nasser T. ............................................................................. 4.1

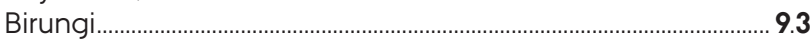

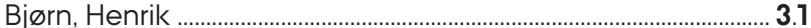

Bockhorn, Britta ............................................................................. 1.5

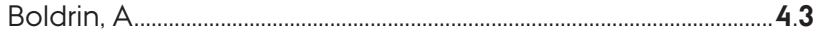

Borgström, Suvi .............................................................................. 12.4

Bosello, Francesco ...................... 1.2. 1.3. 5.2

Boteler, Benjamin ……………………………….....1.2, 10.2, p.1, p.2

Brandt, Urs Steiner

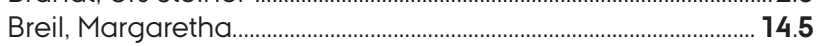

Brenck, Miriam .................................................................................. 1.4

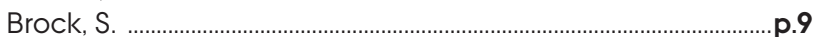

Brooker, Rob ........................................................................... 16.5, p.6

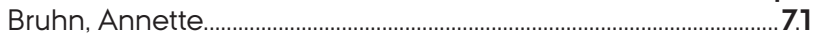

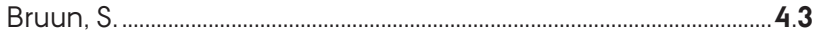

Bugter, Rob .......................................................................... 12.3

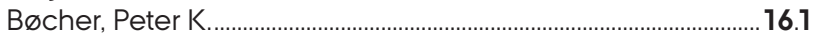

Bønløkke, Jakob Hjort ................................................................... 2.1

Campos, Inês ....................................................................................... 1.2

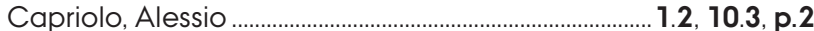

Carstensen, Jacob ..................................................................................... 7.1

Carter, Mette S.

Castellari, Sergio ............................................................. 5.1, 10.3, 10.4

Chiabai, Aline _................................................... 10.5

Cullen, B.

$1.3,10.5$

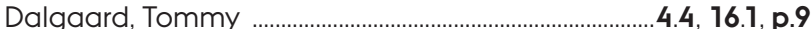

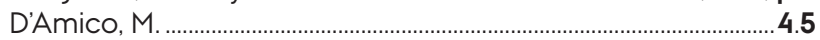

Daptardar, Vaidehi...................................................... 15.5

de Vries, Wim ........................................................................... 6.3, p.9

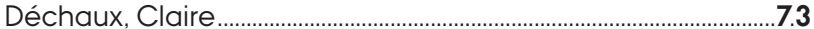

Delgado-Serran, María del Mar......................................................... 15.2

Ditlefsen, Claus .

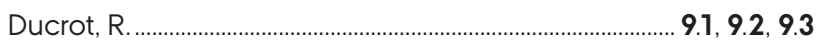

Duel , Harm ............................................................ 5.5

Dütschke, Elisabeth ............................................................................ 8.5

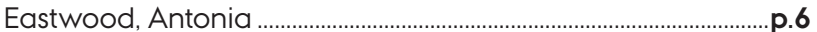

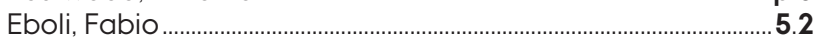

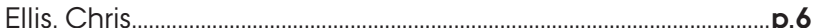

Elsgaard, Lars …………………………………………………....... 2.3

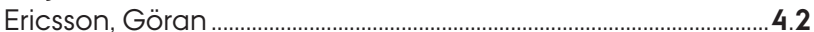

Ferrand, Nils .................................................................... 9.1, 9.2, 9.3

Fredriksen, Karl Sigurd .................................................................. 2.4

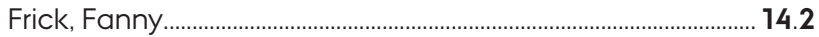

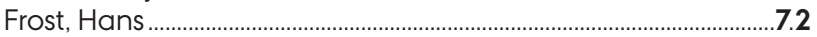

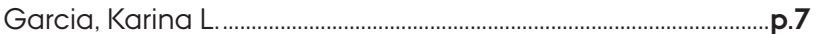

Garnier, Monica ........................................................................................... 3.5

Garrote, Luis ............................................................................ 10.5

Gebhardt, Oliver ………............................................................... 1.4

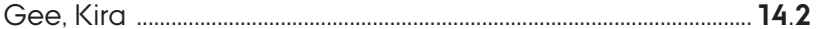

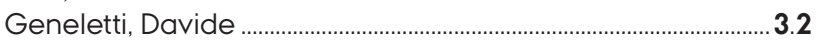

Genney, David _...............................6

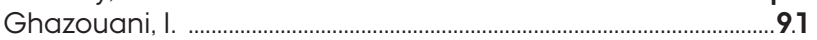

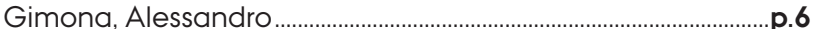

Giordano, Francesca....................................................................

Glœsner, Nadia …....................................................

Gore, Manasi ................................................................................. 15.5

Gradmann, Albrecht ............................................................. 3

Guan, Dabo

Gumpinger, E. .............................................................. 9.2, 9.3

Gyldenkœrne, Steen ................................................................... 16.2

Hansen, Birgitte....................................................................... p.9, p.14

Harmáčková, Zuzana ..................................................................... 4

Harper, David ......................................................................................... 3.5

Harrison, Paula A. ……………………………………………......1. 11

Hasler, Berit.................................................................... 7. 7.2, p.9, p.11

Hassenforder, Emeline...................................................... 9.1, 9.2, 9.3

Hauck, Jennifer ............................................................................... 12.2

Hauggaard-Nielsen, Henrik....................................................... p.13

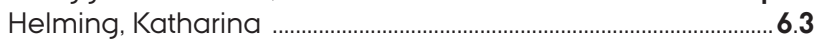

Hertel, O.

Hesselbjerg, Jens .................................................................................. 15.3

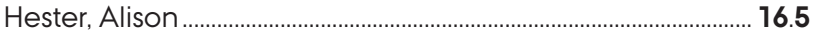

Hildén, Mikael.................................................. 1.2, 10.2, 10.3, 15.1, p.2

Hirschnitz-Garbers, Martin ................................................................. 3.4

Hoffmann, Carl C.................................................................................

Holman, Ian $\ldots$

Holmer, Marianne .................................................................................

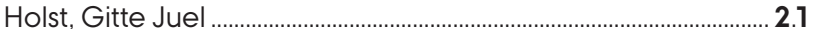

Huesing, Thomas .................................................................................

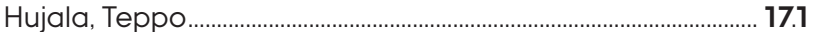

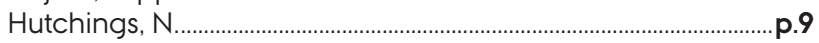

Højberg, Anker Lajer ............................................................................... 3.1

Haasnoot, Marjolijn ..................................................................... 5.5

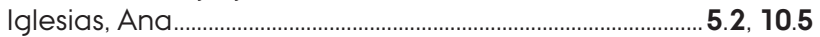


Iglesias, Pedro

10.5

Jacob, Klaus

6.2, 6.4

Jacobsen, B

Jacobsen, Jette Bredahl

Janickova, Ivana

Jansen, Jacques

Janssen, Sander

Jensen, Anne.

Jensen, L. Stoumann.

Jensen, L. S

Jensen, Marina Bergen

Jeuken, Ad

Johannsen, Ib

nders

Jolankai, Géza.

Juhola, Sirkku

Jørgensen, Sisse Liv

Kabaseke, C

Karali, Eleni

Kitti, Laura

Kjaergaard, Charlotte

Kjeldsen, Chris

Klein, Richard J.T.

Klint, Knud Erik S.

Knapen, Rob

Korsholm, Ulrik

Kronvang, B.

Kuhn, Thomas

Kurppa, Sirpa.

Kusemererwa.

Lamorgese, Lydia

Larsen, Martin Mørk .

Larsen, Janus.

Larsen, Søren E.

Lazarova, Tanya

Lemenih, M.

Lemmens, $R$

Leppänen, Maija.

Levin, Gregor.

$\mathrm{Li}, \mathrm{Xin}$

Lorencová, Eliška

Losada, Miquel A.

Loučková, Blanka

Lundhede, Thomas Hedemark.

Løess, Anne-Kristin

Maes, Joachim

Manninen, Kaisa

Markandya, Anil.

Marth, Hans

Martinez, Grit

Martinsen, Louise

Massa, I.

McGlade, Katriona.

Merli, R.

Meyer, Volke

Mickwitz, Per

Mikkelsen, Mette Hjort

Montanarella. Luca

Morardet, S.

Mori, Diallo

Mudgal, Shailendra

Muhumuza, M

Mäkinen, Kirsi

Møller, Flemming

Møller, Ingelise.. ....p.9

... 16.4

2.4

6.1, 6.4

6.4

$5.1,14.5$, p. 3, p. 5

p...p. 9

4.3

$1.2,5.5$ ....7.5

p. 13

p... 3.5

.10 .1

16.2

9.1, 9.3

5.1, 10.4

17.1

.. 2.3

16.1, p.9

... 10.1

.. 1.5

6.2

.. 2.1

p.9

3.3

17.1

9.3

3.2

...7.2

p.11

2.3

... 12.1

.... 9.1

9.1, 9.3

... 17.1

16.2

5.3, 14.5

...p. 4

...14. 1

14.5, p.4

.. 16.3

..p.13

12.5

7.1. 7.4

1.3

8.3

14.2

16.2

... 4.5

5.1, 10.2

4.5

. .1 .4$

17.1

. .7 .3$

6.3

$9.1,9.3$

9.1, 9.4

..... 3.4

9.1, 9.3

.1, 10.3, p.1

...p.11

.... 3.1
Nainggolan, Doan ............................................................................. 16.2

Newman, Marc ………................................................................... 10.5

Newton, Alice .......................................................................................... 15.2

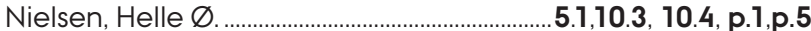

Nielsen, Henrik Kofoed........................................................................... 2.4

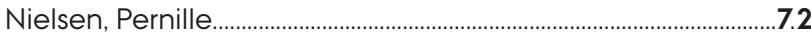

Nummelin, Tuomas ................................................................................ 17.1

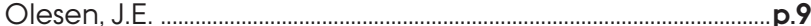

Pedersen, Anders Branth .................................................... 10.4, p.1, p.5

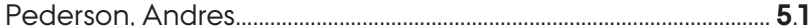

Penha-Lopes, Gil................................................................... 1.2, 5.3, 5.4

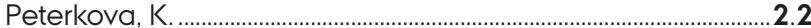

Peters, Anja .................................................................................. 8.3. 8.5

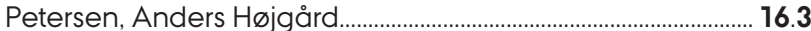

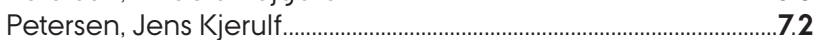

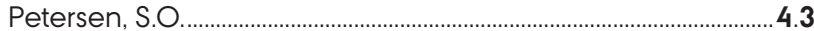

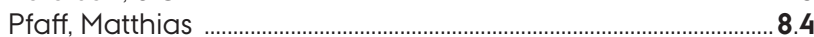

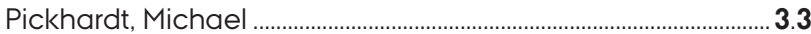

Pickova, Jana …………………………………………………...... 4.2

Polo, Maria J.....................................................................................14.1

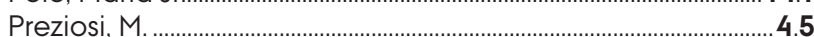

Primmer, Eeva ……………………………………………………...... 12.3

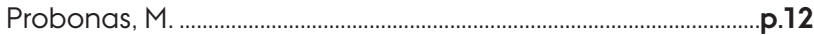

Paavilainen, Leena .............................................................................17.

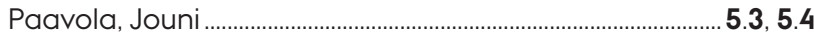

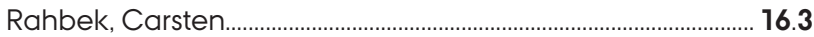

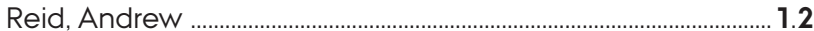

Reis, Stefan ..........................................................................................

Riala, Maria............................................................................ 17.1

Riede, Felix ................................................................................................. 14.4

Roosenschoon, Onno ………………………

Russel, Duncan ........................................................... 10.2, 10.3, p.2

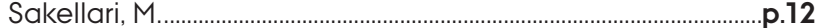

Sarkheil, Hamid ....................................................................... p.10

Sartorius, Christian ................................................................................. 8.4

Schjørring, J.K.

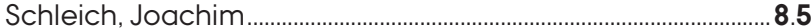

Schleyer, Christian ........................................................................ 12.2

Schnürer, Johan ...... 4.2

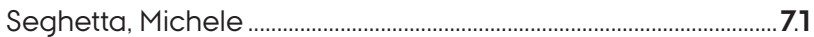

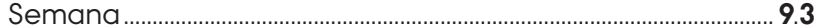

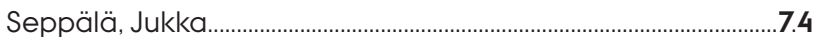

Seppälä, Jyri .......................................................................................... 17.1

Sigsgaard, Torben ………………………………………….......... 2.1, p.9

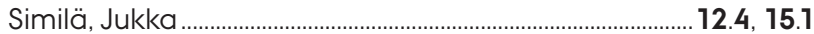

Soland, Martin ................................................................................8.1

Sommer, Svend Gjedde .................................................................... 4.3

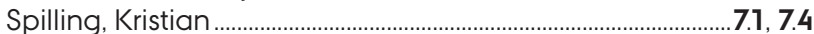

Srebotnjak, Tanja ....................................................................................... 3.4

Staddon, Philip ................................................................................ 1.3

Strange, Niels ...................................................................................... 16.3

Svendsen, Gert Tinggaard.......................................................

Svenning, Jens-Christian .....................................................................16.1

Söderman, Tarja ...

Sørensen, Jens Havskov ....................................................................... 2.1

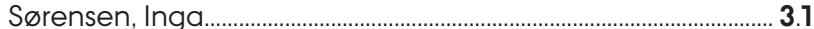

Sørensen, Peter Borgen .........................................................................p.11

Saarela, Sanna-Riikka ......................................................

Tabesh, Niloufar................................................................................ 4.1

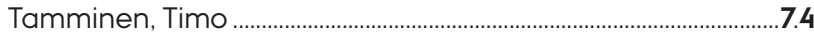

Tan, Adrian R. ................................................................................................ 3.4

Tan, Eu Chye ...............................................................................

Taylor, Tim .................................................................................. 1.3

Termansen, Mette …………………………………………………........ 16.2

Thessler, Sirpa ................................................................................... 17.1 
Thomsen, Marianne

Thorling, Lœrke

Thorsen, Bo Jellesmark

Thorstensen, Rein Terje

Thulin, Carl-Gustaf...

Tibasima.

Timmerman, Karen

Trannin, Maria C.

Trémier, Anne

Triolo, J.M

Tröltzsch, Jenny

Turner, Katrine Grace

Tørring, Ditte

Uddin, Mahatab

Vačkář, David.

van Randen, Yke

van Aalst,Maaike

Vangilde-Pedersen, Thomas

Vedel, Suzanne Elizabeth
7.1, 7.3

p.14

.16.3, 16.4

.... 2.4

4.2

9.3

..7.2

p.7

..7.3

4.3

p. 2

16.1

7.2

15.4

p.4

6.2

5.5

3.1

16.4
Vejre, $\mathrm{H}$. p.9

Vihinen, Hilkka 17.1

Virkamäki, Venla ....................................................................................... 17.1

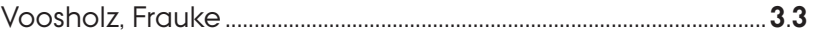

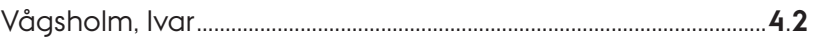

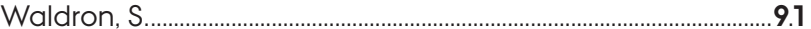

Walnum, Hans Jakob ........................................................................ 8.2

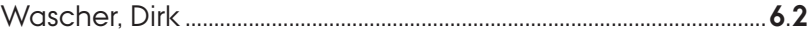

Waylen, Kerry …………………………………………………………... 16.5

Weiland, Sabine $\ldots \ldots \ldots \ldots \ldots \ldots \ldots \ldots \ldots \ldots \ldots \ldots \ldots \ldots \ldots \ldots \ldots \ldots \ldots \ldots \ldots \ldots \ldots . . .1,6.1,10.3$, p. 2

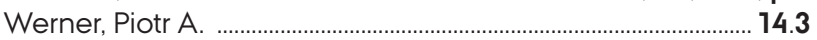

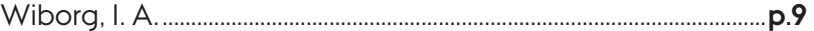

Winding, Anne ................................................................................ 11

Wright, Nigel .....................................................................................

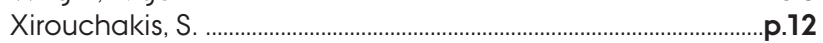

Yee, Chow Fah .................................................................................. 17.2

Zandersen, Marianne............................................... . 16.2, p.3, p.11

Zandvoort, Mark ………….............................................................. 14.5

Ørum, Jens Erik …………………………………………………………. 7.2 


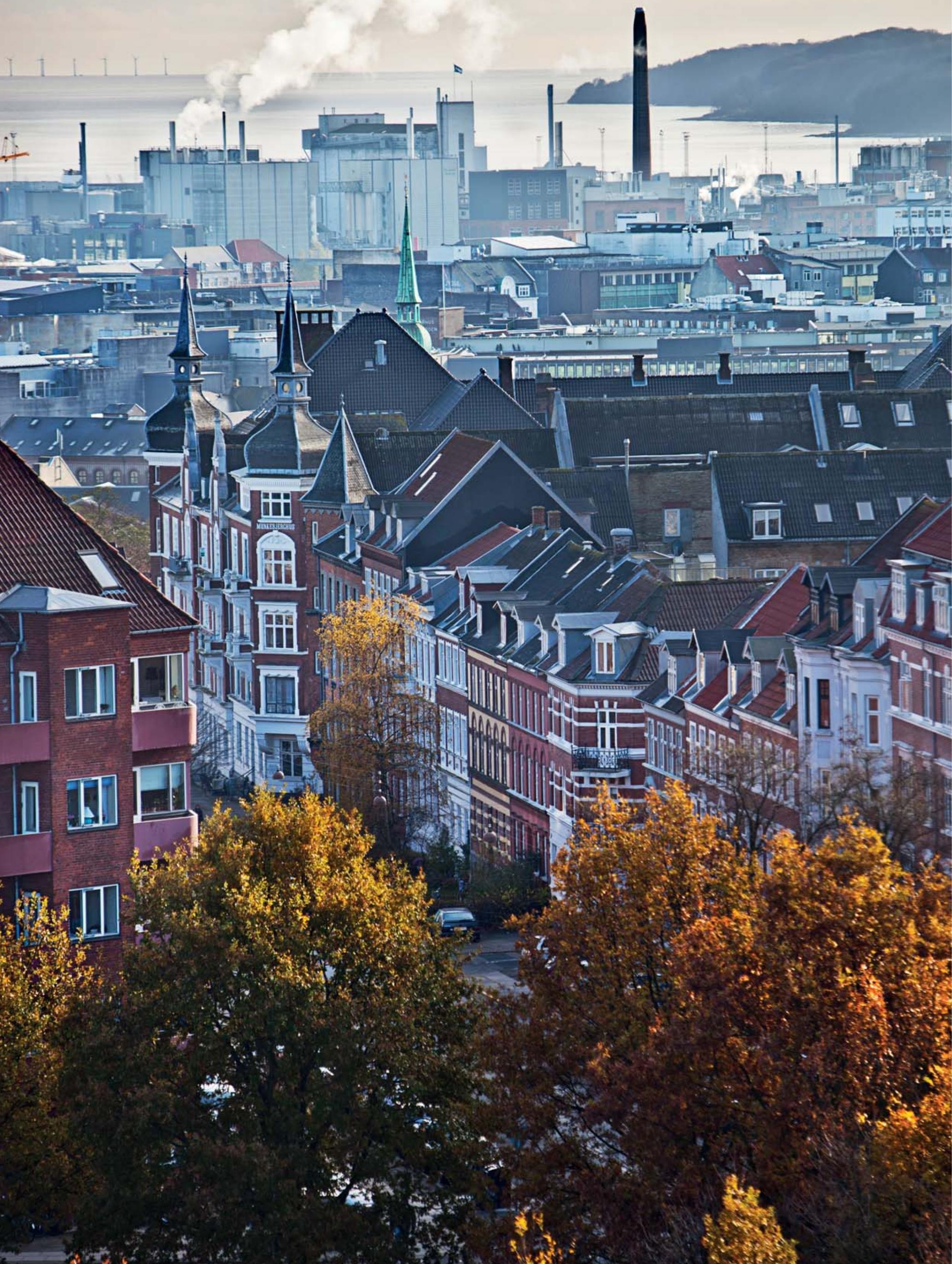




\section{ABOUT DCE}

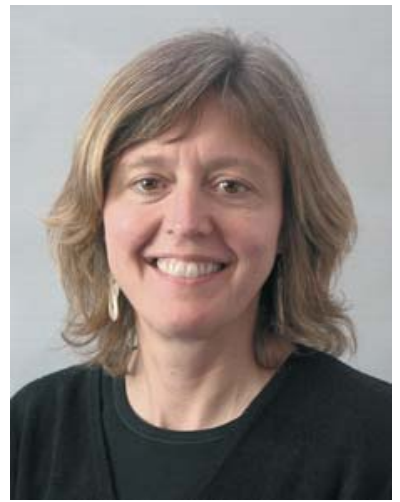

Hanne Bach,

Director of DCE
DCE - Danish Centre for Environment and Energy was established on 1 July, 2011, in connection with a reorganisation of Aarhus University. The Centre is responsible for Aarhus University's knowledge exchange within the area of environment and energy, and is managed by a Director. You can find more information on the website www.dce.au.dk

DCE delivers science-based consultany and solutions at local, national and international scale. Among our customers are the Danish Ministry of the Environment, the Danish Ministry of Climate and Energy, Greenland's self-Government, the Danish municipalities, private businesses and the European Commission. The university Departments of Bioscience and Environmental Science are the units mostly involved in these activities.

The Department of Environmental Science includes research groups on environmental chemistry, microbiology, atmospheric environment and systems analysis. The Department of Bioscience includes research groups on botany, zoology, marine and freshwater ecology, genetics, evolu- tion, microbiology, zoophysiology, ecophysiology, population ecology, ecotoxicology, bioinformatics, wildlife biology, biodiversity, terrestrial ecology and the arctic environment.

With DCE, the Department of Bioscience and the Department of Environmental Science, the Faculty of Science and Technology at Aarhus University is Denmark's leading research environment on applied environmental research. DCE and the two departments cover a very wide range of disciplines and special competences within both the biological and the physico-chemical area. DCE - Danish Centre for Environment and Energy at Aarhus University provides consultancy services and knowledge based on high quality research and, thus, contributes to the national and international community development, including the knowledge basis for the political decisions made by the Danish Parliament, ministries, municipalities and the EU. Public institutions are important clients purchasing the university's consultancy services, but collaboration also exists with private companies, such as both national and international consulting engineers. 


\section{ABOUT PEER}

PEER is a partnership of eight of the largest European environmental centres founded in 2001 with the aim of combining forces to follow a joint strategy in environmental sciences and to enhance research on ecological sustainability. This co-operation was confirmed by a Framework Agreement signed on 25 June, 2002, in Roskilde, and renewed in 2007 and 2012

PEER member centres carry out basic and applied research combining different disciplines from natural and social sciences. Research covers all fields of the environment, particularly addressing the interaction between man and nature.

You can read more about PEER at the website: www.peer.eu

\section{Vision}

To be a world leader in integrating knowledge and expertise for sustainable development.

\section{Mission}

- to build a strategic partnership of major European public environmental research centres:

- to lead a European Research Area that strengthens the knowledge base for the sustainable development of a changing world; and

- to foster innovative interdisciplinary research and cross-cutting approaches in support of national and European policy-makers, industry and society.

\section{Members of PEER:}

- Alterra Wageningen UR, The Netherlands

- Irstea, France

- Centre for Ecology \& Hydrology, United Kingdom

- Finnish Environment Institute SYKE, Finland

- Helmholtz Centre for Environmental Research - UFZ, Germany

- European Commission - Joint Research Centre - Institute for Environment and Sustainability

- CIENS - Oslo Centre for Interdisciplinary Environmental and Social Research, Norway

- DCE - Danish Centre for Environment and Energy, Denmark
Signature of the PEER Agreement in Wallingford, 2012:

(LTR) K. Slingerland (Alterra), M. Betti (JRC-IES), D. Despréaux (Irstea), H. Bach Clausen (DCE, AU), G. Teutsch (UFZ), M. Bailey (CEH), L. Kauppi (SYKE)

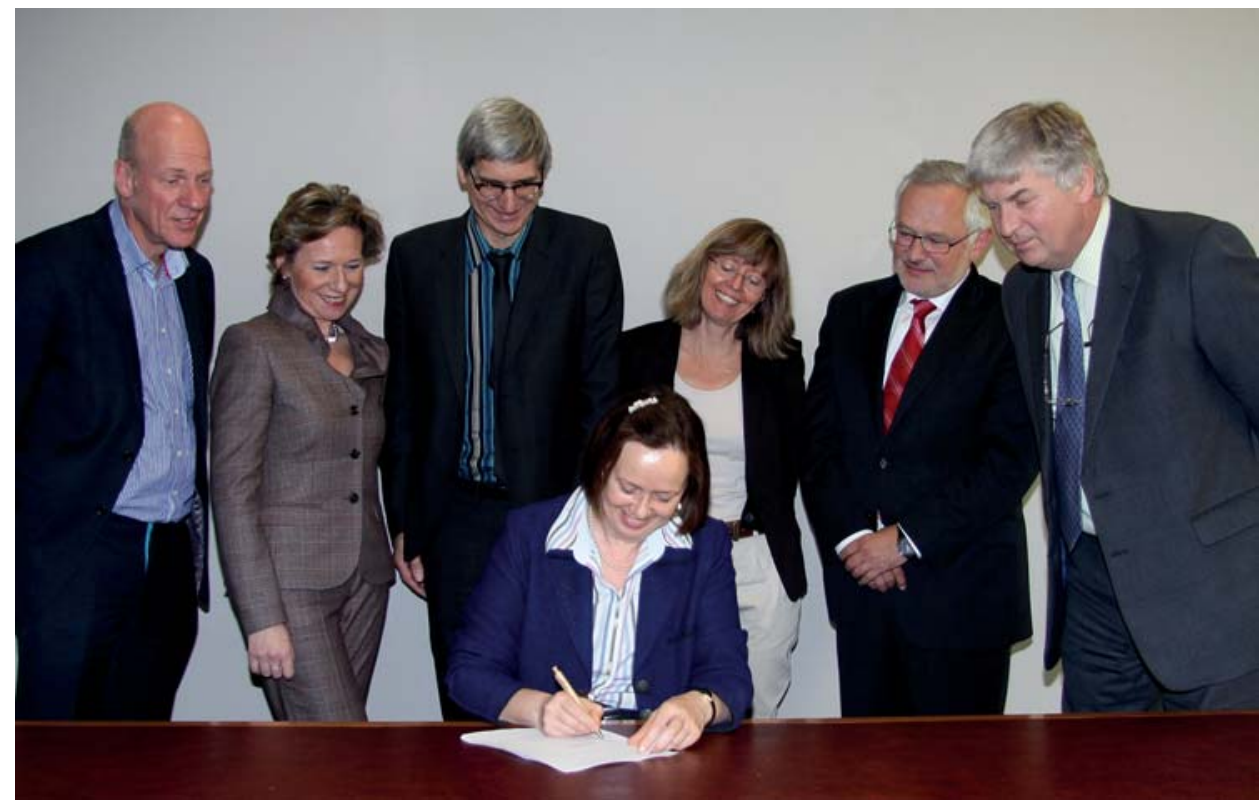

121 


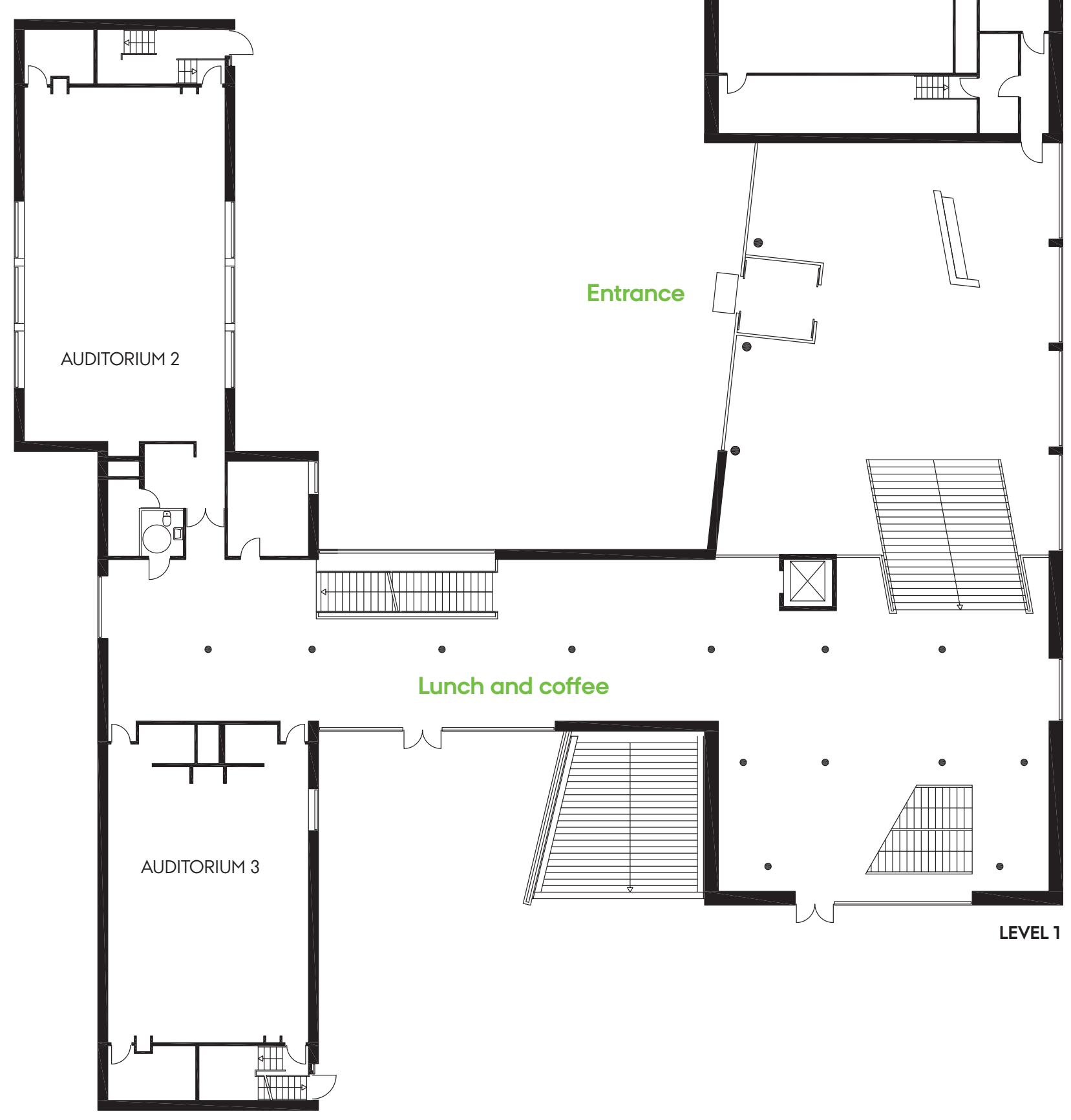




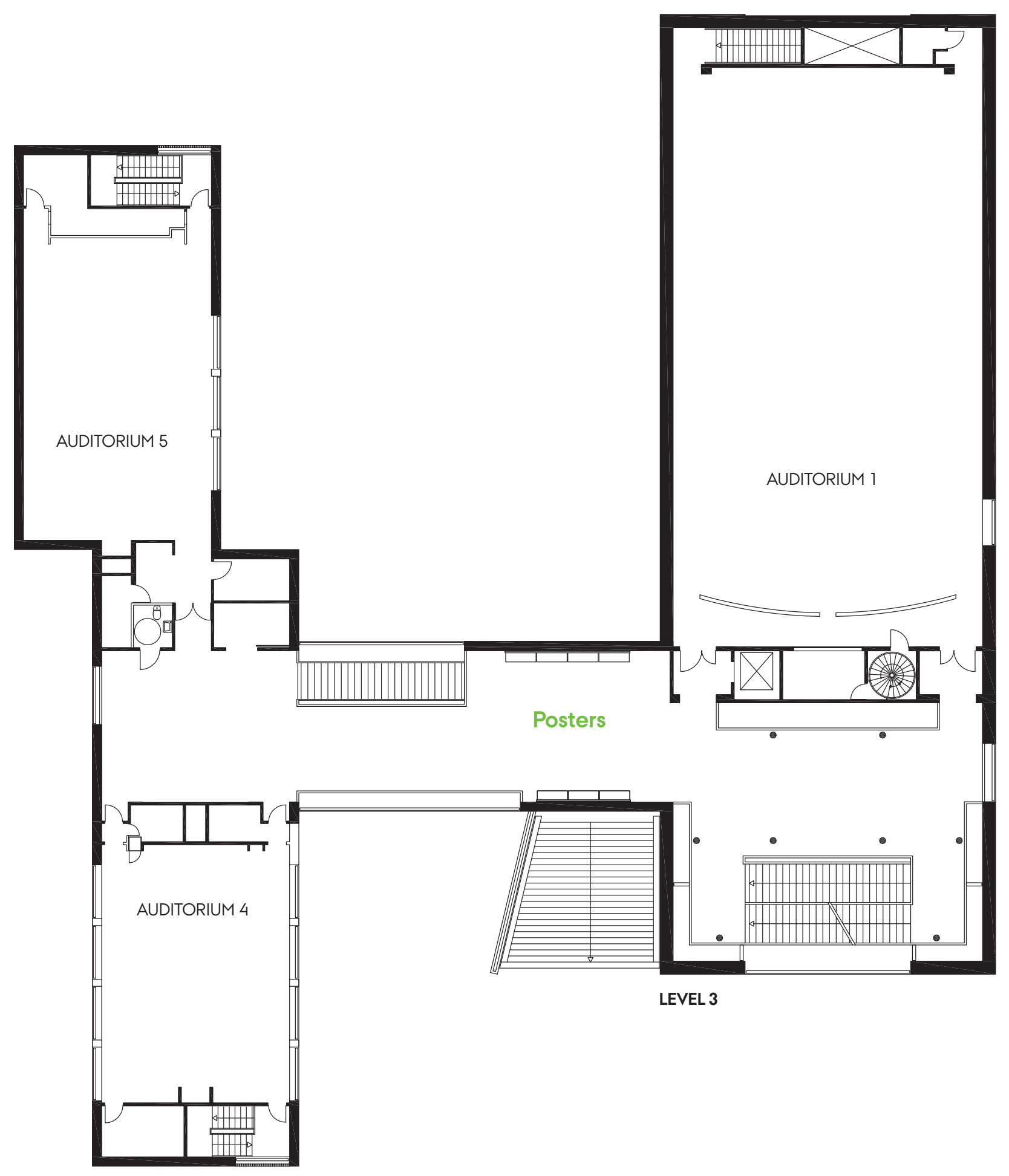


Photos:

(c) skegbydave: page 6

(c) Alexander Chernyakov: page 14

Roar Lava Paaske: page 16, 115

Lars Kruse/AU-foto: page 8, 42

Jesper Rais/AU-foto: page 2, 96, 119 

Aarhus University

Nordre Ringgade

8000 Aarhus C
Tlf.: 8941111

E-mail: au@au.dk www.au.dk 